\title{
Um estudo comparativo entre os métodos GTS e RD para encolhimento de ciclo
}

\author{
Cao Ji Kan
}

Dissertação do Mestrado em Matemática Aplicada na Área de Concentração de Ciência da Computação do IME-USP.

Orientador: Prof. Dr. Siang Wun Song

- São Paulo, SP - Abril de 1998 -

O autor recebeu apoio financeiro da CAPES durante a elaboração deste trabalho. 


\section{Um estudo comparativo entre os métodos GTS e RD para encolhimento de ciclo}

Este exemplar corresponde à redação final da dissertação devidamente corrigida

e defendida por Cao Ji Kan

e aprovada pela comissão julgadora.

São Paulo, 19 de julho de 1998.

Banca examinadora:

- Prof. Dr. Siang Wun Song (orientador) - IME-USP

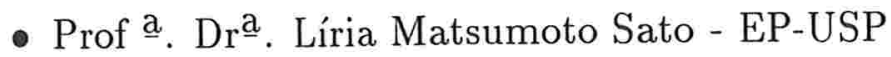

- Prof. Dr. Kunio Okuda - IME-USP 
À minha família, em especial, à minha mãe Li lien Chung. 


\section{Agradecimentos}

Ao Prof. Siang, por seus ensinamentos e estilo cativante que me fizeram conhecer e gostar da área. Pela paciência e incentivo com que me orientou, assim como pelo esforço dedicado para produzirmos este trabalho.

Ao Prof. Kunio, pelas excelentes dicas que nos foram bastante úteis.

À minha querida Hélade, pela correção no final da dissertação e pelo carinho que me incentivou durante este trabalho.

Aos amigos Marco Aurélio, Carla, Carlos, Claus, Elói, Fábio, Marcelo, Mary e Rosa que estiveram sempre presentes e diretamente me ajudaram em diversos momentos difíceis. Aos amigos Cibele, Eveline, Flávio, Fran e Jair pelo companheirismo. 


\section{Resumo}

$\mathrm{Na}$ área de computação paralela, as estruturas de laços constituem-se na maior fonte de paralelismo em programas seqüenciais. Como os laços costumam consumir muito tempo na execução do processo seqüencial, a procura de paralelismo em laços é crucial para atingir um bom desempenho. Neste trabalho, mostramos várias técnicas de transformação de laços seriais com ciclos de dependência em laços paralelos: $o$ encolhimento de ciclo simples, o encolhimento de ciclo seletivo, o encolhimento de ciclo seletivo generalizado (GSS), escalonamento por travessia em grafo (GTS - Graph Traverse Scheduling) e redução de dependências (RD). Elas transformam laços seqüenciais em laços paralelos baseada em estudo e análise de grafos de dependências. O resultado mais importante deste trabalho é um estudo comparativo entre os métodos RD e GTS. Neste estudo, analisamos os dois casos: caso de laços simples com uma recorrência hamiltoniana e caso de laços simples com múltiplas recorrências. Através das comparações e análises, conseguimos mostrar que GTS é um caso particular do RD no caso um. Por outro lado, no caso dois, mostramos que os casos não tratados por RD podem ser tratados pelo método GTS utilizando o mecanismo de sincronização explícita. 


\begin{abstract}
In Parallel Computing loop structures constitute the major source of parallelism in sequential programs. As loops usually consume much execution time in a sequential process, the search for parallelism in loops is crucial to obtain a good performance. In this work, we show several techniques to transform serial loops with dependence cycles into parallel loops: simple cycle shrinking, selective cycle shrinking, generalized selective cycle shrinking (GSS), graph traverse scheduling (GTS), and dependence reduction $(\mathrm{RD})$. These methods transform sequential loops into parallel loops based on the study and analysis of the dependence graph. The most important result of this work is a comparative study between RD and GTS. In this study, we analyze two cases: the case of simple loops with a Hamiltonian recurrence and the case of simple loops with multiple recurrences. Through the comparisons and analysis, we manage to show that GTS is a special case of RD in the first case. In case two, on the other hand, we show that the cases not handled by RD can be handled by the GTS method by utilizing the explicit synchronization mechanism.
\end{abstract}




\section{Conteúdo}

Lista de Figuras

iii

1 Introdução 1

1.1 Introdução. . . . . . . . . . . . . . . . . . . . 1

1.2 Estrutura da dissertação . . . . . . . . . . . . . . . . 3

2 Definições e nomenclatura $\quad 4$

2.1 Definição e formalização . . . . . . . . . . . . . . . . . 4

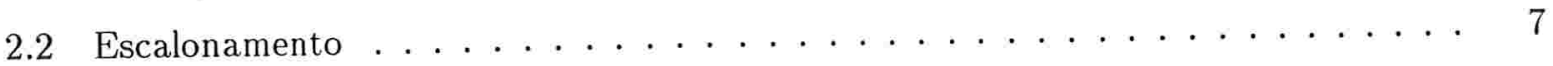

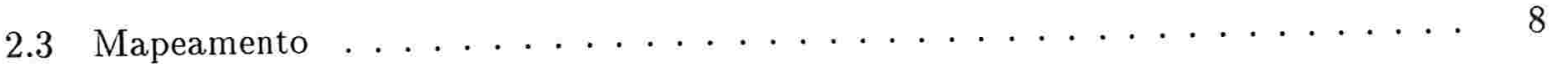

2.4 Modelo para computação paralela . . . . . . . . . . . . . . 9

3 Métodos conhecidos para encolhimento de ciclo 11

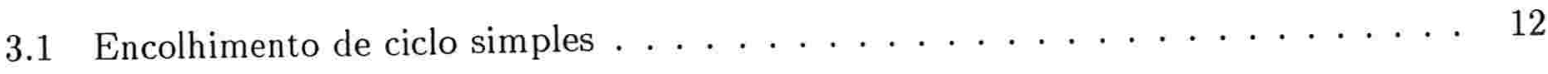

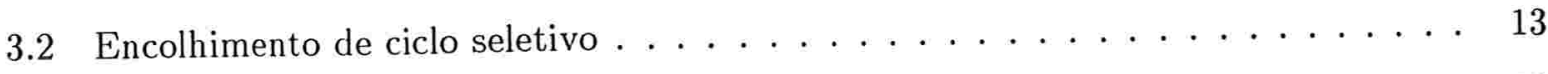

3.3 Método GSS - Generalized Selective Shrinking . . . . . . . . . . . 16

4 Método GTS (Graph Traverse Scheduling) 23

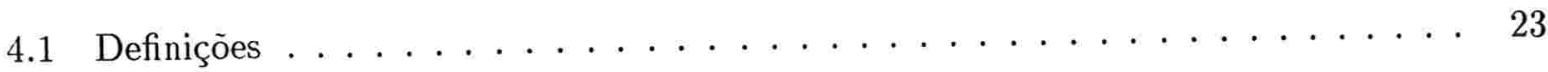

4.2 Paralelização de laços com uma recorrência hamiltoniana . . . . . . . . . . 24

5 Método por Redução de Dependência (RD) 29

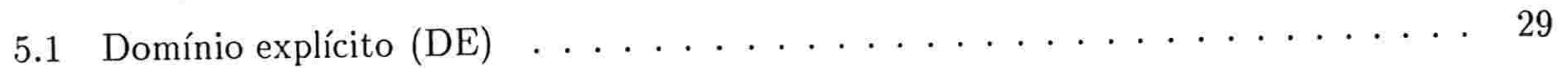

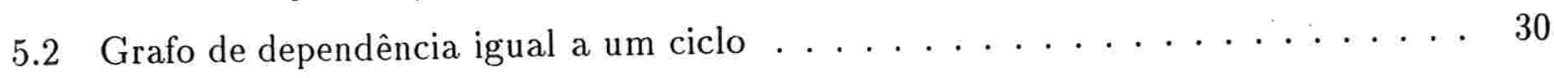

5.3 Grafo de dependência com mais de um ciclo . . . . . . . . . . . . . . 34 
6 Estudo comparativo entre os métodos RD e GTS para laços simples

6.1 Método RD . . . . . . . . . . . . . . . . . . . . 40

6.2 Comparação entre dois métodos GTS e RD para um laço simples com uma recorrência hamiltoniana . . . . . . . . . . . . . . . . . . 42

6.3 GTS pode tratar casos não tratados por RD utilizando a sincronização explícita 45

7 Conclusão 48

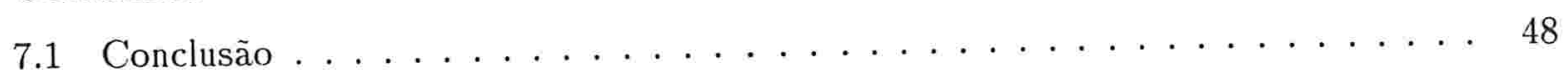

Apêndice A $\quad 50$

A Adição de dependências ou arestas $\quad 50$

Apêndice $B$

B Paralelização livre de sincronização explícita 52

56 


\section{Lista de Figuras}

2.1 (a) - Dom e (b) - Grafo de dependência . . . . . . . . . . . . . 7

2.2 O escalonamento do exemplo $2.2 \ldots \ldots \ldots \ldots \ldots$

2.3 Exemplos para o mapeamento . . . . . . . . . . . . . 9

2.4 Modelo geral de computadores paralelos de memória distribuída . . . . . . . . 10

3.1 (a) - Grafo de dependência (b) - Relação de dependência entre as iterações . . . 12

3.2 (a) - Dom e vetores de dependência do exemplo 3.2 (b) - Grafo de dependência * 14

3.3 Execução paralela e escalonamento do exemplo $3.2 \ldots \ldots \ldots \ldots$

3.4 (a) - Dom e as dependências (b) - Grafo de dependência do exemplo $3.3 \ldots \ldots$

3.5 A execução paralela trivial para o exemplo $3.3 \ldots \ldots \ldots \ldots \ldots$

3.6 Mapeamento entre os pontos do Dom e tempo . . . . . . . . . . . . . 18

3.7 Mapeamento de dois pontos extremos . . . . . . . . . . . . . . . 19

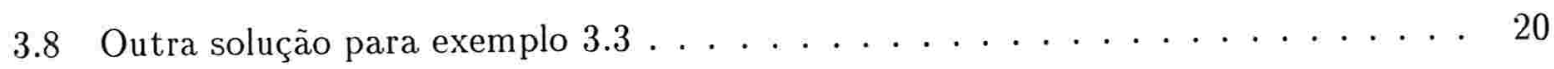

3.9 Dom e grafo de dependência do exemplo $3.4 \ldots \ldots \ldots \ldots \ldots \ldots$

3.10 Uma solução paralela e $\pi_{0}$ para o exemplo $3.4 \ldots \ldots \ldots \ldots \ldots \ldots \ldots$. . . . . . . . 22

4.1 O grafo de dependência e o caminho para obter o escalonamento . . . . . . 25

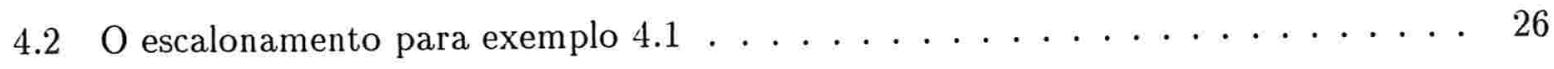

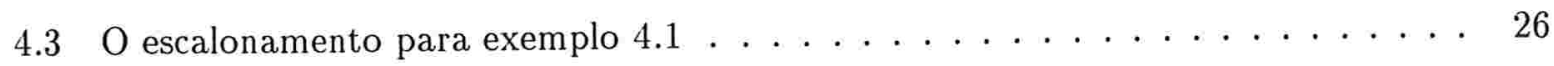

4.4 Escalonamento e as "correntes" de dependências entre as iterações . . . . . . . . 27

4.5 Alocação dos processadores e as dependências entre as iterações . . . . . . . . . . 28

5.1 Dom e grafo de dependência do exemplo $5.1 \ldots \ldots \ldots \ldots \ldots$

5.2 (a) - Grafo de dependência (b) - Grafo de dependência transformado . . . . . . 32

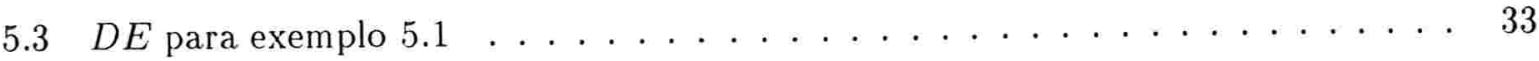


5.4 Redução de dependência para exemplo $5.1 \ldots \ldots \ldots$. . . . . . . . . . . 34

5.5 Após a redução de dependência (exemplo 5.1 ) . . . . . . . . . . . . . 34

5.6 Mapeamento dos processadores . . . . . . . . . . . . . 35

5.7 Dom e as dependências e o grafo de dependência do exemplo $5.2 \ldots \ldots$. . . . 36

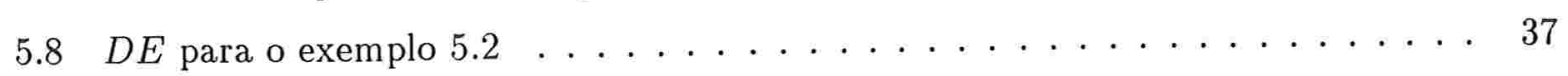

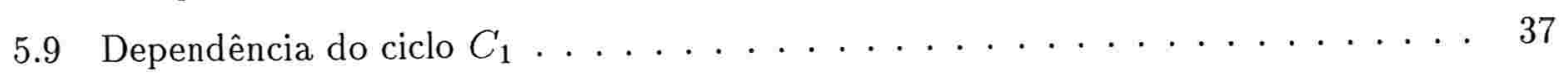

5.10 Dependência do ciclo $C_{2} \ldots \ldots \ldots \ldots \ldots \ldots \ldots \ldots$

5.11 Dependência para $S_{1}$ e nova dependência para macro $\bar{S}(i, j) \ldots \ldots \ldots$

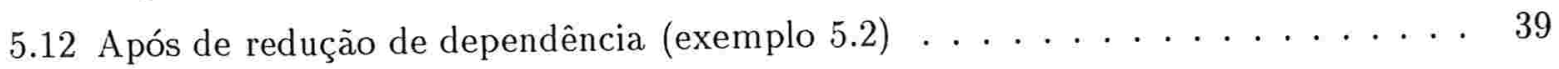

5.13 Novo grafo de dependência para o exemplo $5.2 \ldots \ldots \ldots \ldots$

6.1 Redução de dependência e a formação de um macro . . . . . . . . . . . . . . . . . . . . . . . . . . . .

6.2 Após da redução de dependência . . . . . . . . . . . . . . . . 41

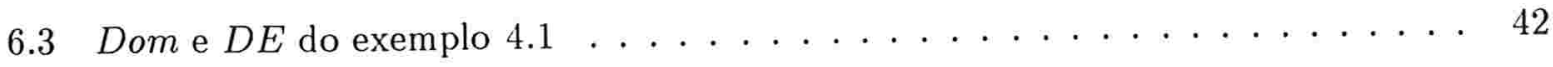

6.4 A redução de dependência . . . . . . . . . . . . . . . . 43

6.5 Após da redução de dependência . . . . . . . . . . . . . . . . 44

6.6 Alocação dos processadores e as dependência entre os macros . . . . . . . . . . 44

6.7 o grafo de dependências . . . . . . . . . . . . . . . 45

6.8 O escalonamento e a sincronização para exemplo 6.1 e alocação de processadores e a sincronização usando o RD' . . . . . . . . . . . . . . . . 46

A.1 O grafo de dependências e o grafo de dependências com uma aresta adicional . . 51

B.1 O grafo de dependências (a) e o grafo de dependências com as arestas adicionais

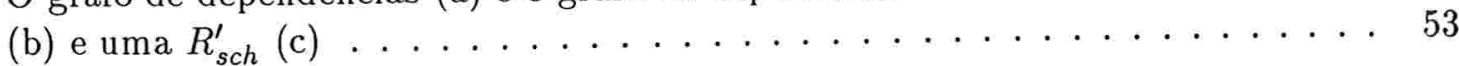

B.2 O grafo de dependências (a) e o grafo de dependências com as arestas adicionais

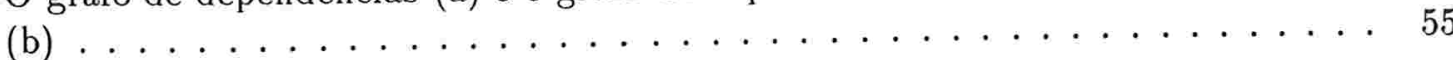




\section{Capítulo 1}

\section{Introdução}

- Na seção 1.1, introduzimos uma breve descrição do assunto desta dissertação e comentamos alguns trabalhos relacionados.

- Na seção 1.2 , mostramos as estruturas gerais e conteúdo desta dissertação.

\subsection{Introdução}

Sistemas de processadores paralelos oferecem um potencial enorme para a redução do tempo de execução de aplicações que requerem cálculos intensivos. A execução de programas em tais sistemas paralelos, se devidamente paralelizados, pode ser acelerada de modo substancial em relação à execução seqüencial.

As estruturas de laços constituem-se na maior fonte de paralelismo em programas seqüenciais. Como os laços costumam consumir muito tempo na execução do processo seqüencial, a procura de paralelismo em laços é crucial para atingir um bom desempenho. Se pudermos substituir a execução serial de cada iteração do laço pela execução em paralelo de todas as iterações do laço, o ganho (speedup) pode ser em teoria tão grande quando o número máximo de iterações do laço.

Hoje, existem compiladores paralelizadores para computadores paralelos de alto desempenho para executar eficientemente programas seqüenciais escritos em linguagens convencionais como Fortran e C. Esses compiladores, tais como Parafrase, PFC ou UFTN [J. 89], examinam laços do e tentam obter códigos paralelos. Eles constróem um grafo de dependências através da análise de dependência de dados dentro do escopo de cada laço e a paralelização do laço é baseada nesta análise de dependências.

Várias técnicas de transformação de laços seriais com ciclos de dependência em laços paralelos já foram propostas. Por exemplo, o encolhimento de ciclo (cycle shrinking) foi introduzido por Polychronopoulos em 1988 [Pol88b, Pol88a]. Encolhimento de ciclo é uma técnica para paralelizar laços seriais com ciclos de dependência. Ela transforma laços seqüenciais em laços paralelos baseado em uso da distância de dependências. 
Encolhimento de ciclo simples (simple cycle shrinking) e encolhimento de ciclo seletivo (selective cycle shrinking) são duas versões desta transformação para os laços encaixados. Mas o encolhimento de ciclo seletivo é sempre melhor que o encolhimento de ciclo simples, pois ele procura um determinado laço a partir do qual todos os laços internos a ele possam ser executados em paralelo (em forma de doall) [Pol88b].

Porém, o método do encolhimento de ciclo (cycle shrinking) apresenta certas limitações e não se aplica mesmo para algoritmos que têm paralelização trivial. Estas limitações levaram Shang, O'Keefe e Fortes, em 1992, a apresentarem o encolhimento de ciclo seletivo generalizado(GSS) [M. 91] aperfeiçoando a técnica do encolhimento de ciclo. A generalização permite uma maior liberdade na escolha da solução. Este método particiona o conjunto de índices em hiperplanos paralelos e todos os pontos situados no mesmo hiperplano são executados paralelamente, ou seja, todos os pontos situados no mesmo hiperplano são executados ao mesmo tempo.

Uma outra técnica para melhorar o paralelismo do laço foi introduzido por Liu, Ho e Sheu [C. 90] como sendo deslocamento de índice (index shift method (ISM)). A idéia deste método é adiar ou avançar os passos de execução de alguns comandos tal que o tempo total de execução de laços possa ser reduzido, ou seja, o método ISM faz deslocamento de índices em comandos sem violar a semântica do algoritmo e torna o ciclo de dependência mais balanceado de modo a explorar mais paralelismo implícito. Na realidade, ele pode ser visto como um refinamento de GSS. Porém aplicar ISM após GSS nem sempre garante resultado melhor. Robert e Song propuseram um método que combina GSS com ISM de modo mais eficiente [RS92]. Eles deram também um interessante exemplo no qual este novo método tem fator de melhoria arbitrariamente grande em relação a GSS.

Um outro método chamado de escalonamento por travessia em grafo (GTS - Graph Traverse Scheduling) [LA89, J. 89] foi desenvolvido por Labarta e Ayguadé em 1989. Baseado em análise de um grafo de dependências de um laço, o método gera um escalonamento para distribuir as iterações do laço entre tarefas, as dependências não incluídas na execução seqüencial de cada tarefa deverão ser explicitamente sincronizadas ou ficarão livres de sincronização explícita usando a técnica de adição de dependências ou arestas artificiais. O artigo [Jes94] sobre o sucesso da implementação deste método na máquina AllianFX/40 foi publicado em julho de 1994. por Barrado, Labarta e Borensztejn.

Recentemente, uma nova técnica de encolhimento de ciclos foi proposta por K. Okuda [Kun95a, Kun95b, Kun96a, Kun96b], denominada de Redução de Dependência $(R D)$. Este método começa com a introdução de domínio explícito, uma nova representação de dependência de dados. Ele ilustra as dependências de modo mais explícito que outras representações como grafo de dependências ou conjunto de índices junto com vetores de dependência. Os exemplos 2-dimensionais, apesar de simples, são ilustrativos no sentido de mostrar as dependências com maior clareza e dar uma base intuitiva do método denominado redução de dependências. $\mathrm{O}$ método RD tranforma o grafo de dependência, define um macro comando que corresponde à certa seqüência de comandos de um algoritmo, reduz o número de comunicações entre processadores e o número de passos paralelos, identifica as dependências essenciais e permite uma análise simplificada para escalonamento.

$\mathrm{Na}$ dissertação serão mostradas algumas técnicas mencionadas acima, e será feito um estudo 
comparativo entre os métodos RD e GTS. No início deste estudo, introduzimos o método RD' que é equivalente ao método RD. A seguir, comparamos os método RD' e GTS no caso de laço simples com uma recorrência hamiltoniana. Mostramos que GTS é um caso particular do RD'. Como RD' é equivalente ao método RD, mostramos que GTS é um caso particular do RD, ou seja, podemos usar o método RD para formalizar o método GTS. Por outro lado, no caso de laços com múltiplas recorrências mostramos que os casos não tratados por RD podem ser tratados pelo método GTS utilizando o mecanismo de sincronização explícita. Se não existir uma recorrência hamiltoniana no laço com múltiplas recorrências, usaremos a técnica de adição de dependências ou arestas artificiais para formar uma recorrência hamiltoniana, para pssibilitar a aplicação do método GTS. Com a utilização da técnica de adição de dependências, temos a possibilidade de resolver alguns casos aplicando o método GTS livre de sincronização explícita. Um importante resultado obtido é que podemos utilizar a sincronização explícita e adição de dependências ou arestas artificiais que foram usadas no método GTS junto com método RD para estender o método RD.

\subsection{Estrutura da dissertação}

A dissertação está organizada do seguinte modo:

- No início de cada capítulo, temos uma breve descrição das seções que compõem o capítulo.

- No capítulo 2, definimos a terminologia que será utilizada no resto desta dissertação. Esta parte de definições não é completa. Novos conceitos ou novas definições serão introduzidos no início de outros capítulos.

- No capítulo 3, descrevemos duas versões do método encolhimento de ciclo (cycle shrinking): encolhimento de ciclo simples (simple cycle shrinking) e encolhimento de ciclo seletivo (selective cycle shrinking) e encolhimento de ciclo generalizado (generalized selective cycle shrinking (GSS)), e correlatos.

- No capítulo 4, apresentamos detalhadamente o método escalonamento por travessia em grafo (GTS - Graph Traverse Scheduling) para o caso de laço simples.

- No capítulo 5, explicamos o método Redução de Dependência $(R D)$ utilizando alguns exemplos.

- No capítulo 6, fazemos um estudo comparativo entre os métodos RD e GTS e através das comparações, conseguimos contribuir com alguns resultados importantes.

- No capítulo 7, damos a conclusão final. 


\section{Capítulo 2}

\section{Definições e nomenclatura}

- Na seção 2.1 definimos laços encaixados gerais (GLN - General Loop Nest), domínio, dependência, grafo de dependências, matriz de dependências, GLN uniforme e laços encaixados uniformes e regulares (RUN - Regular Uniform Nest) e alguns exemplos para esclarecer as definições.

- Nas seções 2.2 e 2.3 definimos respectivamente escalonamento e mapeamento, ilustrados com algumas figuras.

- Na seção 2.4 definimos o modelo de computação paralela para esta dissertação.

\subsection{Definição e formalização}

Vamos considerar a seguinte estrutura para um algoritmo expresso como laços encaixados, denominada laços encaixados gerais (GLN - General Loop Nest) [DR94]:

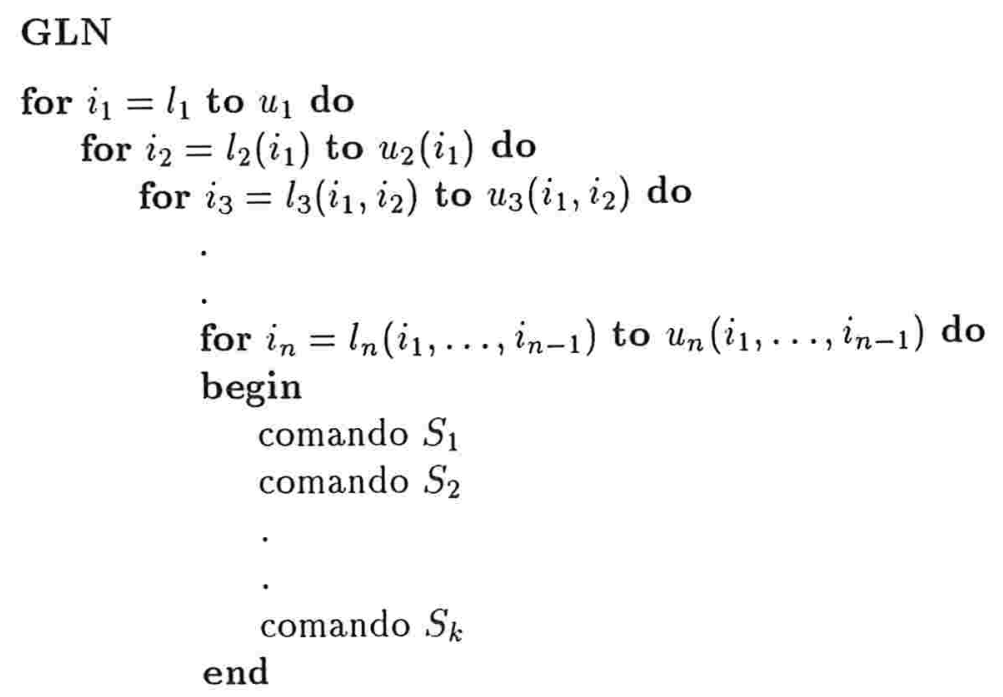


onde $l_{1}$ e $u_{1}$ são constantes, $l_{j}\left(i_{1}, \ldots, i_{j-1}\right)$ e $u_{j}\left(i_{1}, \ldots, i_{j-1}\right)$ são os limites mínimo e máximo de laço, onde $1<j \leq n$ e todas as variáveis usadas em comandos de $S_{1}$ a $S_{k}$ têm índices como funções afins de índices $i_{1}$ a $i_{n}$.

O conjunto de índices para este algoritmo, chamado domínio, é definido como:

Dom $=\left\{I=\left(i_{1}, \ldots, i_{n}\right) \in Z^{n} \mid l_{j}\left(i_{1}, \ldots, i_{j-1}\right) \leq i_{j} \leq u_{j}\left(i_{1}, \ldots, i_{j-1}\right), 1<j \leq n\right\}$

Dom é o conjunto de pontos com coordenadas inteiras num poliedro convexo [Wol89, M. 91, RS92, Kun95a].

Para o estudo de paralelismo, o conceito de dependência é fundamental [Wol89, Wol96, Pol88b, Pol88a]. Um comando $S_{j}$ depende de um comando $S_{i}$ (denotado por $S_{i} \delta S_{j}$ ) se existem $S_{i}(I)$, a instância $I$ de $S_{i}$, e $S_{j}(J)$, a instância $J$ de $S_{j}$, e uma posição $M$ da memória tais que:

- $S_{i}(I)$ é executado antes de $S_{j}(J)$ (na execução seqüencial).

- $S_{i}(I)$ e $S_{j}(J)$ fazem referência a $M$ e pelo menos uma das referências é escrita.

- $M$ não é escrita entre $S_{i}(I)$ e $S_{j}(J)$.

Há três tipos de dependências:

Dependência de Fluxo $\left(S_{i} \delta^{f} S_{j}\right)$ : se $S_{i}(I)$ escreve em $M$ e $S_{j}(J)$ a lê.

Anti-Dependência $\left(S_{i} \delta^{a} S_{j}\right)$ : se $S_{i}(I)$ lê $M$ e $S_{j}(J)$ escreve em $M$.

Dependência de Saída $\left(S_{i} \delta^{\circ} S_{j}\right)$ : se $S_{i}(I)$ escreve em $M$ e $S_{j}(J)$ também.

Vejamos o seguinte exemplo que inclui estes três casos:

\section{Exemplo 2.1}

$S_{1}: \mathrm{A}=\mathrm{B}+\mathrm{D}$

$S_{2}: \mathrm{C}=\mathrm{A} * 3$

$S_{3}: \mathrm{A}=\mathrm{A}+\mathrm{C}$

$S_{4}: \mathrm{E}=\mathrm{A} / 2$

No exemplo 2.1, temos $S_{1} \delta^{f} S_{2}, S_{2} \delta^{a} S_{3}, S_{2} \delta^{f} S_{3}, S_{1} \delta^{\circ} S_{3}, S_{3} \delta^{f} S_{4}$.

Se $S_{j}\left(j_{1}, \ldots, j_{n}\right)$ depende de $S_{i}\left(i_{1}, \ldots, i_{n}\right)$, então $d_{i j}=\left(j_{1}-i_{1}, \ldots, j_{n}-i_{n}\right)^{t}$ será chamado de vetor de dependência entre os dois comandos. Adotaremos a notação $S_{i} \rightarrow S_{j}$ no lugar de $S_{i} \delta S_{j}$ e todas as dependências serão de fluxo (também chamada dependência verdadeira) daqui para frente, sendo esta a que apresenta maior dificuldade para tratar [Pol88b]. Estudaremos casos comuns em que todos os vetores de dependência são lexicograficamente positivos e não há dependências entre comandos dentro de uma mesma iteração (i.e., não existe $d_{i j}=(0, \ldots, 0)^{t}$ ).

Dados dois comandos $S_{i}$ e $S_{j}$, podem existir vários pares de índices $(I, J), I, J \in$ Dom tais que $S_{j}(J)$ depende de $S_{i}(I)$. Restringiremos nossa atenção à importante subclasse GLN chamada 
GLN uniforme na qual o vetor de dependência entre dois comandos independe dos índices da particular instância, ou seja, não depende de $I, J$.

As vantagens de GLN uniforme sobre GLN são:

- Muitos algoritmos para aplicações científicas têm essa estrutura.

- A análise de dependência fica mais simples.

- A sua estrutura regular permite explorar bem seu paralelismo implícito.

Dado um GLN uniforme, a matriz de dependência $D$ é uma matriz cujas colunas são os vetores de dependência e o grafo de dependência de um programa é o grafo orientado $G(V, E)$ com conjunto de nós $V=\left\{S_{1}, \ldots, S_{n}\right\}$ representando os comandos no corpo do laço, e um conjunto de arcos $E=\left\{d_{i j} \mid S_{i}, S_{j} \in V\right\}$ representando dependências de dados entre comandos $S_{i}$ e $S_{j}$.

Para facilitar e simplificar as descrições subsequentes, definimos laços encaixados uniformes e regulares (RUN - Regular Uniform Nest) [DR92, RS92]:

RUN

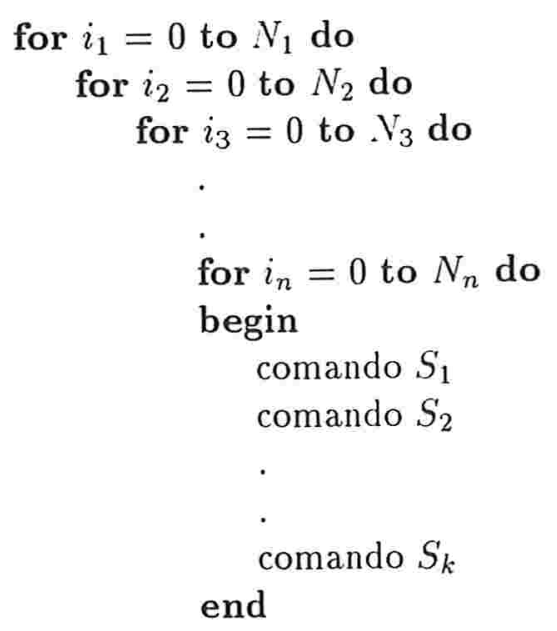

Consideramos o seguinte exemplo [Pol88a, Pol88b].

Exemplo 2.2

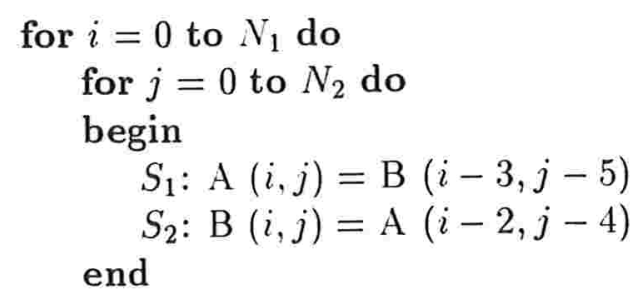

Neste exemplo, o conjunto de índice é um retângulo: 


$$
\text { Dom }=\left\{(i, j) \in Z^{2} .0 \leq i \leq N_{1}, 0 \leq j \leq N_{2}\right\}
$$

A variável $A(i, j)$ é produzida no comando $S_{1}(i, j)$ e consumida no comando $S_{2}(i+2, j+4)$. Portanto, existe uma dependência entre $S_{1}$ e $S_{2}$ com vetor de dependência $(2,4)^{t}$. Semelhantemente, existe uma dependência entre $S_{2}$ e $S_{1}$ com vetor de dependência $(3,5)^{t}$ e temos uma matriz de dependência $D=\left(d_{12}, d_{21}\right)=\left(\begin{array}{ll}2 & 3 \\ 4 & 5\end{array}\right)$. Notamos que, para este exemplo, existe um ciclo de dependência onde as dependências formam um circuito (ver a figura 2.1).

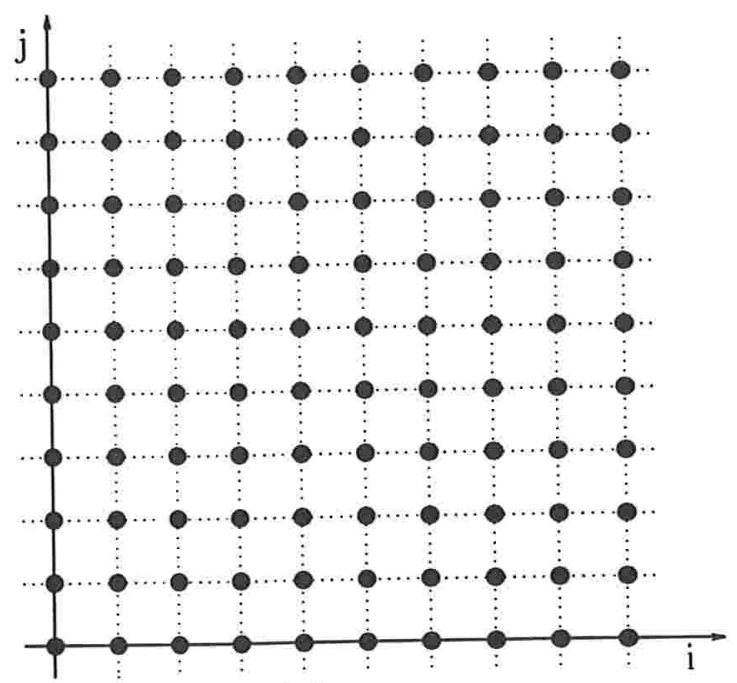

(a)

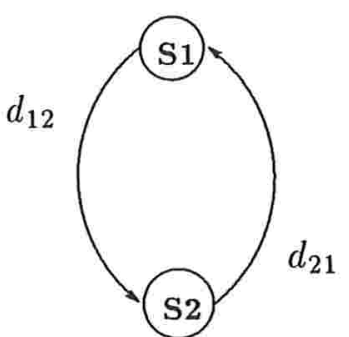

(b)

Figura 2.1: (a) - Dom e (b) - Grafo de dependência

\subsection{Escalonamento}

Definimos o que é um escalonamento para execução paralela. Dado um RUN, escalonamento é uma função $\mathcal{F}: Z^{n} \rightarrow Z$ tal que a computação correspondente ao ponto $\left(i_{1}, \ldots, i_{n}\right) \in D o m$ é executada no passo $\mathcal{F}\left(i_{1}, \ldots, i_{n}\right)$ [DR92]. Para que uma função $\mathcal{F}: Z^{n} \rightarrow Z$ seja um escalonamento, ela deve satisfazer à seguinte condição:

Se $S_{i}\left(i_{1}, \ldots, i_{n}\right) \delta S_{j}\left(j_{1}, \ldots, j_{n}\right)$, então $\mathcal{F}\left(i_{1}, \ldots, i_{n}\right)<\mathcal{F}\left(j_{1}, \ldots, j_{n}\right)$.

A execução paralela de RUN é a seguinte:

for $i=$ tempomin to tempomax do

execute as computações em todos os pontos $\left(i_{1}, \ldots, i_{n}\right) \in$ Dom

tais que $\mathcal{F}\left(i_{1}, \ldots, i_{n}\right)=i$.

onde tempomin $=\min \{\mathcal{F}(I) \mid I \in \operatorname{Dom}\}$ e tempomax $=\max \{\mathcal{F}(I) \mid I \in \operatorname{Dom}\}$.

$\mathrm{O}$ número total de passos será tempomax - tempomin +1 . A figura 2.2 ilustra a definição do escalonamento. Observamos que, pela figura 2.2 , existe uma função $f: Z^{2} \rightarrow Z$ tal que a 
computação correspondente ao pontos $(i, j) \in$ Dom é executada no passo (tempo) $f(i, j)$. Por exemplo, $f(1,1)=0, f(3,2)=1, f(4,3)=2$ e $f(5,2)=2$. Veremos o detalhe no exemplo da seção 3.3 do capítulo 3 .

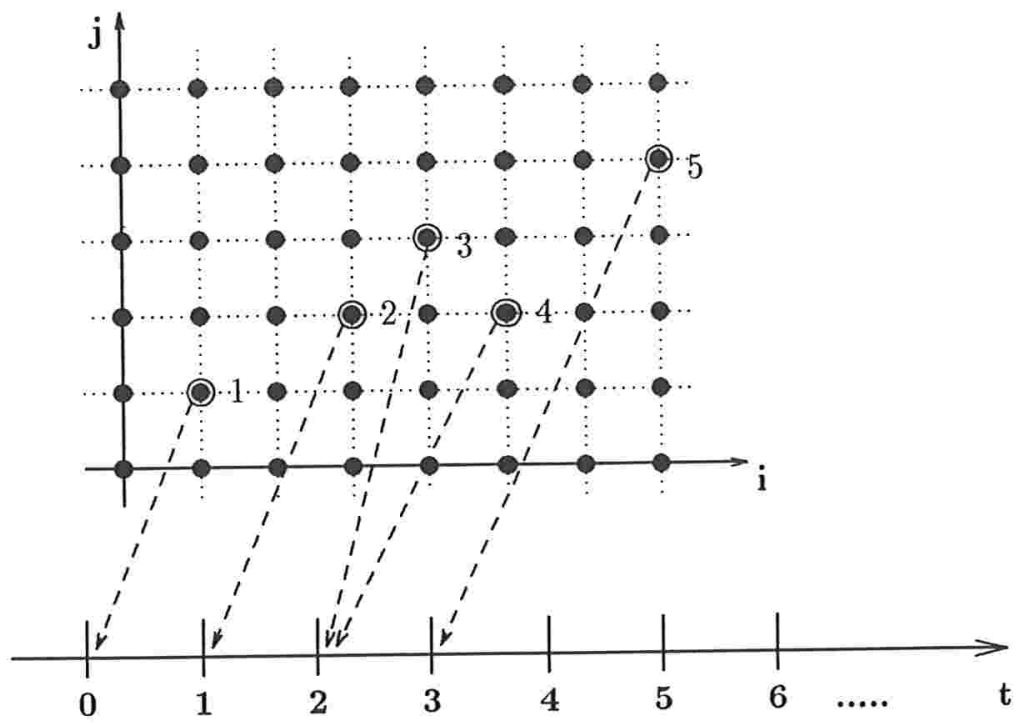

Figura 2.2: $\mathrm{O}$ escalonamento do exemplo 2.2

\subsection{Mapeamento}

Dado um RUN, mapeamento é uma função $\mathcal{G}: Z^{n} \rightarrow Z^{m}$ tal que a computação $\left(i_{1}, \ldots, i_{n}\right)$ é executada no ponto (ou processador) $\mathcal{G}\left(i_{1}, \ldots, i_{n}\right)$ [DR94].

Se $\mathcal{F}\left(i_{1}, \ldots, i_{n}\right)=\mathcal{F}\left(j_{1}, \ldots, j_{n}\right)$, então $\mathcal{G}\left(i_{1}, \ldots, i_{n}\right) \neq \mathcal{G}\left(j_{1}, \ldots, j_{n}\right)$ para que as computações escalonadas no mesmo passo sejam mapeadas em pontos (processadores) diferentes.

Quando Dom é mapeado a $Z^{m}, \mathcal{G}(D o m)$ pode ser interpretado como uma rede de processadores. Cada $\mathcal{G}\left(i_{1}, \ldots, i_{n}\right)$ é um processador e os vetores de dependência projetados na rede de processadores representarão comunicações entre processadores nesta rede (veja a figura 2.3(a)). Um mapeamento típico é uma projeção na direção de um vetor. Se o vetor de dependência for paralelo ao vetor de projeção, não há então comunicação entre processadores, pois os dados estão no mesmo processador (veja a figura 2.3(b)).

Para calcular o tempo de computação paralela, consideramos a seguinte notação:

$$
\begin{aligned}
& T_{\text {com }}=\text { tempo gasto para comunicação entre processadores } \\
& T_{\text {exec }}=\text { tempo gasto para executar um comando } \\
& N_{p p}=\text { número total de passos para execução paralela }
\end{aligned}
$$

Portanto, o tempo total gasto geralmente será $N_{p p} \times\left(T_{\text {com }}+T_{\text {exec }}\right)$. Observamos que se todos os vetores de dependência forem paralelos ao vetor de projeção, o tempo total gasto será apenas 


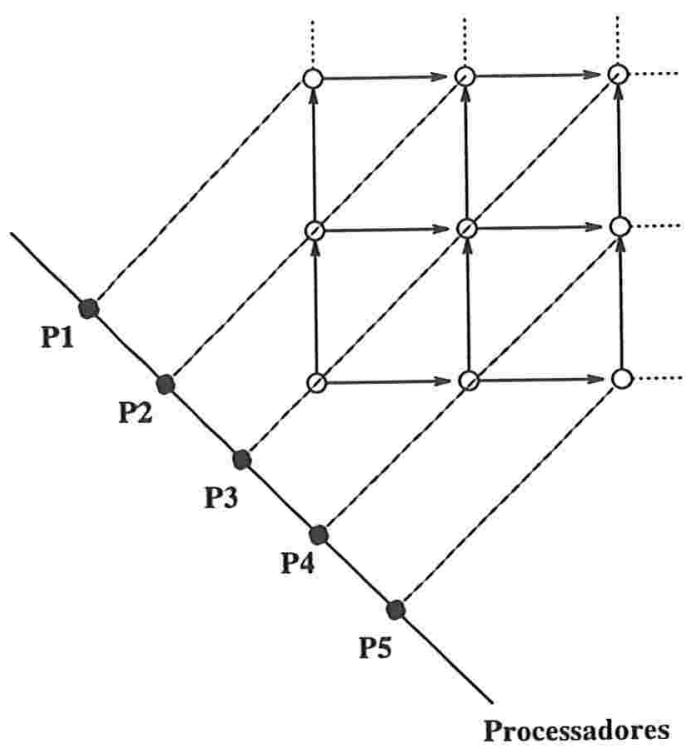

(a)

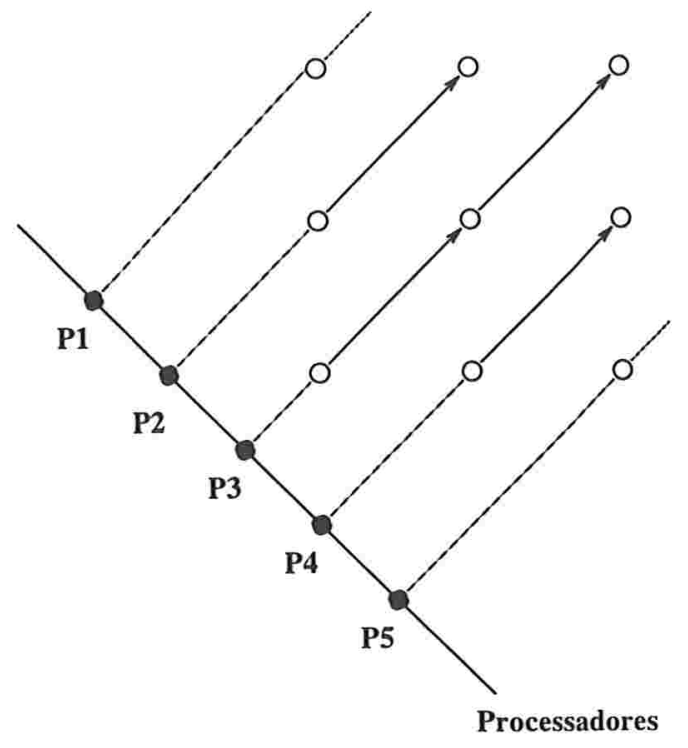

(b)

Figura 2.3: Exemplos para o mapeamento

$N_{p p} \times T_{\text {exec }}$.

\subsection{Modelo para computação paralela}

Neste trabalho vamos adotar o modelo de computadores paralelos de memória distribuída com paradigma SPMD (Single Program Multiple Data) [IKK92].

A arquitetura deste modelo consiste de multiprocessadores independentes interligados através de uma rede de interconexão. Cada processador tem sua memória própria, não existindo memória global ou memória compartilhada. A comunicação é assíncrona através de troca de mensagens [Wol96, DR94] (veja a figura 2.4).

SPMD (Single Program Multiple Data) [IKK92] é um modelo de operação assíncrona que significa "rodando o mesmo programa com dados diferentes". Pois um programa completo executado em dados separados pode causar desvios diferentes, conduzindo, assim, ao paralelismo assíncrono. Apesar de executarem o mesmo programa, os processadores não estão fazendo exatamente a mesma coisa em cada passo, ou seja, eles estão executando instruções diferentes de mesmo programa. 


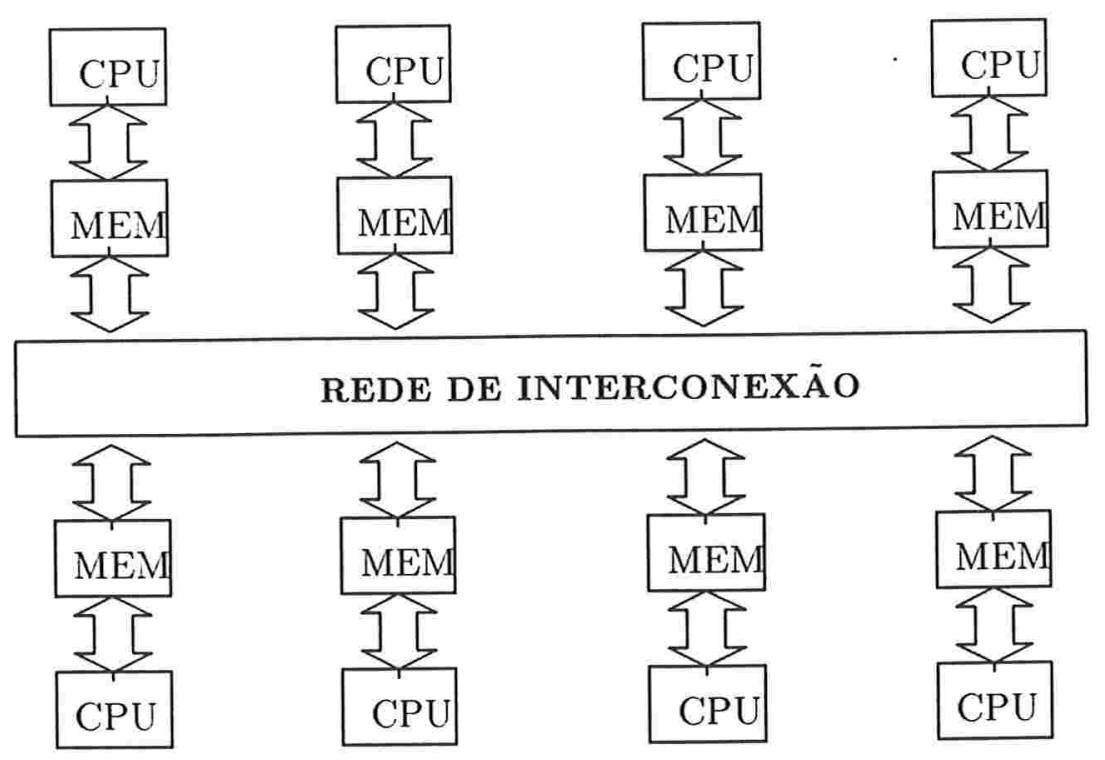

Figura 2.4: Modelo geral de computadores paralelos de memória distribuída 


\section{Capítulo 3}

\section{Métodos conhecidos para encolhimento de ciclo}

O encolhimento de ciclo (cycle shrinking) é uma técnica para a transformação de laços seriais onde existem ciclo de dependência em laços paralelos. Essa transformação ultiliza o grafo de dependência de um laço para determinar se as dependências existentes permitem que este laço, ou uma parte dele, seja executado em paralelo. Mas esta técnica apresenta certas limitações, as quais levaram Shang, O'Keefe e Fortes a propor sua generalização: encolhimento de ciclo seletivo generalizado (generalized selective cycle shrinking (GSS)) [M. 91].

Neste capítulo descrevemos alguns métodos existentes para paralelização de RUN com ciclo de dependência.

- Na seções 3.1 e 3.2 mostraremos as duas versões do método encolhimento de ciclo [Pol88a, Pol88b] - encolhimento de ciclo simples (simple cycle shrinking) e encolhimento do ciclo seletivo (selective cycle shrinking) e suas limitações.

- Na seção 3.3 descrevemos a generalização do encolhimento de ciclo seletivo (generalized selective cycle shrinking (GSS)) e suas vantagens. 


\subsection{Encolhimento de ciclo simples}

Nesta seção, consideraremos laços simples (laços não aninhados ou encaixados). Neste caso o vetor de dependência será do tipo $d_{i j}=(a)$, onde $a$ será a distância de dependência associada.

Para laços simples, encolhimento de ciclo é útil no caso em que as distâncias das dependências de um ciclo de um laço sejam maiores do que um. A menor distância $\lambda=\min \left(d_{i j} \mid 1 \leq i, j \leq m\right)$, onde $m$ é o número de comandos dentro de um laço, será o fator de speedup do encolhimento de ciclo sobre um laço ou chamado de fator de redução. Este esquema transfoma um laço do em dois laços encaixados: o laço externo continua ser seqüencial e o laço interno será paralelizado, ou seja, do tipo doall, onde todas as iterações podem ser executadas em paralelo.

Para esclarecer a idéia do encolhimento de ciclo, mostraremos um exemplo simples [Pol88a, Pol88b]:

\section{Exemplo 3.1}

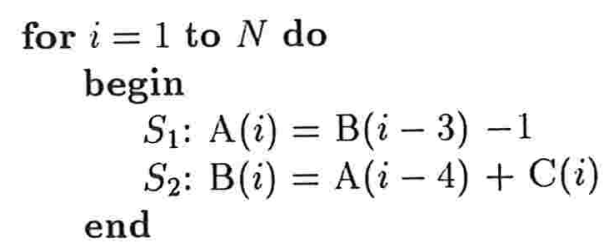

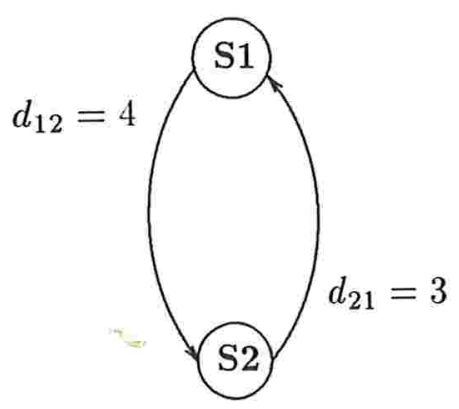

(a)

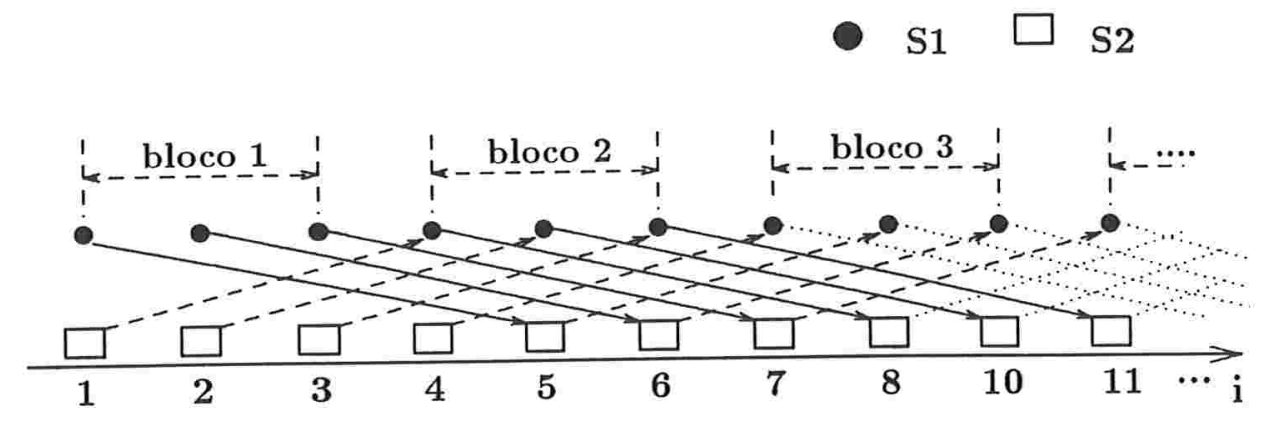

(b)

Figura 3.1: (a) - Grafo de dependência (b) - Relação de dependência entre as iterações

É fácil verificar que os vetores de dependência são $d_{12}=4, d_{21}=3$ e o fator de redução $\lambda=\min \left(d_{i j} \mid 1 \leq i, j \leq 2\right)=d_{21}=3$. Pela figura $3.1(\mathrm{~b})$ percebemos claramente que os blocos têm que ser executados sequecialmente, ou seja, bloco $\mathbf{b}_{\mathbf{i}} \delta$ bloco $_{\mathbf{i}-\mathbf{1}}$ e onde $1<i<N$, porém em cada bloco as iterações podem ser executadas paralelamente. Portanto o algoritmo será transformado na seguinte forma:

\section{Algoritmo transformado:}

for $i=1$ to $N$ step 3 do 


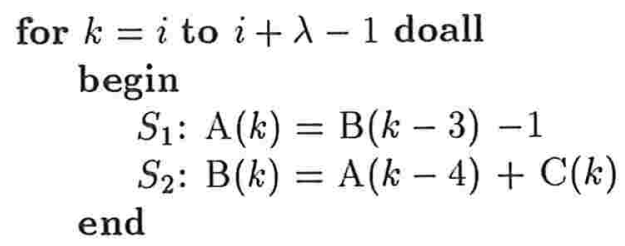

Obsevamos que se o fator de redução $\lambda=1$, o encolhimento de ciclo não paraleliza o laço serial.

\subsection{Encolhimento de ciclo seletivo}

Sejam $A$ um algoritmo RUN com $n$ laços e $m$ vetores de dependência, $D=\left\{\left(e_{i j}\right) \mid 1 \leq i \leq\right.$ $n, 1 \leq j \leq m\}$ sua matriz de dependência, onde $e_{i j}$ denota o elemento na linha $i$ e coluna $j$, e $\lambda_{i}=\min \left\{\left(e_{i j}\right) \mid 1 \leq i \leq n\right\}$ chamado de fator de redução [Pol88b].

No caso do encolhimento de ciclo seletivo, para determinar o fator de redução, acharemos o menor $i$ tal que $\lambda_{i}>0$, i.e., o primeiro $\lambda_{i}$ positivo. Todos os laços internos $(i+1, \ldots, n)$ são transformados em tipo doall, todos os laços externos $(1, \ldots, i-1)$ são seqüenciais e o laço $i$ também é executado seqüencialmente, mas com incremento $\lambda_{i}$ (fator de redução).

Vejamos o seguinte exemplo:

\section{Exemplo 3.2}

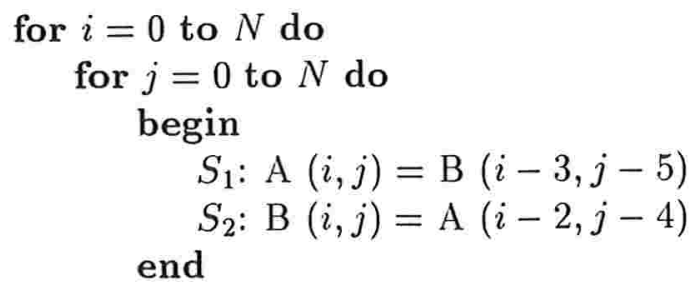

Para este exemplo, temos $d_{12}=\left(\begin{array}{l}2 \\ 4\end{array}\right), d_{21}=\left(\begin{array}{l}3 \\ 5\end{array}\right), D=\left(\begin{array}{ll}2 & 3 \\ 4 & 5\end{array}\right)$ (ver a figura 3.2) e $\lambda_{1}=\min \{2,3\}=2$ e $\lambda_{2}=\min \{4,5\}=4$. Como o primeiro $\lambda_{i}$ positivo é $\lambda_{1}=2$, temos o algoritimo transformado a seguir:

\section{Algoritmo transformado:}

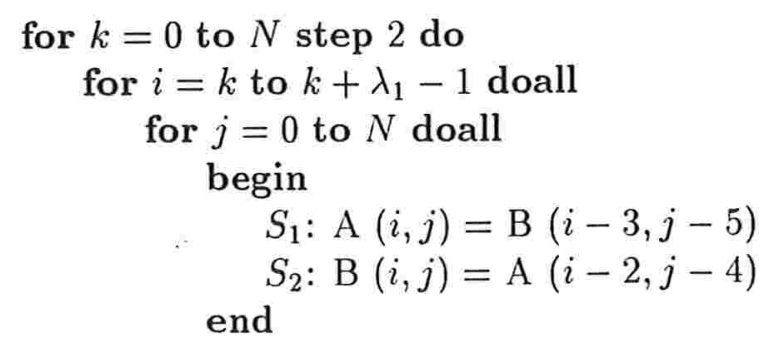




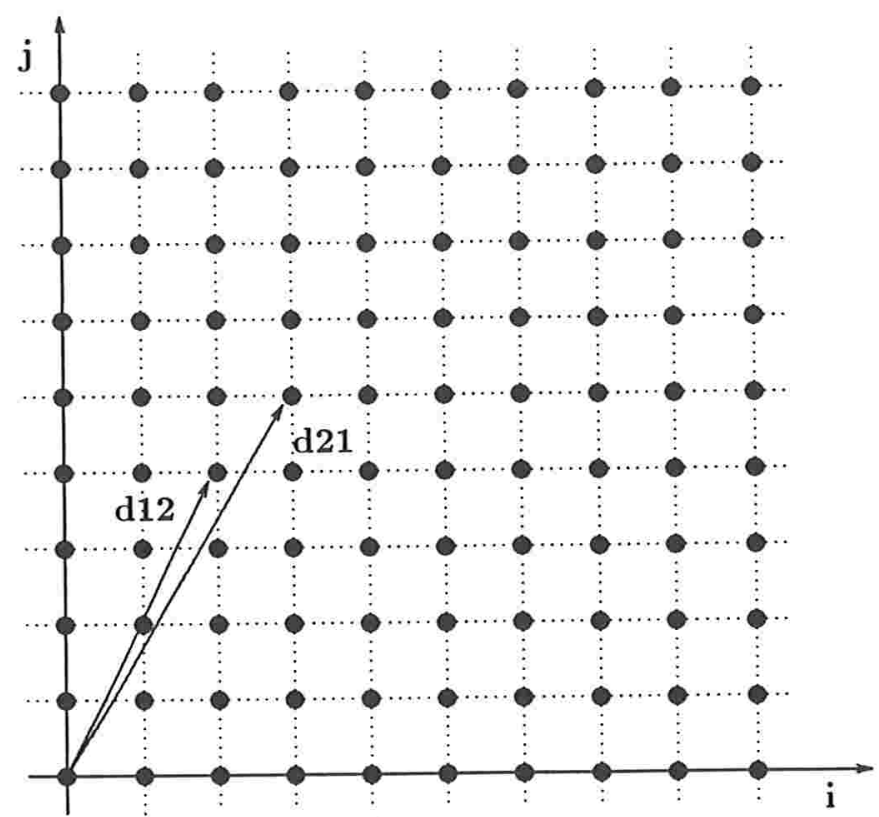

(a)

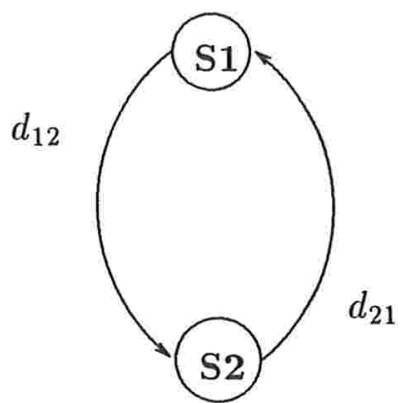

(b)

Figura 3.2: (a) - Dom e vetores de dependência do exemplo 3.2 (b) - Grafo de dependência

Pelo método de encolhimento de ciclo seletivo, o tempo de execução paralela é $\frac{N}{2}$ (ver a figura 3.3).

Para os laços encaixados, o encolhimento de ciclo seletivo (selective shrinking) é sempre melhor do que o encolhimento de ciclo simples (simple shrinking). Pois, neste caso, o ciclo de dependência é considerado separadamente para cada laço individual em laços encaixados. Para um $l$-ésimo laço dos laços encaixados, somente $l$-ésimos elementos dos vetores de dependências são considerados. Para cada laço dentro dos laços encaixados, o encolhimento de ciclo simples é aplicado separadamente como o caso de um laço simples. No exemplo 3.2 , se aplicarmos o encolhimento de ciclo simples, obteremos o algoritmo transformado em duas etapas. Vejamos a seguir:

\section{Algoritmo transformado:}

\section{Primeira etapa:}

$$
\begin{aligned}
& \text { for } i=0 \text { to } N \text { do } \\
& \text { for } j=0 \text { to } N \text { step } 4 \text { do } \\
& \text { for } k=j \text { to } j+\lambda_{2}-1 \text { doall } \\
& \text { begin } \\
& \quad S_{1}: \mathrm{A}(i, k)=\mathrm{B}(i-3, k-5) \\
& S_{2}: \mathrm{B}(i, k)=\mathrm{A}(i-2, k-4) \\
& \text { end }
\end{aligned}
$$

Segunda etapa: 


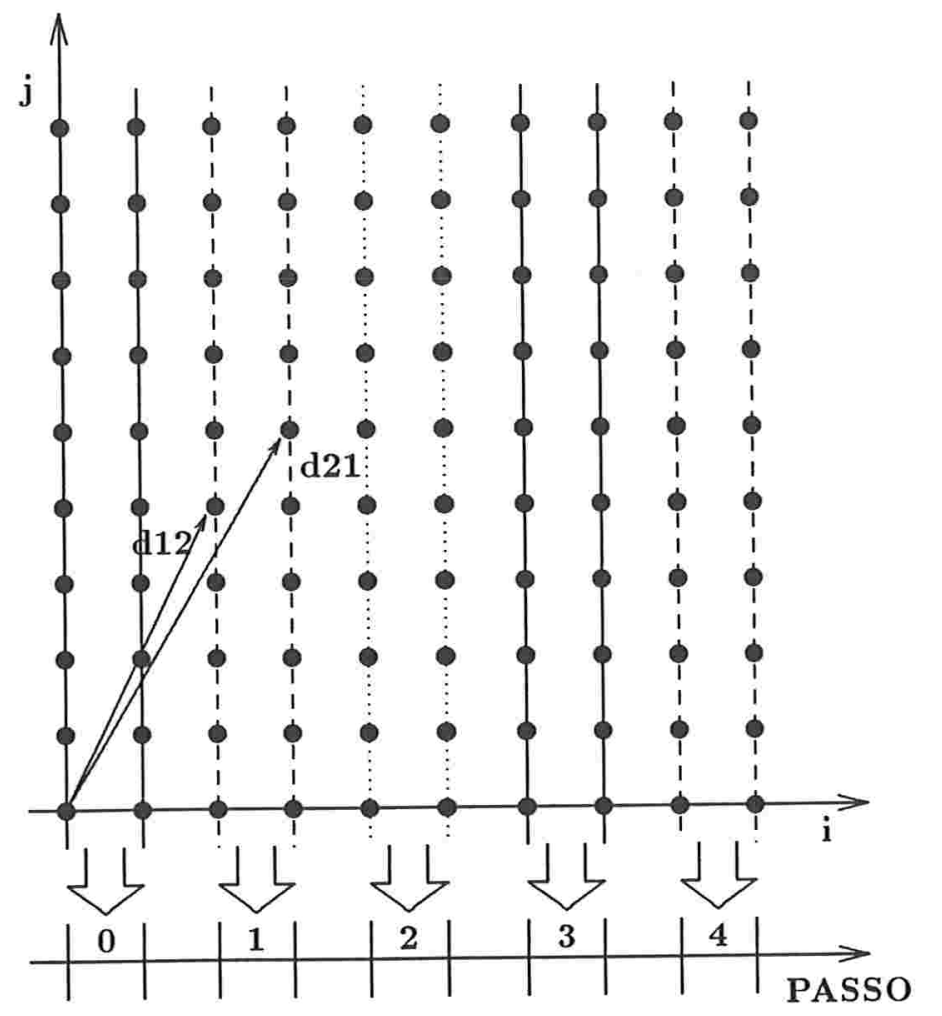

Figura 3.3: Execução paralela e escalonamento do exemplo 3.2

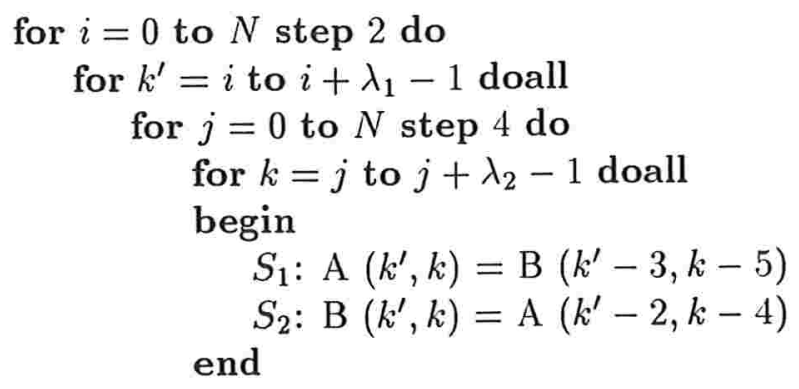

Pelo algoritmo transformado acima, notamos que o tempo de execução paralela é $\frac{N}{4} \times \frac{N}{2}=\frac{N^{2}}{8}$ que é muito pior que o tempo de execução paralela do encolhimento de ciclo seletivo, $\frac{\hbar}{2}$. Mas para o tempo de execução paralela existe ainda uma solução que é melhor que $\frac{N}{2}$ (veja a seção seguinte).

Agora vejamos o outro exemplo (ver a figura 3.4 ).

\section{Exemplo 3.3}

for $i=0$ to $N$ do

for $j=0$ to $N$ do begin 


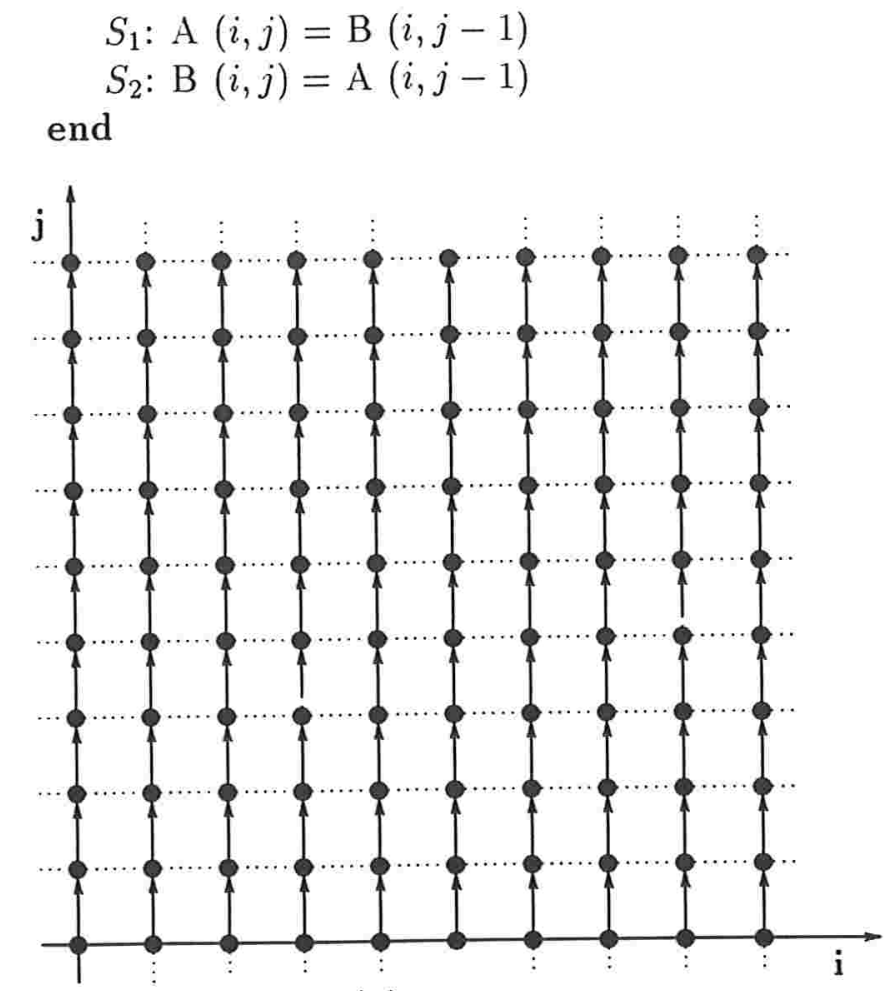

(a)

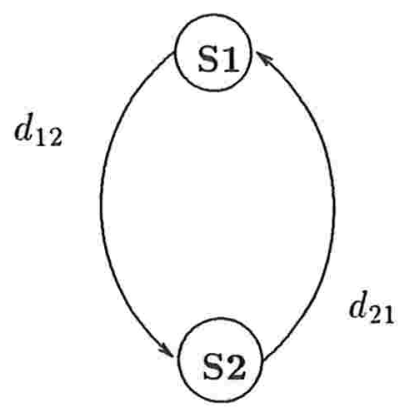

(b)

Figura 3.4: (a) - Dom e as dependências (b) - Grafo de dependência do exemplo 3.3

Para este exemplo, temos $d_{12}=\left(\begin{array}{l}0 \\ 1\end{array}\right), d_{21}=\left(\begin{array}{l}0 \\ 1\end{array}\right), D=\left(\begin{array}{ll}0 & 0 \\ 1 & 1\end{array}\right)$ e $\lambda_{1}=\min \{0,0\}=0$ e $\lambda_{2}=\min \{1,1\}=1$. Pelo método do encolhimento de ciclo seletivo, o laço $j$ será executado seqüencialmente com incremento $\lambda_{2}=1$, ou seja, sem nenhuma paralelização. Porém a figura 3.5 mostra uma execução paralela trivial para este exemplo. Esta observação mostra a limitação do método do encolhimento de ciclo seletivo. Na seção seguinte veremos um caso não tratado pelo encolhimento de ciclo seletivo, mas tratado pelo encolhimento de ciclo seletivo generalizado (Generalized Selective Shrinking - GSS).

\subsection{Método GSS - Generalized Selective Shrinking}

O método GSS [M. 91] generaliza o resultado de Polychronopoulos [Pol88b, Pol88a]. No capítulo 2 vimos o conceito de função de escalonamento. Nesta seção vamos usar outros nomes equivalentes: vetor de escalonamento (schedule vector), ou função de tempo. Vamos definir o vetor de escalonamento, ou função de tempo como sendo um vetor $\pi=\left(x_{1}, \ldots, x_{n}\right)$, onde cada $x_{i}$ $(1 \leq i \leq n)$ é um número inteiro. Determinaremos um vetor $\pi$, tal que os pontos $I, J \in$ Dom $\operatorname{com} \pi \cdot I=\pi \cdot J$ possam ser executados ao mesmo tempo.

\section{MÉTODO GSS:}



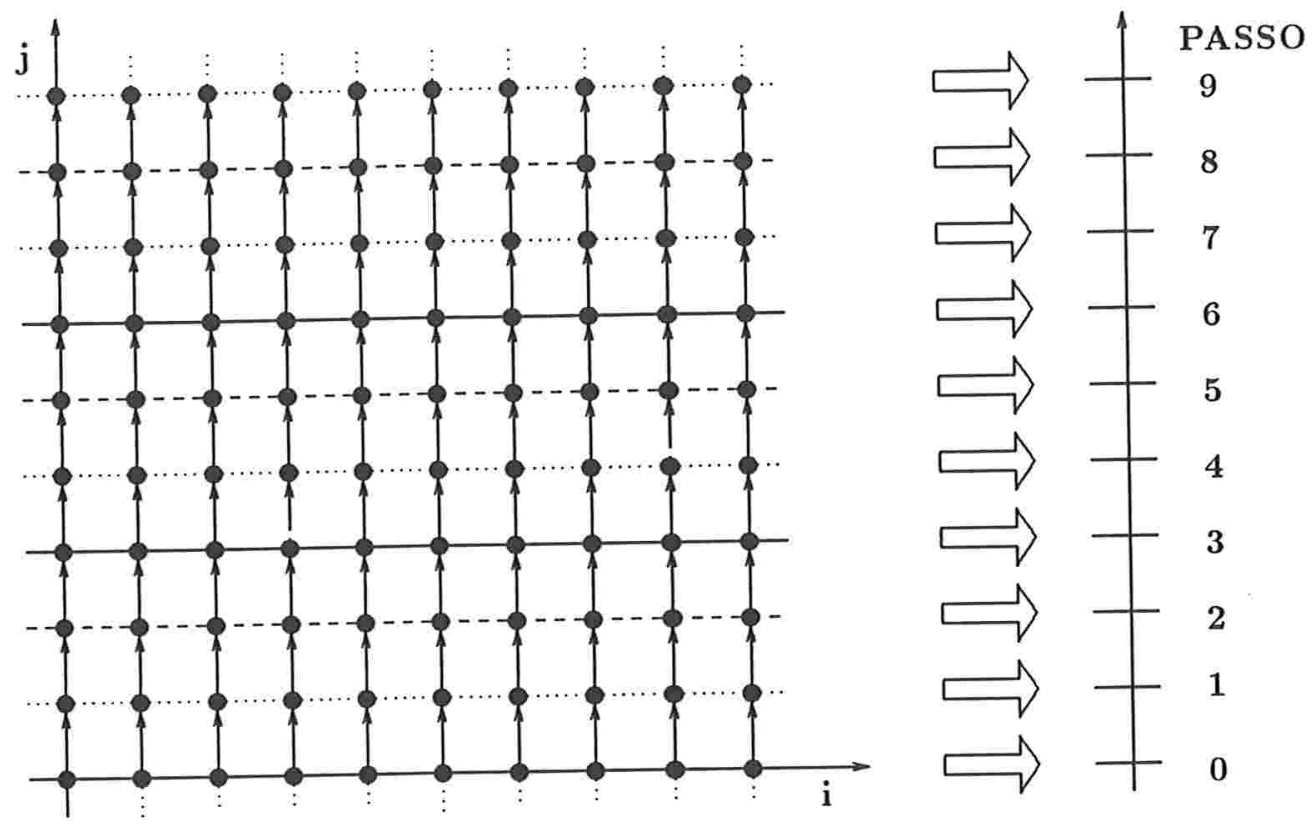

Figura 3.5: A execução paralela trivial para o exemplo 3.3

Considere um RUN com $n$ laços e sua matriz de dependência $n \times m, D=\left\{\left(e_{i j} \mid 1 \leq i \leq\right.\right.$ $n, 1 \leq j \leq m\}$. Qualquer $\pi \in Z^{1 \times n}$ tal que

1. $\pi \cdot D>0$

2. $\operatorname{mdc}\left\{x_{1}, \ldots, x_{n}\right\}=1$

pode ser usado como vetor de escalonamento. Qualquer ponto $I \in$ Dom é executado no tempo ou passo $\left\lfloor\frac{\pi \cdot I}{\operatorname{disp}(\pi)}\right\rfloor$, onde $\operatorname{disp}(\pi)=\min \left\{\pi \cdot d_{j} \mid 1 \leq j \leq m\right\}$ é chamado fator de redução. Note que $\operatorname{disp}(\pi)$ hiperplanos consecutivos são executados simultaneamente. Tais hiperplanos serão chamados hiperplanos de tempo. Agora, acharemos o melhor vetor $\pi$ que minimiza

$$
\frac{\max \{\pi \cdot I-\pi \cdot J \mid I, J \in D o m\}}{\operatorname{disp}(\pi)}=\operatorname{GSS}(\pi)
$$

Vejamos de novo o exemplo 3.2. Vamos mostrar um mapeamento entre qualquer ponto $I \in D o m$ e o tempo de execução.

Suponha que foi determinado $\pi=(1,0)$. Calcularemos $\operatorname{disp}(\pi)$ :

$$
\begin{aligned}
& \pi \cdot d_{1}=(1,0) \cdot(2,4)^{t}=2 \\
& \pi \cdot d_{2}=(1,0) \cdot(3,5)^{t}=3
\end{aligned}
$$

Como $\operatorname{disp}(\pi)=\min \left\{\pi \cdot d_{j} \mid 1 \leq j \leq m\right\}$, temos $\operatorname{disp}(\pi)=2$. Para exemplificar, escolheremos 5 pontos quaisquer que pertencem a $\bar{D}$ om. Veja a figura 3.6 , temos $(1,1),(3,2),(4,3),(5,2)$ e $(7,4)$. Determinaremos o tempo (passo) $\left\lfloor\frac{\pi \cdot I}{\operatorname{disp}(\pi)}\right\rfloor$ : 


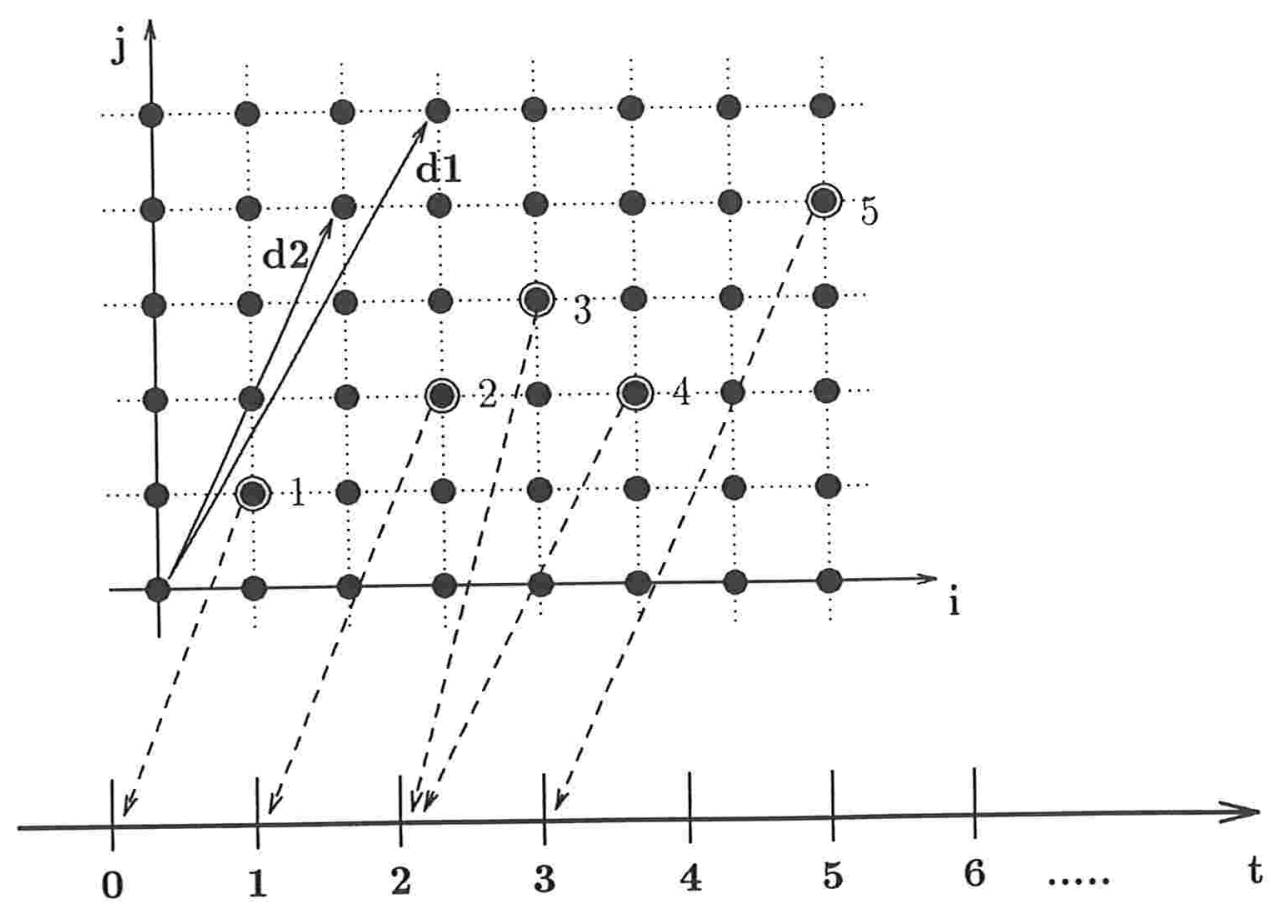

Figura 3.6: Mapeamento entre os pontos do Dom e tempo

$$
\begin{aligned}
& \left\lfloor\frac{\pi \cdot I_{1}}{2}\right\rfloor=\left\lfloor\frac{(1,0) \cdot(1,1)^{t}}{2}\right\rfloor=\left\lfloor\frac{1}{2}\right\rfloor=0 \\
& \left\lfloor\frac{\pi \cdot I_{2}}{2}\right\rfloor=\left\lfloor\frac{(1,0) \cdot(3,2)^{t}}{2}\right\rfloor=\left\lfloor\frac{3}{2}\right\rfloor=1 \\
& \left\lfloor\frac{\pi \cdot I_{3}}{2}\right\rfloor=\left\lfloor\frac{(1,0) \cdot(4,3)^{t}}{2}\right\rfloor=\left\lfloor\frac{4}{2}\right\rfloor=2 \\
& \left\lfloor\frac{\pi \cdot I_{4}}{2}\right\rfloor=\left\lfloor\frac{(1,0) \cdot(5,2)^{t}}{2}\right\rfloor=\left\lfloor\frac{5}{2}\right\rfloor=2 \\
& \left\lfloor\frac{\pi \cdot I_{5}}{2}\right\rfloor=\left\lfloor\frac{(1,0) \cdot(7,4)^{t}}{2}\right\rfloor=\left\lfloor\frac{7}{2}\right\rfloor=3
\end{aligned}
$$

Pelo resultado acima, temos que:

O ponto $(1,1)$ está mapeado ao tempo 0 ;

$\mathrm{O}$ ponto $(3,2)$ está mapeado ao tempo 1 ;

Os pontos $(4,3),(5,2)$ estão mapeados ao tempo 2 ;

O ponto $(7,4)$ está mapeado ao tempo 3 .

Agora, vamos ver como determinar o vetor $\pi$ para o exemplo 3.2: Seja $\pi=(a, b)$. Queremos 
obter $a, b$ que minimizem

$$
\frac{\max \{\pi \cdot I-\pi \cdot J \mid I, J \in D o m\}}{\operatorname{disp}(\pi)}=\operatorname{GSS}(\pi)
$$

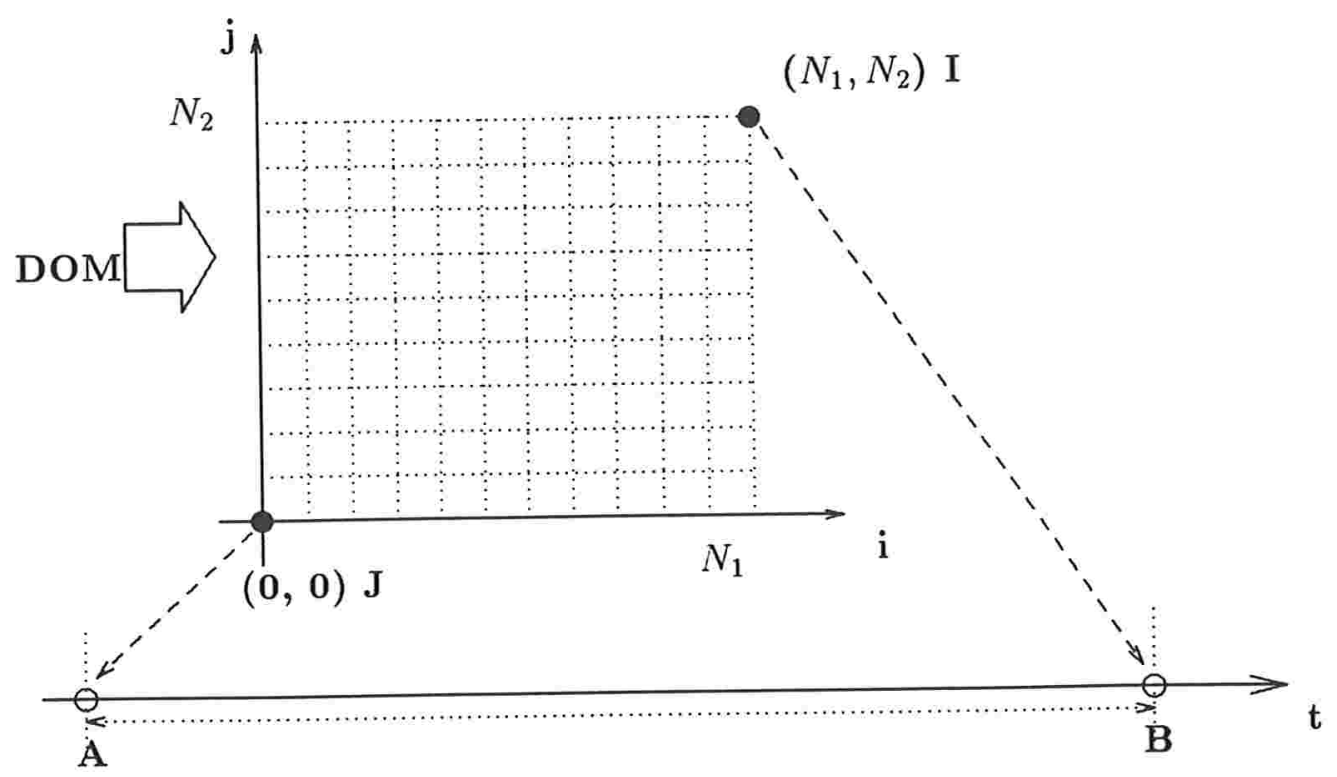

Figura 3.7: Mapeamento de dois pontos extremos

Veja a figura 3.7. Queremos minimizar a distância entre A e B. Temos $\max \{\pi \cdot I-\pi \cdot J\}=$ $\left(|a| N_{1}+|b| N_{2}\right)$ e $\operatorname{disp}(\pi)=\min \left\{\pi \cdot d_{j} \mid 1 \leq j \leq 2\right\}=\min \{2 a+4 b, 3 a+5 b\}$. Pelo método GSS, a condição é

$$
\left\{\begin{array}{c}
m d c(a, b)=1 \\
2 a+4 b \geq 1 \\
3 a+5 b \geq 1
\end{array}\right.
$$

Assim, obtemos:

$$
\begin{aligned}
& \pi=(1,0) \Rightarrow \operatorname{GSS}(\pi)=\frac{N_{1}}{2} \\
& \pi^{\prime}=(0,1) \Rightarrow \operatorname{GSS}(\pi)=\frac{N_{2}}{4}
\end{aligned}
$$

Observamos se $N_{2}<2 N_{1}$, escolheremos $\pi^{\prime}$. Caso contrário, escolheremos $\pi$. Para o exemplo 3.2 temos $N_{1}=N_{2}=N$, neste caso, claramente vamos escolher $\pi^{\prime}$. O tempo de execução paralela obtida é portanto $\frac{N}{4}$ (ver a figura 3.8 ), melhor que o tempo obtido pelo método encolhimento de ciclos seletivo que nos dá apenas uma dessas soluções.

Vejamos o outro exemplo (ver a figura 3.9 ):

\section{Exemplo 3.4}

for $i=0$ to $N$ do

for $j=0$ to $N$ do 


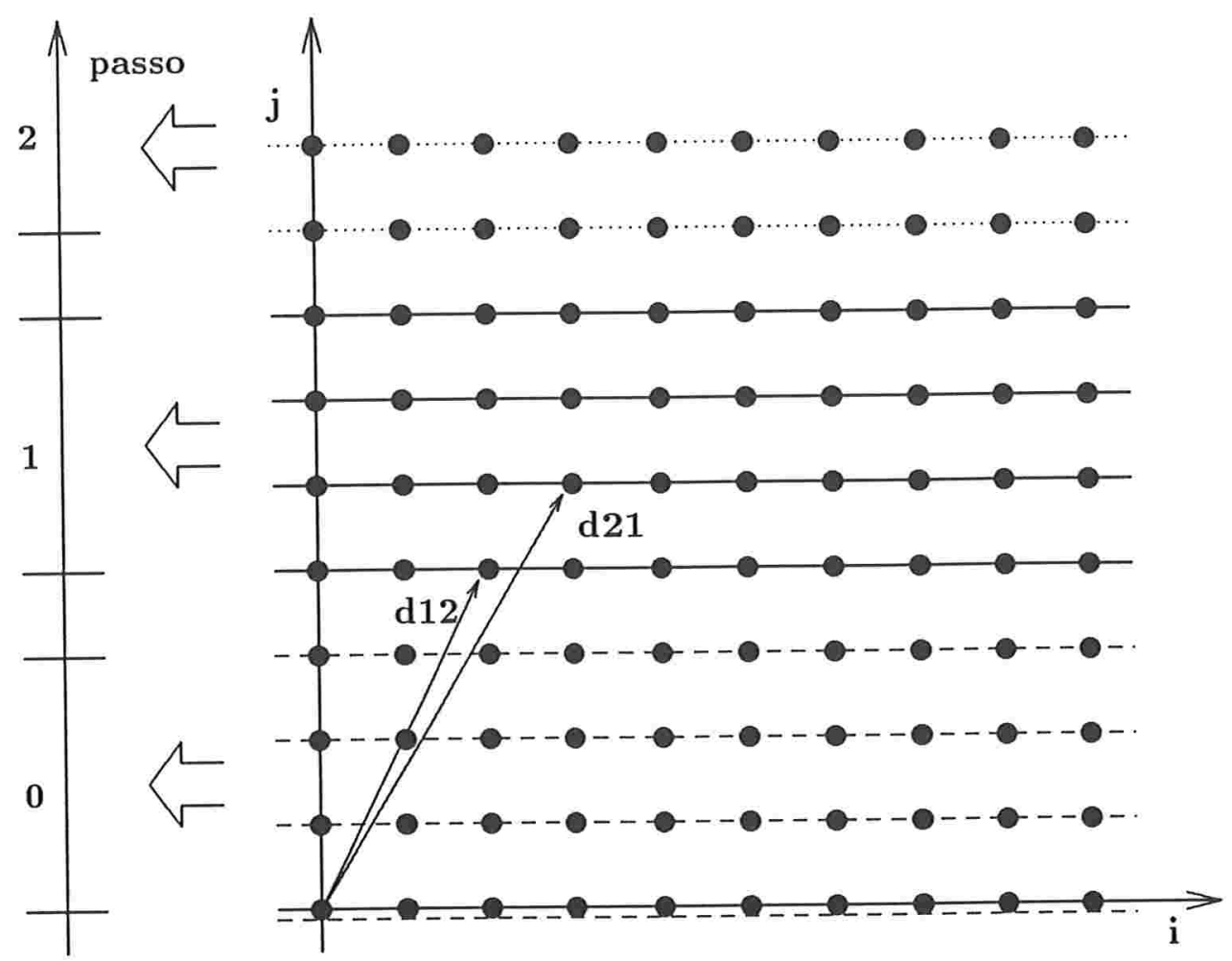

Figura 3.8: Outra solução para exemplo 3.3

\section{begin}

$S_{1}: \mathrm{A}(i, j)=\mathrm{B}(i-1, j)$

$S_{2}: \mathrm{B}(i, j)=\mathrm{C}(i, j-1)$

$S_{3}: \mathrm{C}(i, j)=\mathrm{A}(i-1, j)$

end

Para este exemplo, temos $d_{21}=\left(\begin{array}{l}1 \\ 0\end{array}\right), d_{32}=\left(\begin{array}{l}0 \\ 1\end{array}\right), d_{13}=\left(\begin{array}{l}1 \\ 0\end{array}\right)$ e $D=\left(\begin{array}{lll}1 & 0 & 1 \\ 0 & 1 & 0\end{array}\right)$. Assim, pelo encolhimento de ciclo seletivo é impossível paralelizar, mas se aplicarmos GSS a este exemplo, obteramos uma solução desejada.

Pelo teorema GSS, temos que achar $\pi_{0}=(x, y)$ que minimize GSS $(\pi)=\frac{\max \{\pi \cdot I-\pi \cdot J \mid I, J \in D o m\}}{\min \left\{\pi \cdot d_{12}, \pi \cdot d_{23}, \pi \cdot d_{31}\right\}}$ sob condições:

1. $\pi \cdot d_{12}=\pi \cdot d_{31}>0, \pi \cdot d_{23}>0$

2. $m d c\{x, y\}=1$

Das condições impostas, temos que $x>0$ e $y>0$ e $\operatorname{GSS}(\pi)=\frac{(x+y) N}{\min \{x, y\}}$. A solução ótima será $x=y=1$ e $\operatorname{GSS}\left(\pi_{0}\right)=2 N$ passos com $\pi_{0}=(1,1)$ (ver a figura 3.10 ). 

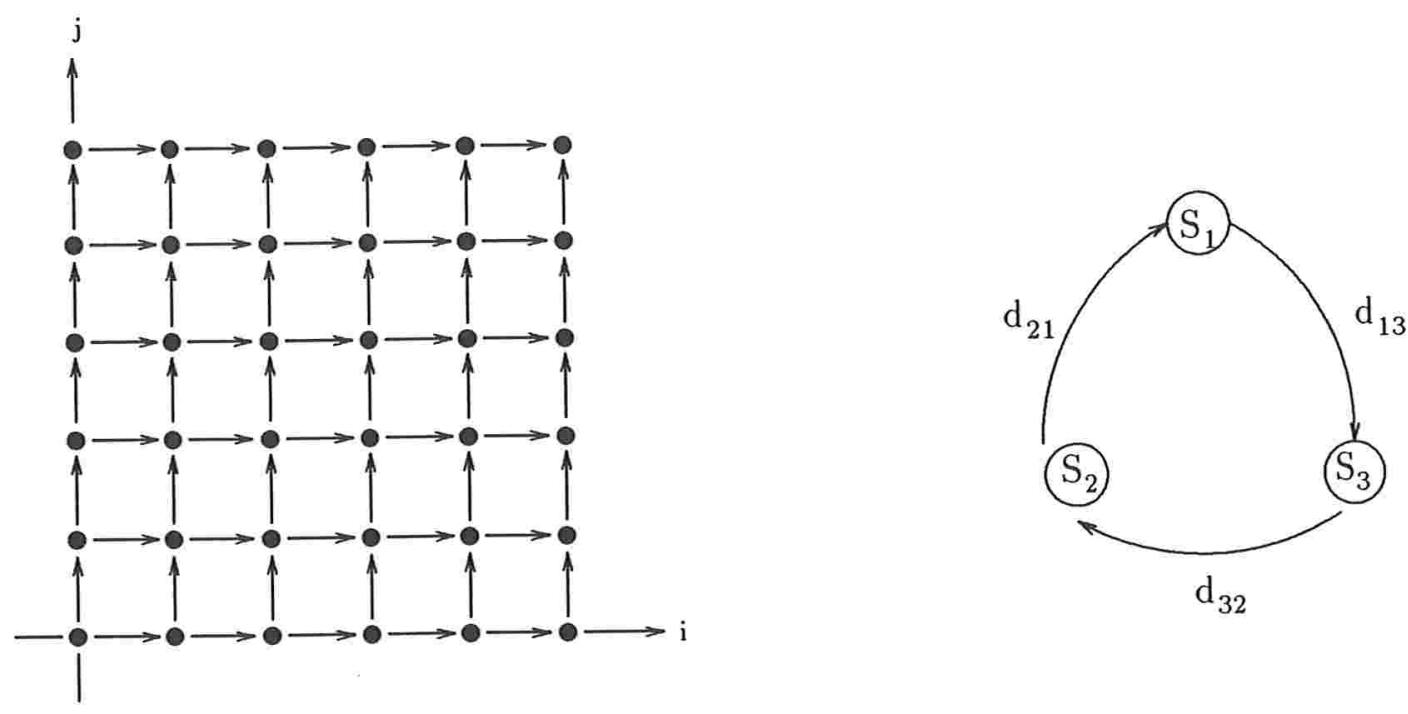

Figura 3.9: Dom e grafo de dependência do exemplo 3.4

\section{Obervações:}

- A condição $\pi \cdot D>0$ é para garantir que $\pi \cdot d>0$, onde $d$ é um vetor de dependência qualquer e $\pi \neq(0,0)$. Caso $\pi=(0,0)$, todos os pontos do domínio serão mapeados ao tempo zero. Isso significa que não existem dependências entre os comandos. Sejam $I\left(i_{1}, j_{1}\right)$ e $J\left(i_{2}, j_{2}\right)$ dois pontos quaisquer, $I, J \in D o m$. Se o ponto $J$ depende do ponto $I$, então o ponto $J$ tem que ser executado depois do $I$. Portanto, temos $\left\lfloor\frac{\pi \cdot J}{\operatorname{disp}(\pi)}\right\rfloor-\left\lfloor\frac{\pi \cdot I}{\operatorname{disp}(\pi)}\right\rfloor>0$, ou seja, $\pi \cdot J-\pi \cdot I>0 \Rightarrow \pi\left(\begin{array}{c}i_{2} \\ j_{2}\end{array}\right)-\pi\left(\begin{array}{c}i_{1} \\ j_{1}\end{array}\right)>0 \Rightarrow \pi\left[\left(\begin{array}{c}i_{2} \\ j_{2}\end{array}\right)-\left(\begin{array}{c}i_{1} \\ j_{1}\end{array}\right)\right]>0$. Pela definição de um vetor de dependência, temos $\left(\begin{array}{c}i_{2} \\ j_{2}\end{array}\right)-\left(\begin{array}{c}i_{1} \\ j_{1}\end{array}\right)=d \Rightarrow \pi \cdot d>0$.

- A condição $m d c\left\{x_{1}, \ldots, x_{n}\right\}=1$ é para evitar o vetor que é o produto de um vetor com um escalar não nulo. Estes vetores têm mesmo escalonamento e são equivalentes do ponto de vista do escalonamento. Seja $\pi_{0}=k \pi$, onde $k$ é um escalar não nulo, então $\left\lfloor\frac{\pi_{0} \cdot I}{\operatorname{disp}\left(\pi_{0}\right)}\right\rfloor=\left\lfloor\frac{k \pi \cdot I}{\operatorname{disp}(k \pi)}\right\rfloor=\left\lfloor\frac{k \pi \cdot I}{k \operatorname{disp}(\pi)}\right\rfloor=\left\lfloor\frac{\pi \cdot I}{\operatorname{disp}(\pi)}\right\rfloor$. 


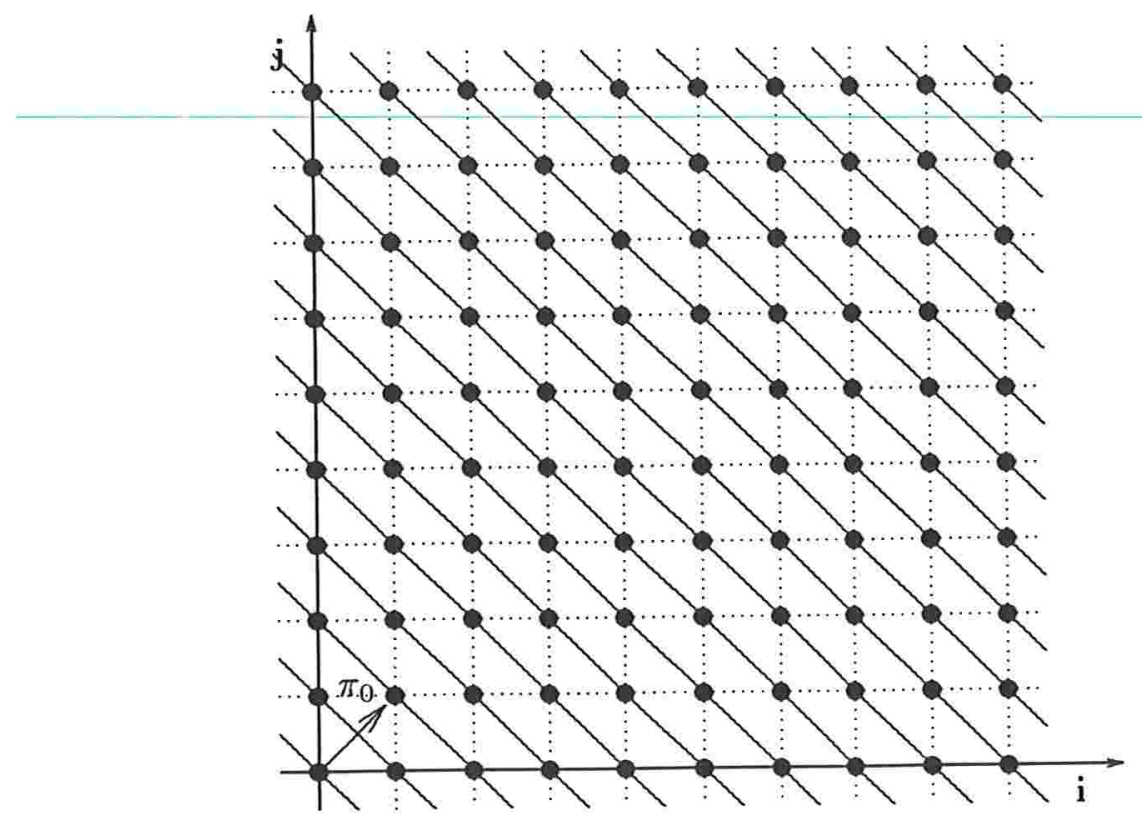

Figura 3.10: Uma solução paralela e $\pi_{0}$ para o exemplo 3.4 


\section{Capítulo 4}

\section{Método GTS (Graph Traverse Scheduling)}

GTS ou Escalonamento por Travessia em Grafo é um método para extrair o paralelismo de laços do com fortes recorrências, onde há um ou mais ciclos de dependência. Essa paralelização é baseada na análise de dependências dentro de escopo de cada laço [LA89, J. 89, Jes94].

Neste capítulo, consideraremos laços simples (laços não aninhados ou encaixados) com uma ou mais recorrências. Neste caso o vetor de dependência será do tipo $d=(a)$, onde o elemento $a$ será a distância de dependência associada.

- Na seção 4.1, introduzimos algumas definições como caminho, recorrência, recorrência hamiltoniana, doacross.

- Na seção 4.2, mostramos o método GTS para laços simples com uma recorrência hamiltoniana sem necessidade de sincronização.

\subsection{Definições}

Consideramos um grafo orientado $G(V, E)$ com conjunto de nós $V=\left\{S_{1}, \ldots, S_{n}\right\}$ representando os comandos no corpo do laço, e um conjunto de $\operatorname{arcos} E=\left\{d_{i j} \mid S_{i}, S_{j} \in V\right\}$ representando dependências de dados entre comandos $S_{i}$ e $S_{j}$ e sua distância de dependência associada.

Um caminho $C_{i j}$ entre os nós $i$ e $j$ é um conjunto de arcos:

$$
C_{i j}=\left\{d_{i k}, d_{k l}, \ldots, d_{m j}\right\}
$$

tal que cada nó é visitado somente uma vez. Para não carregar a notação, vamos usar o próprio símbolo $d_{i j}$ para denotar a distância associada ao arco $d_{i j}$. O peso de um caminho $C_{i j}$ é definido como

$$
W\left(C_{i j}\right)=\sum_{d_{k l} \in C_{i j}} d_{k l}
$$


Uma recorréncia $R$ é um ciclo ou um caminho fechado $C_{i i}$ com pelos menos um arco. Isto é $|R| \geq 1$, onde $|R|$ representa o número de $\operatorname{arcos}$ em $R$.

Dada uma recorrência $R$, definimos seu conjunto transformado $R^{*}$ como sendo o conjunto de nós incluídos na recorrência. Isto é,

$$
R^{*}=\left\{S_{i} \mid \exists k, d_{i k} \in R\right\}
$$

Uma recorrência hamiltoniana é uma recorrência que envolve todos os nós do grafo. Se um grafo tem uma recorrência hamiltoniana, ele é chamado de grafo hamiltoniano e seu laço associado de laço hamiltoniano.

Quando um laço não contém dependências entre iterações, a paralelização pode ser realizada por um laço doall. Por outro lado, existe o laço doacross [Pol88b, LA89, J. 89], onde as dependências entre iterações permitem sobrepor parcialmente a execução de iterações sucessivas.

\subsection{Paralelização de laços com uma recorrência hamiltoniana}

Nesta seção, apresentamos o método GTS para laços simples com uma recorrência hamiltoniana e o algoritmo de escalonamento [J. 89, LA89]. Aplicando o método GTS para laços simples com uma recorrência hamiltoniana é possível paralelizar tais laços sem necessidade de sincronização.

O paralelismo de um laço é definido como sendo o número médio de processadores ativos executando iterações de um laço, se não ocorrer nenhuma sincronização e nem overhead de escalonamento.

Chamaremos de tarefa a sequência de comandos executados por um processador.

A distância de um arco determina o número de iterações do comando associado ao nó destino que pode ser executado inicialmente. Então, a soma das distâncias dos arcos que formam um ciclo ou uma recorrência $R$ determina o número de tarefas $P$ que pode ser o paralelismo do laço:

$$
P=W(R)=\sum_{d_{i j} \in R} d_{i j}
$$

O escalonamento, para uma recorrência hamiltoniana, atribui inicialmente a cada tarefa um comando e um índice de iteração sem dependência inicial. Este escalonamento é obtido através do percurso no grafo hamiltoniano no sentido contrário aos arcos e atribuindo às tarefas consecutivas todos os índices de iterações inicialmente livres de dependência de cada comando.

Para uma recorrência genérica $R=\left\{d_{l j}, d_{j k}, \ldots, d_{m n}, d_{n l}\right\}$, incluída em um laço simples do, o escalonamento gerará $P$ tarefas, numeradas de zero até $P-1$, cada uma delas começando com o comando como mostrado abaixo:

$$
S_{l(1)}, S_{l(2)}, \ldots, S_{l\left(d_{n l}\right)}, S_{n(1)} S_{n(2)}, \ldots, S_{n\left(d_{m n}\right)}, \ldots, S_{k(1)}, S_{k(2)}, \ldots, S_{k\left(d_{j k}\right)}, S_{j(1)}, S_{j(2)}, \ldots, S_{j\left(d_{l}\right)}
$$

onde $S_{i(j)}$ representa comando $S_{i}$ e índice de iteração $j$. Para não carregar a notação, neste capítulo, vamos usar $S_{i j}$ para representar comando $S_{i}$ e índice de iteração $j$. 
Começando com o comando inicial escalonado, cada tarefa executa seqüencialmente os comandos e os índices que dependem diretamente do anterior. Veja o seguinte exemplo e as figuras abaixo [LA89]:

\section{Exemplo 4.1}
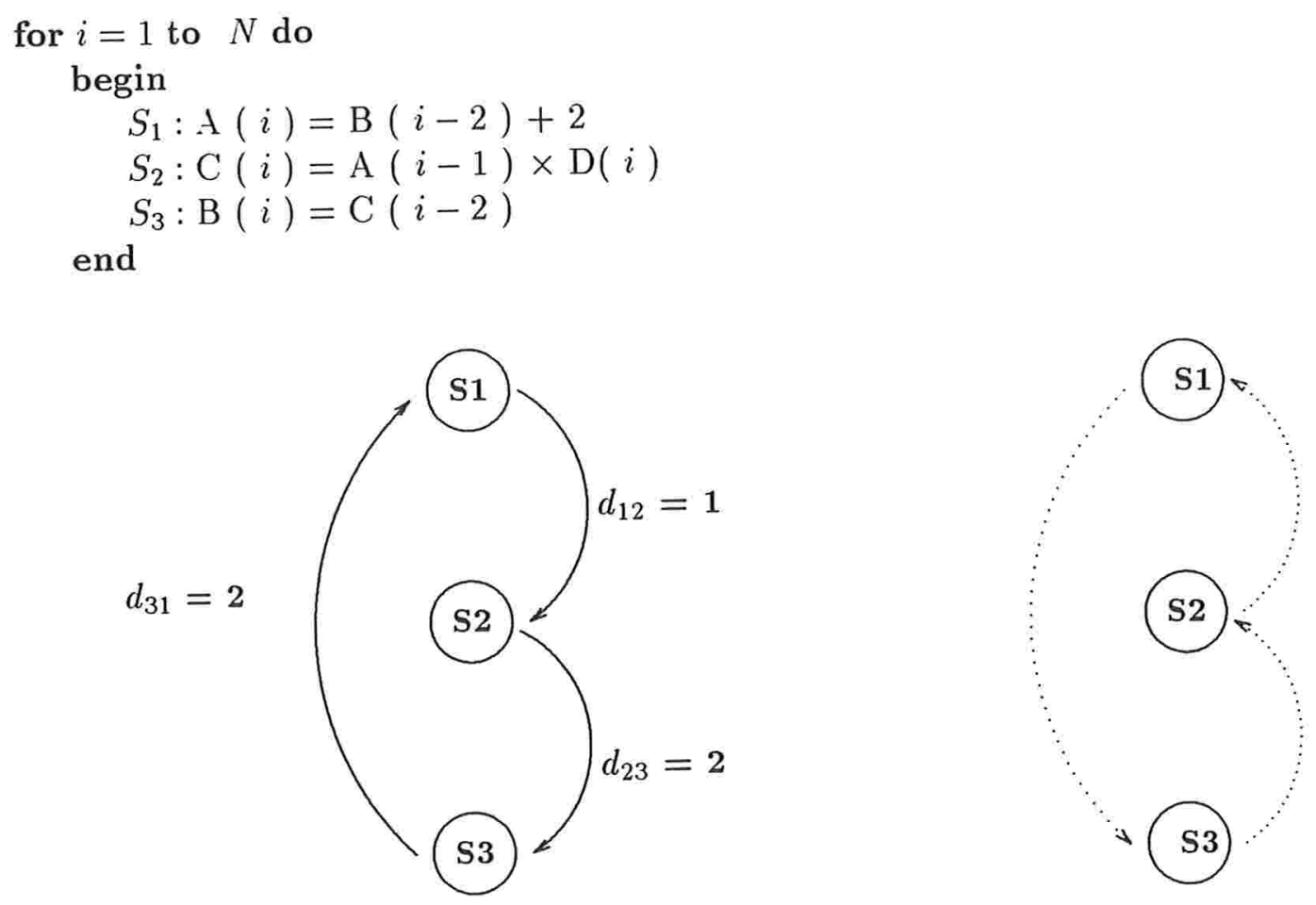

Figura 4.1: O grafo de dependência e o caminho para obter o escalonamento

Para podermos ilustrar melhor este exemplo, tomamos $N=10$. Para este exemplo, temos $R=\left\{d_{12}, d_{23}, d_{31}\right\}$ (ver a figura 4.1), o paralelismo é $P=W(R)=\sum_{d_{i j} \in R} d_{i j}=1+2+2=5$ e o escalonamento gera 5 tarefas através da análise do grafo de dependência (veja a figura 4.2 e a figura 4.4), cada uma delas começando com o comando apresentado abaixo (as iterações dentro das linhas tracejadas na figura 4.2):

$$
S_{11}, S_{12}, S_{31}, S_{32}, S_{21}
$$

Pela figura 4.4, podemos ver que a partir destes comandos iniciais escalonados, para cada tarefa, todos os comandos e os índices que dependem diretamente do anterior formam uma "corrente" de dependências, ou seja, todos os comandos dentro de uma tarefa serão executados seqüencialmente conforme o escalonamento.

Agora, mostramos o código paralelo gerado pelo laço seqüencial do Exemplo 4.1. Observamos que alguns comandos e iterações são extraídos dentro do laço do para que possamos usar o mesmo 


\begin{tabular}{ccccc} 
tarefa 0 & tarefa 1 & tarefa 2 & tarefa 3 & tarefa 4 \\
\hline & $S_{12}$ & $S_{31}$ & $S_{32}$ & $S_{21}$ \\
$S_{11}$ & $S_{23}$ & $S_{13}$ & $S_{14}$ & $S_{33}$ \\
$S_{22}$ & $S_{35}$ & $S_{24}$ & $S_{25}$ & $S_{15}$ \\
$S_{34}$ & $S_{17}$ & $S_{36}$ & $S_{37}$ & $S_{26}$ \\
$S_{16}$ & $S_{28}$ & $S_{18}$ & $S_{19}$ & $S_{38}$ \\
$S_{27}$ & $S_{310}$ & $S_{29}$ & $S_{210}$ & $S_{110}$ \\
$S_{39}$ & & &
\end{tabular}

Figura 4.2: O escalonamento para exemplo 4.1

\begin{tabular}{llllll} 
tarefa 0 & tarefa 1 & tarefa 2 & tarefa 3 & tarefa 4 \\
\hline$\ldots \ldots \ldots \ldots \ldots \ldots \ldots \ldots \ldots \ldots$ & & & \\
$S_{11}$ & $S_{12}$ & $S_{31}$ & $S_{32}$ & $S_{21}$ \\
$S_{22}$ & $S_{23}$ & $S_{13}$ & $S_{14}$ & $S_{33} \ldots \ldots \ldots$ \\
$S_{34}$ & $S_{35}$ & $S_{24}$ & $S_{25}$ & $S_{15}$ \\
$S_{16}$ & $S_{17}$ & $S_{36}$ & $S_{37}$ & $S_{26}$ \\
$S_{27}$ & $S_{28}$ & $S_{18}$ & $S_{19}$ & $S_{38}$ \\
$S_{39}$ & $S_{310}$ & $S_{29} \ldots$ & $S_{210}$ & $S_{110} \ldots \ldots$
\end{tabular}

Figura 4.3: O escalonamento para exemplo 4.1 
código para todas as tarefas. A execução dos comandos no início do laço doall é dependente do número de identificação da tarefa (as iterações acima da linha pontilhada (veja na figura 4.3)). Os comandos após o laço do são executados somente pelas tarefas que não chegaram ao final da computação conforme o escalonamento (as iterações dentro dos quadrados com as linhas pontilhadas (veja na figura 4.3)).

\section{Algoritmo transformado:}
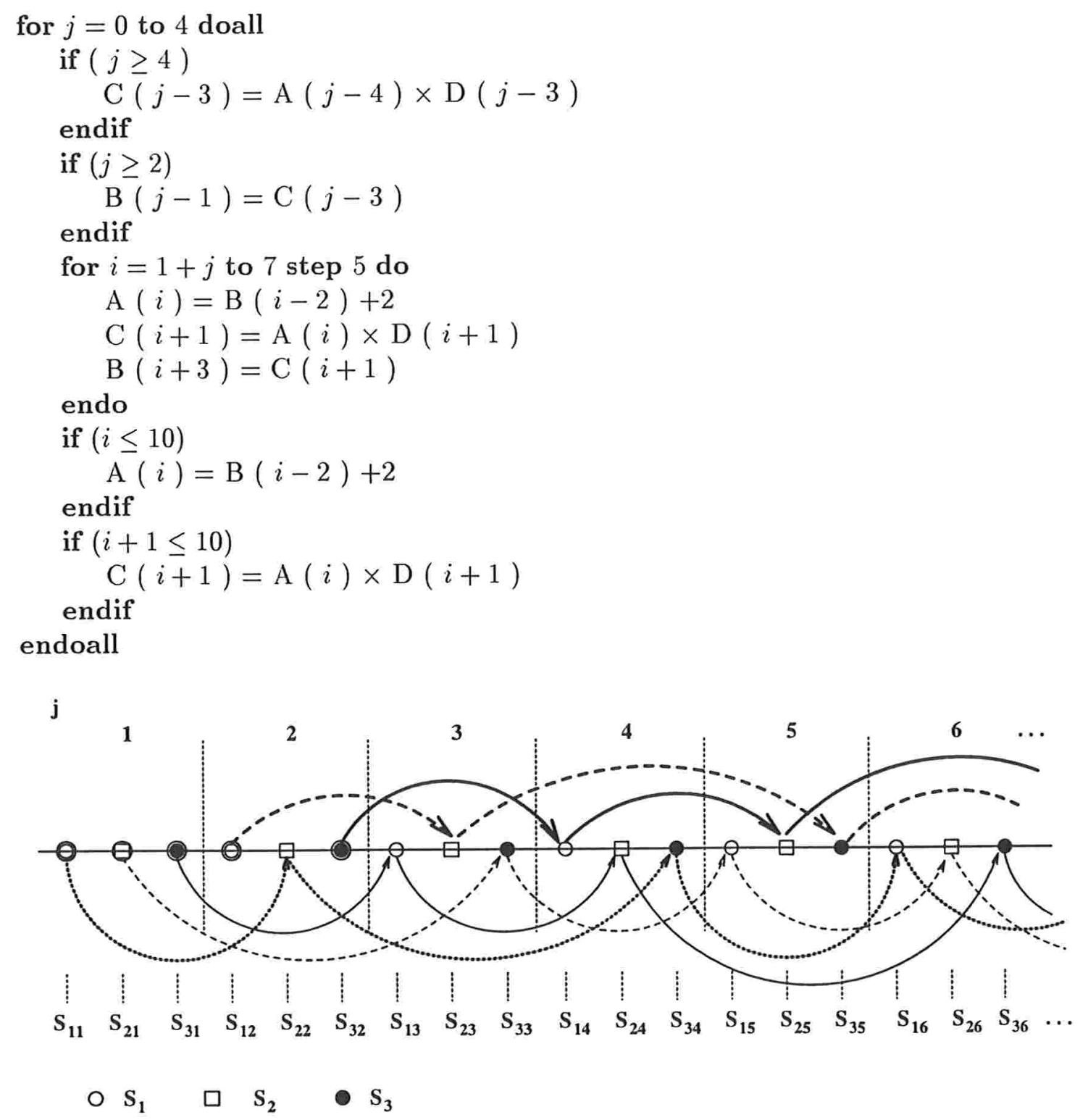

Figura 4.4: Escalonamento e as "correntes" de dependências entre as iterações

Notamos que também o código original de cada comando é modificado no laço do do algoritmo transformado pelo acréscimo à variável indexada do laço, de uma compensação igual ao peso 
do caminho desde o comando inicial da tarefa. Por outro lado, através da figura 4.5, podemos ilustrar a alocação dos processadores e as dependências entre as iterações. Isso será útil para o estudo comparativo entre os métodos GTS e RD, o qual será apresentado no capítulo 6 .

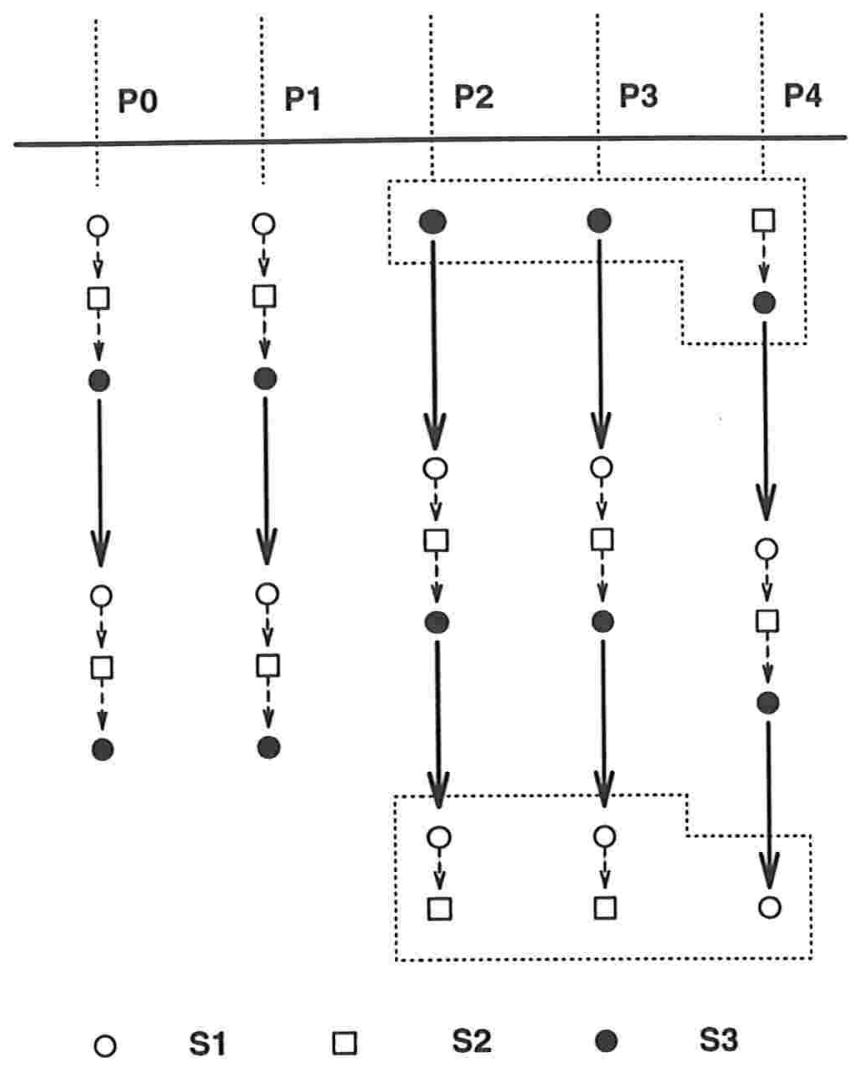

Figura 4.5: Alocação dos processadores e as dependências entre as iterações

\section{Observação:}

- O método GTS consegue extrair mais paralelismo que o encolhimento de ciclos [Pol88b, Pol88a] em caso de laços simples. Como foi dito no capítulo anterior se a distância mínima for um, o método do encolhimento de ciclos não paraleliza. No entanto, esta restrição não está presente em GTS. Na realidade, o encolhimento de ciclos obtém o mesmo paralelismo que GTS somente no caso em que $d_{i j}=$ constante, $\forall i, j$.

Discutiremos sobre a paralelização de laços com múltiplas recorrências no capítulo 6 . 


\section{Capítulo 5}

\section{Método por Redução de Dependência (RD)}

Neste capítulo será apresentado o método de redução de dependência proposto por Kunio Okuda [Kun96b]. Este método transforma o grafo de dependência, reduz o número de vetores de dependência e o número de comunicações entre processadores afim de obter um menor tempo total de execução paralela, resultando numa análise mais simplificada do escalonamento.

- Na seção 5.1, introduzimos o conceito de domínio explícito (DE), uma nova representação de dependências entre comandos em laços.

- Na seção 5.2, descrevemos o método RD para o caso do grafo de dependência igual um ciclo e analisamos o mapeamento através de um exemplo.

- Na seção 5.3, mostramos o método RD no caso do grafo de dependência com mais de um ciclo e fazemos alguns comentários sobre este caso.

\subsection{Domínio explícito (DE)}

O objetivo de definir o domínio explícito $(D E)$ é para explicar as dependências em Dom de modo mais claro.

Considere sempre um RUN de $n$ laços, $k$ comandos e $m$ vetores de dependência para o capítulo 5 .

\section{RUN}

for $i_{1}=0$ to $N_{1}$ do

for $i_{2}=0$ to $N_{2}$ do

for $i_{3}=0$ to $N_{3}$ do 


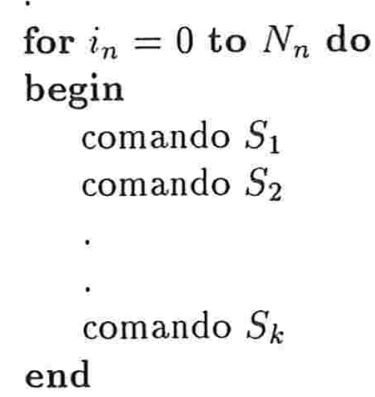

Adotaremos a seguinte definição:

$D E=$ domínio explícito $=\left\{S_{1}, \ldots, S_{k}\right\} \times D o m$

$D O M$ é o espaço cartesiano discreto com $n$ dimensões no qual cada ponto representa a execução dos comandos em cada iteração dos laços. Para sua representação $D E$ será sempre identificado como um subconjunto de $R^{n+1}$ de modo que cada $\left\{S_{\alpha}\right\} \times D o m$, onde $1 \leq \alpha \leq k$, seja identificado com $\{\alpha\} \times D o m$ e todos os pontos de $D E$ serão ligados por vetores de dependência explicitamente.

Para visualizar melhor na representação 2-dimencional, podemos projetar cada $\left\{S_{\alpha}\right\} \times$ Dom , onde $1 \leq \alpha \leq k$, ligeiramente deslocado em relação aos outros $\left\{S_{\beta}\right\} \times D o m$ projetados, onde $\beta \neq \alpha$, evitando sobreposição.

A vantagem desta representação é que ela mostrará a relação explícita entre as dependências e os comandos, de modo a facilitar sua análise e compreensão. Veremos os exemplos na próxima seção, onde serão utilizados Dom e $D E$, de acordo com a conveniência.

\subsection{Grafo de dependência igual a um ciclo}

Vejamos o seguinte exemplo [Kun96b] (o mesmo exemplo 3.4).

\section{Exemplo 5.1}

for $i=0$ to $N$ do

for $j=0$ to $N$ do

begin

$$
\begin{aligned}
& \qquad \begin{array}{r}
S_{1}: \mathrm{A}(i, j) \\
S_{2}: \mathrm{B}(i, j)=\mathrm{B}(i-1, j) \\
S_{3}: \mathrm{C}(i, j)
\end{array}=\mathrm{A}(i-1, j) \\
& \text { end }
\end{aligned}
$$

Para este exemplo, temos $d_{21}=\left(\begin{array}{l}1 \\ 0\end{array}\right), d_{32}=\left(\begin{array}{l}0 \\ 1\end{array}\right)$, e $d_{13}=\left(\begin{array}{l}1 \\ 0\end{array}\right)$ e $D E=\left\{S_{1}, S_{2}, S_{3}\right\} \times D o m$. Para obter a representação 2-dimensional de $D E$, projetaremos cada 
$\left\{\left(S_{a} . i, j\right) \mid \alpha \in\{1,2,3\},(i, j) \in D o m\right\}$ em $R^{2}$ de modo ligeiramente deslocado um em relação ao outro. evitando que $S_{1}(i, j), S_{2}(i, j)$ e $S_{2}(i, j)$ sejam sobrepostos (veja a figura 5.1 e a figura 5.3 ).
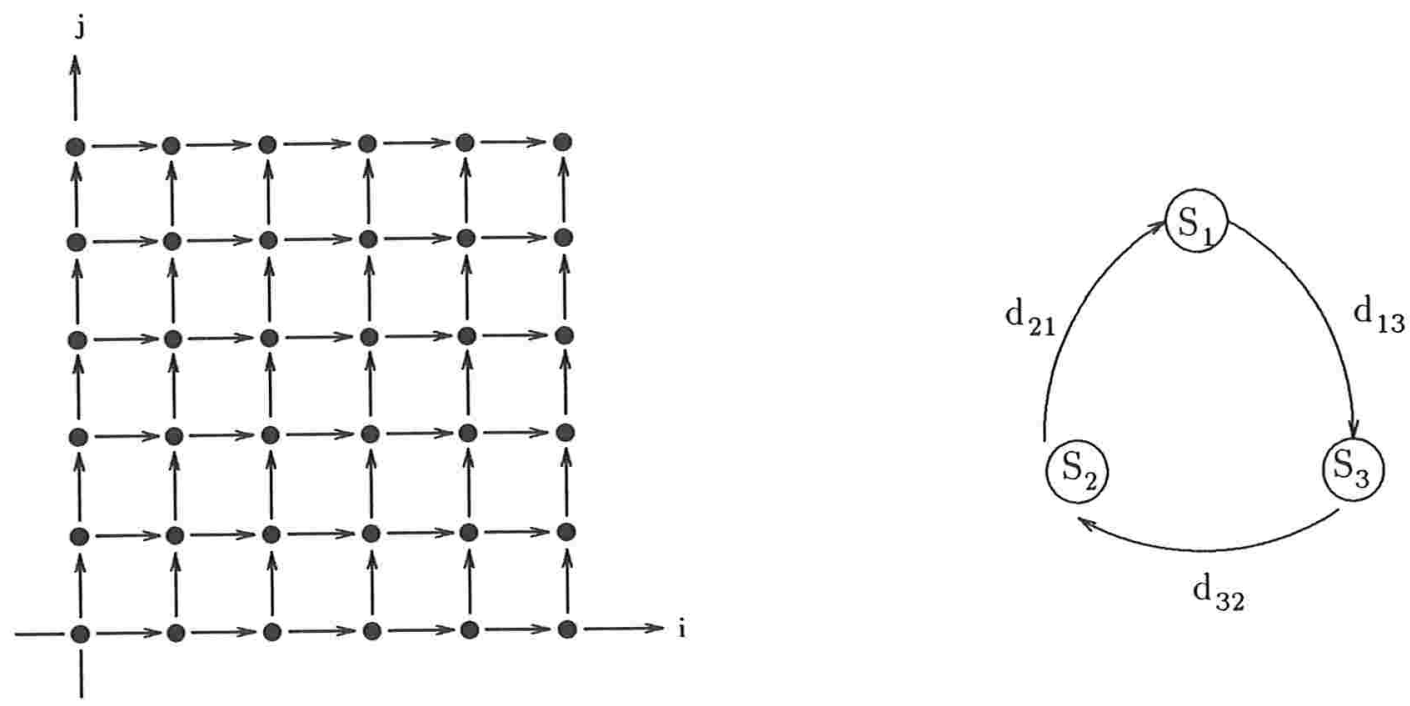

Figura 5.1: Dom e grafo de dependência do exemplo 5.1

Notamos que, na figura 5.3, temos vários "zig-zag's" de dependências que não se interferem um ao outro. Por exemplo (veja a figura 5.4(a)), considere o "zig-zag" constituído pelo ciclo $S_{1}(2,1) \rightarrow S_{3}(3,1) \rightarrow S_{2}(3,2) \rightarrow S_{1}(4,2)$. Agora, vamos juntar as computações $S_{3}(3,1)$ e $S_{2}(3,2)$ em $S_{1}(4,2)$ para formar um macro comando $\bar{S}$ que corresponde à sequência de comandos:

$$
\bar{S} \begin{cases}S_{3}: & C(i-1, j-1)=A(i-2, j-1) \\ S_{2}: & B(i-1, j)=C(i-1, j-1) \\ S_{1}: & A(i, j)=B(i-1, j)\end{cases}
$$

Depois desta transformação a todos os pontos de $D E$, temos o seguinte:

- O macro comando $\bar{S}$ será mapeado em um processador. Note que dentro de $\bar{S}$, em $S_{3}$ calcula-se $\mathrm{C}(i-1, j-1)$, que é usado em $S_{2}$ para calcular $\mathrm{B}(i-1, j)$ que, por sua vez, é usado em $S_{1}$ para calcular $\mathrm{A}(i, j)$. Como esses valores estão no mesmo processador, não há, portanto, necessidade de comunicações entre $S_{3}, S_{2}$ e $S_{1}$.

- O macro comando $\bar{S}$ gastará mais tempo de execução por envolver a execução de três comandos.

- O vetor de dependência do macro comando $\bar{S}$ será a soma dos vetores de dependências de um ciclo $\left(d=d_{21}+d_{32}+d_{13}=(2,1)^{t}\right)$. Isto é, reduzimos os vetores de dependências em um só vetor, dando origem ao método de nome redução de dependência RD (veja a figura $5.4(\mathrm{~b}))$.

Pela figura 5.5, torna-se fácil verificar que o número total de passos requeridos é $\frac{N}{2}$. Como cada ponto, ou seja, cada macro $\bar{S}$, envolve a execução de três comandos $S_{3}, S_{2}$ e $S_{1}$, o tempo 
total de execução será calculado da seguinte maneira. Sejam $T_{\text {com }}$ e $T_{\text {exec }}$ como visto na seção 2.3 e consideramos nulo o tempo para a comunicação interna num processador. Então, para este exemplo, o tempo total gasto é $\frac{N}{2}\left(T_{\text {com }}+3 T_{\text {exec }}\right)$. Além disso, para o mapeamento, podemos fazer a projeção ao longo do vetor de dependência, resultando no tempo total gasto igual a $\frac{3 N}{2} T_{\text {exec }}$ (ver a figura 5.6(a)). Comparando com o resutado obtido pelo método GSS com tempo $2 N\left(T_{\text {com }}+T_{\text {exec }}\right)$, o método RD é melhor. Notamos ainda que com o método GSS não podemos eliminar a comunicação entre processadores, pois temos dois vetores de dependência não colineares (ver a figura 5.6(b)).

O método RD para o caso simples de um grafo de dependência igual a um ciclo pode ser resumido como segue. Sem perda de generalidade, vamos supor que todos os comandos do laço RUN façam parte do ciclo conforme a figura 5.2(a). Este ciclo é transformado para o grafo da figura $5.2(\mathrm{~b})$, onde $d=d_{1}+d_{2}+\ldots+d_{k}$ e $\bar{S}$ o macro comando englobando os comando de $S_{2} \rightarrow S_{3} \rightarrow \ldots \rightarrow S_{k} \rightarrow S_{1}$.

O tempo gasto será:

$$
\min _{j}\left\lfloor\frac{N}{d_{j}}\right\rfloor\left(T_{\text {com }}+k \cdot T_{\text {exec }}\right)
$$

onde $d_{j}=j$-ésimo elemento de $d=d_{1}+d_{2}+\ldots+d_{k}$.

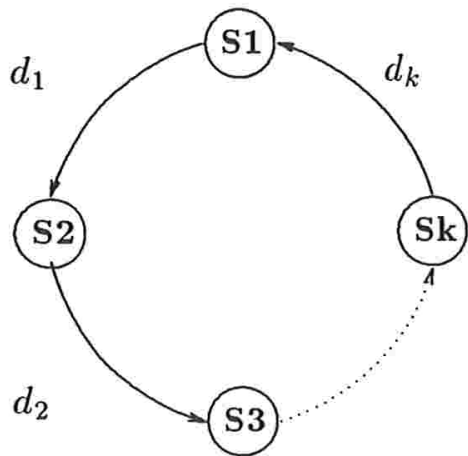

( a )

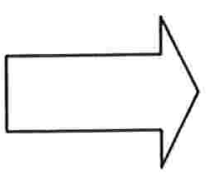

( b )

Figura 5.2: (a) - Grafo de dependência (b) - Grafo de dependência transformado 


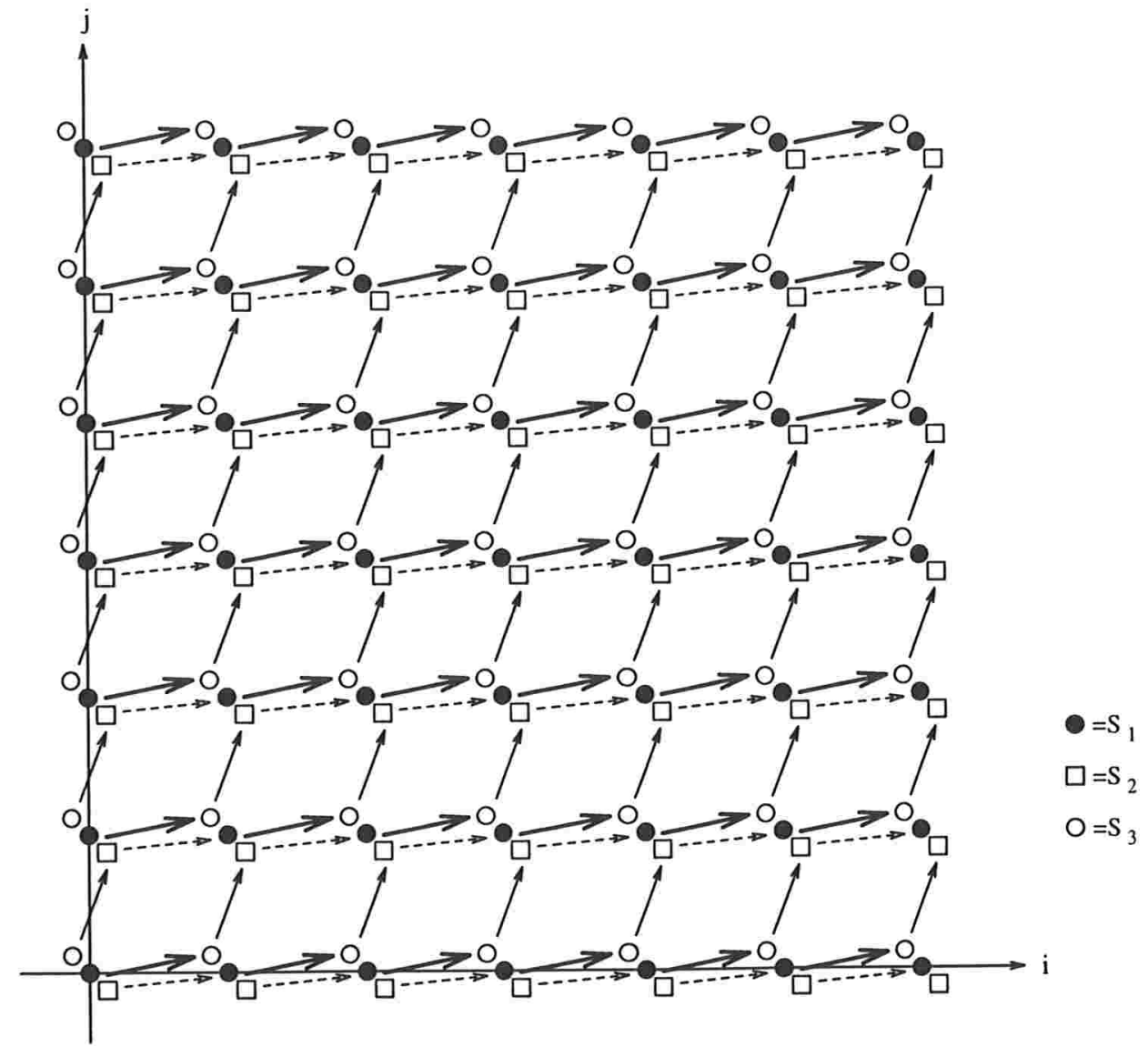

Figura 5.3: $D E$ para exemplo 5.1 


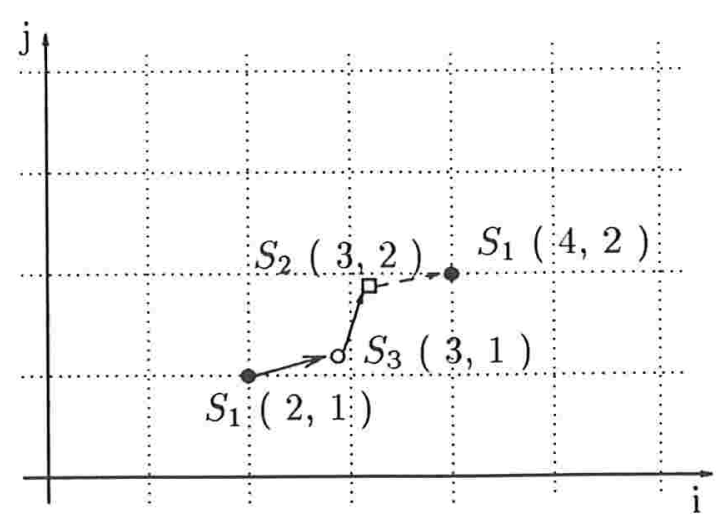

( a )

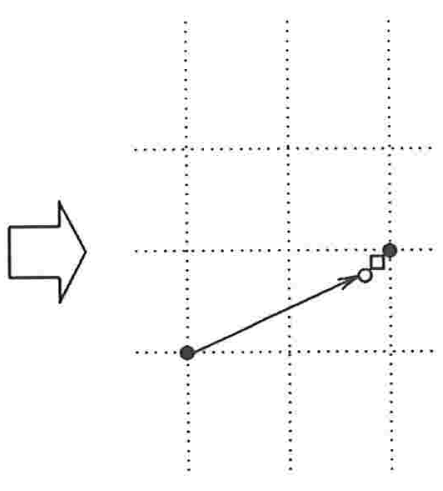

( b )

Figura 5.4: Redução de dependência para exemplo 5.1
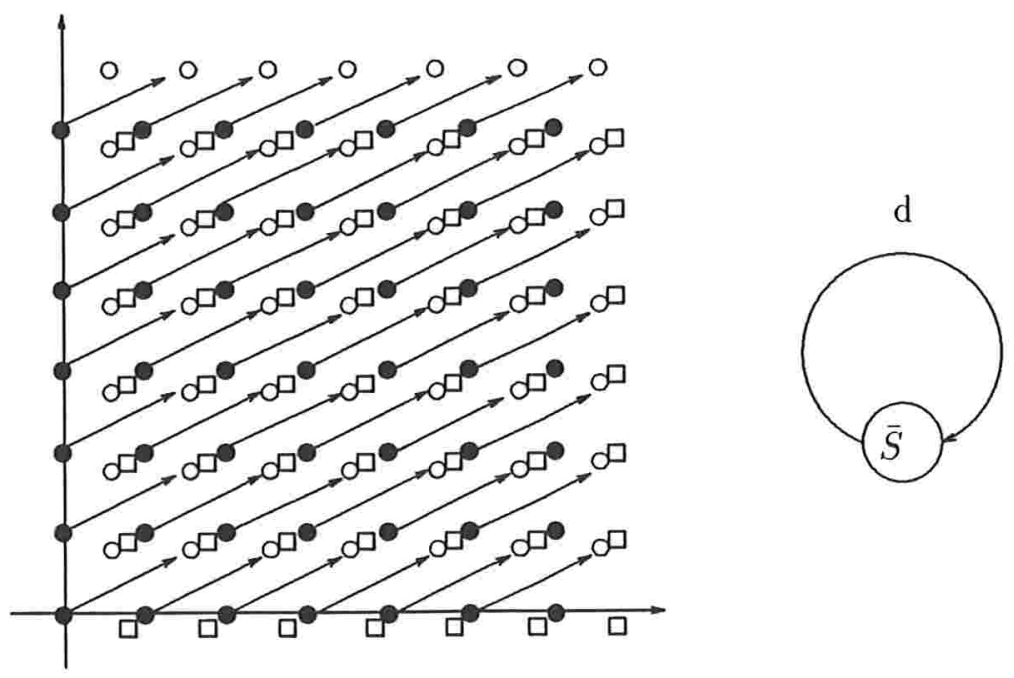

Figura 5.5: Após a redução de dependência (exemplo 5.1)

\subsection{Grafo de dependência com mais de um ciclo}

A formalização para o caso de laços cujo grafo de dependência tem mais de um ciclo está mostrada no Capítulo 4 na tese de doutorado de Kunio Okuda [Kun96b].

Ilustrtaremos o método aqui com um exemplo [Kun96b] no qual temos dois ciclos no grafo de dependência.

\section{Exemplo 5.2}

for $i=0$ to $N$ do 


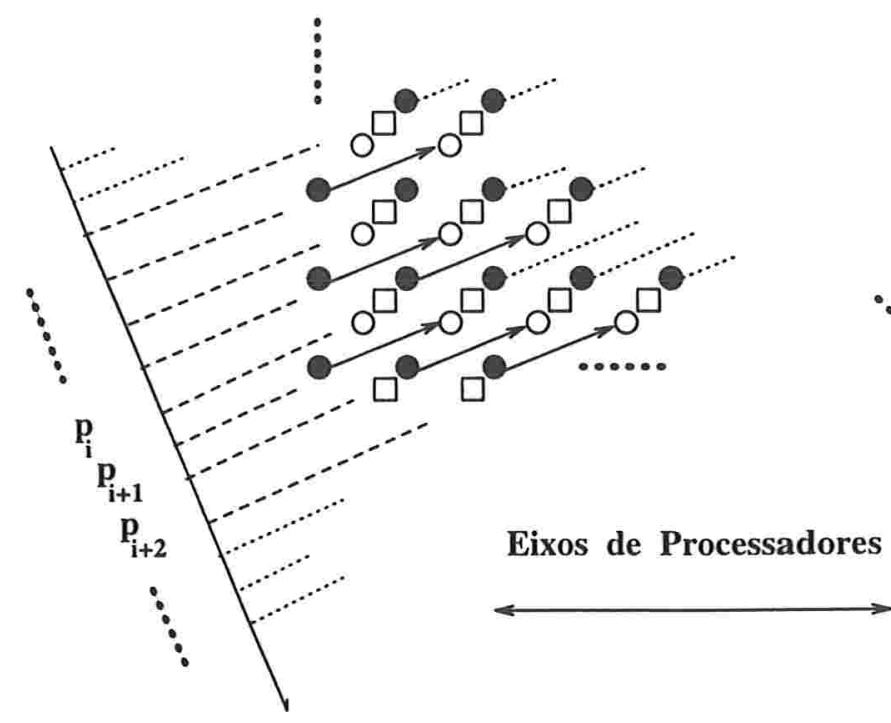

( a )

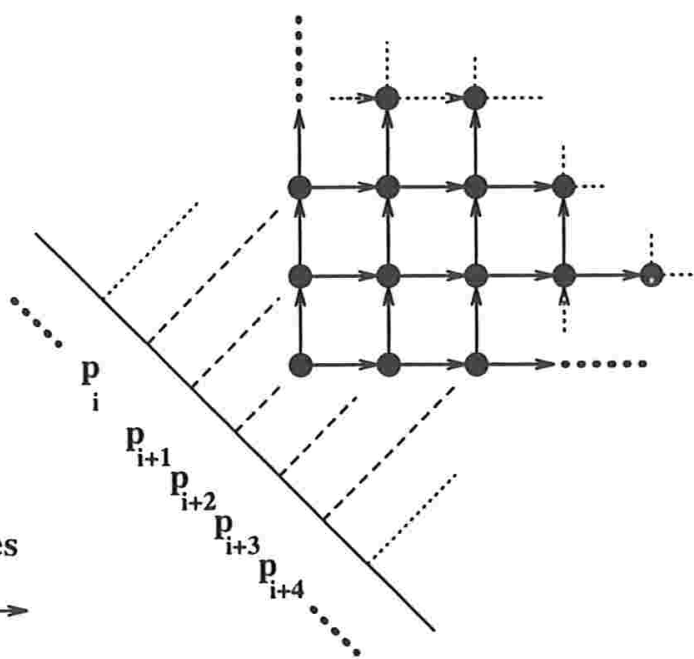

( b )

Figura 5.6: Mapeamento dos processadores

for $j=0$ to $N$ do

begin

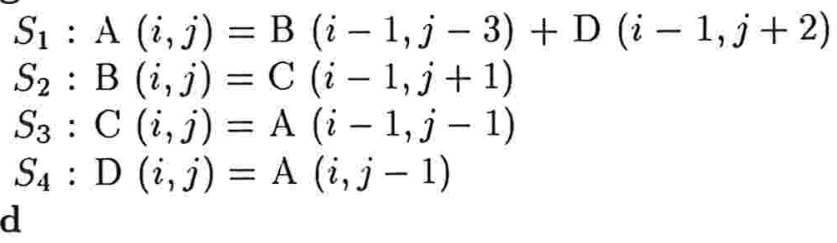

A partir de Dom e o grafo de dependência, construímos $D E=\left\{S_{1}, S_{2}, S_{3}, S_{4}\right\} \times D o m$ e obtemos a figura 5.8. Para ilustrar melhor as dependências, decompomos a figura 5.8 na figura 5.9 e na figura 5.10, que mostram as dependências nos ciclos $C_{1}$ e $C_{2}$ separadamente.

Observamos que nas figuras 5.9 e figura 5.10 temos novamente "zig-zag's" independentes, cada um dos quais pode ser tratado como no exemplo 5.1. Mas o exemplo 5.2 é mais restritivo que o exemplo 5.1. O escalonamento do ciclo $C_{1}$ deve ser compatível com o escalonamento do ciclo $C_{2}$ por possuírem um ponto de intersecção $S_{1}$, que é esssencial para escalonamento (ver a figura 5.11).

Desta maneira, analisamos as dependências no ponto $S_{1}$. Como foi feito no exemplo 5.1 , juntaremos as computações de $S_{2}(i-1, j-3), S_{3}(i-2, j-2)$ e $S_{4}(i-1, j+2)$ em $S_{1}(i, j)$ para formar o macro comando $\bar{S}$ que corresponde à seqüência de comandos:

$$
\bar{S} \begin{cases}S_{2}: & B(i-1, j-3)=C(i-2, j-2) \\ S_{3}: & C(i-2, j-2)=A(i-3, j-3) \\ S_{4}: & D(i-1, j+2)=A(i-1, j+1) \\ S_{1}: & A(i, j)=B(i-1, j-3)+D(i-1, j+2)\end{cases}
$$



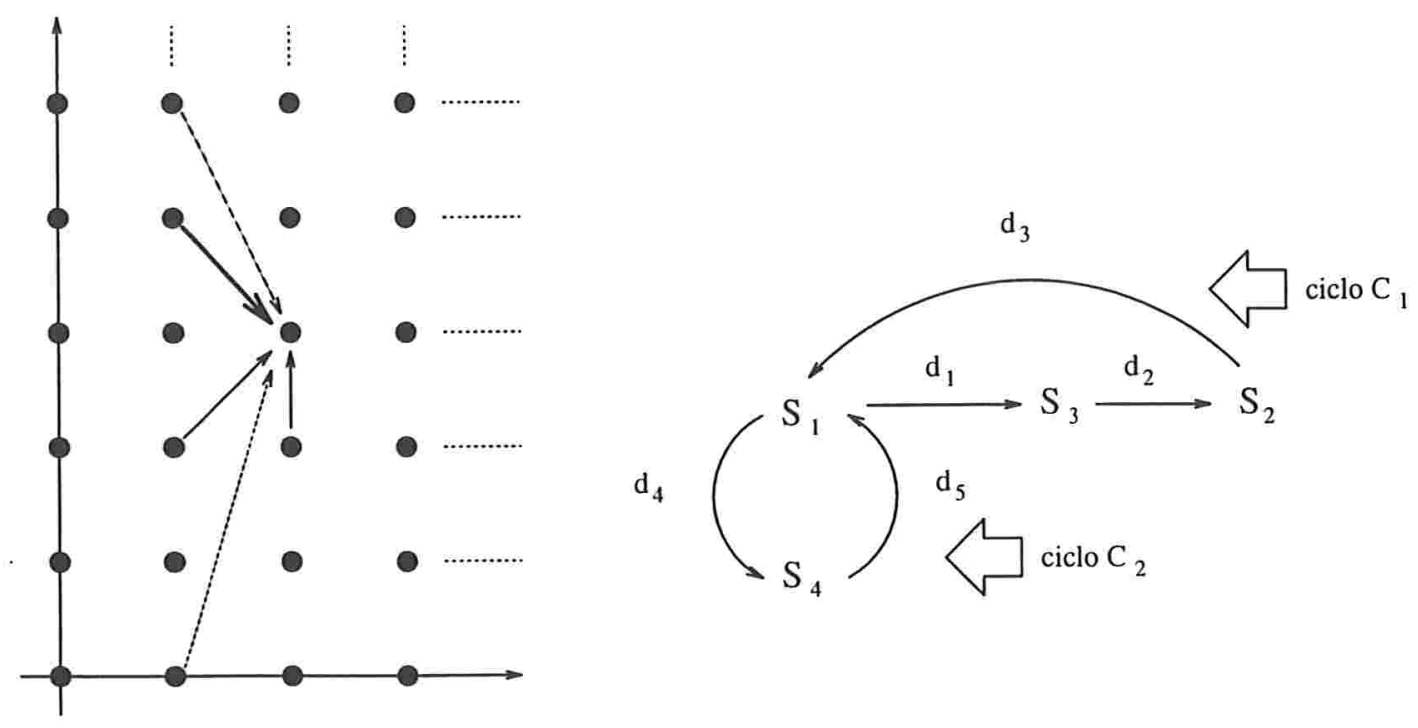

Figura 5.7: Dom e as dependências e o grafo de dependência do exemplo 5.2

A figura 5.11 mostra a transformação para o ciclo $C_{1}$ e o ciclo $C_{2}$. O grafo de dependência com esta transformação está ilustrado na figura 5.13 , onde os dois novos vetores de dependência são obtidos como somas dos vetores de cada ciclo.

\section{Observação:}

- A criação do macro e o número de vetores de dependência reduzido significam transferir algumas comunicações inter-processadores para dentro de um mesmo processador. Isso pode contribuir para a redução de comunicações entre processadores, e pode resultar na redução do tempo total gasto.

- Pela figura 5.12, notamos que o número total de passos requeridos é $N$. 


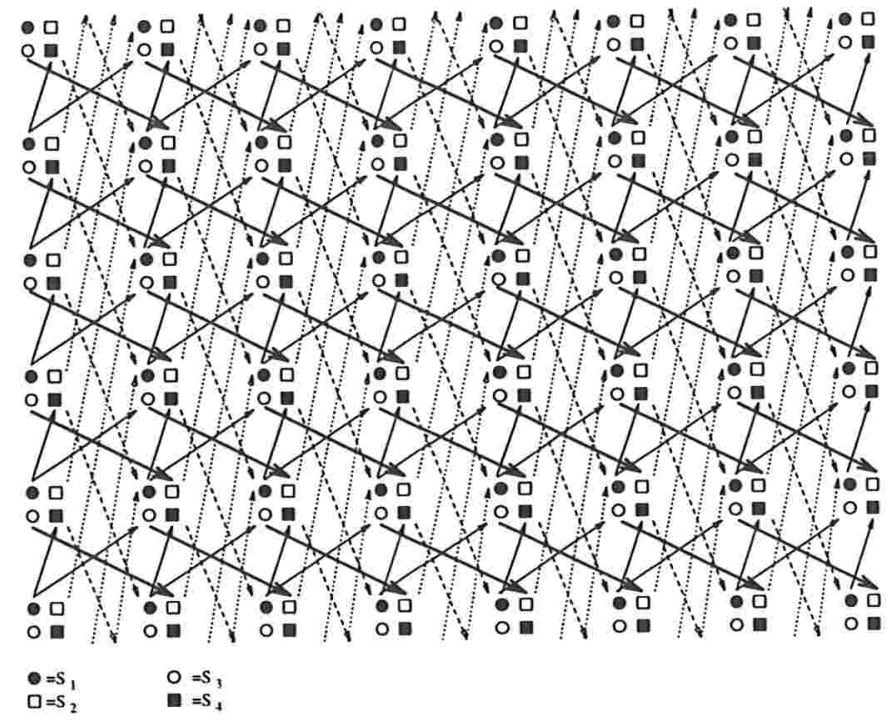

Figura 5.8: $D E$ para o exemplo 5.2

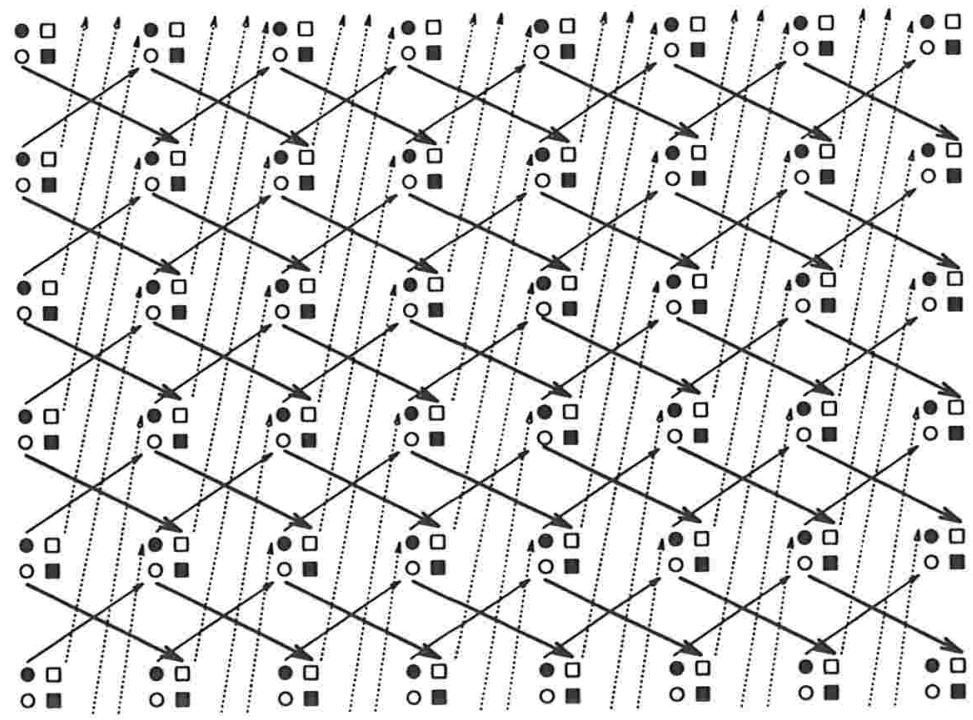

Figura 5.9: Dependência do ciclo $C_{1}$ 


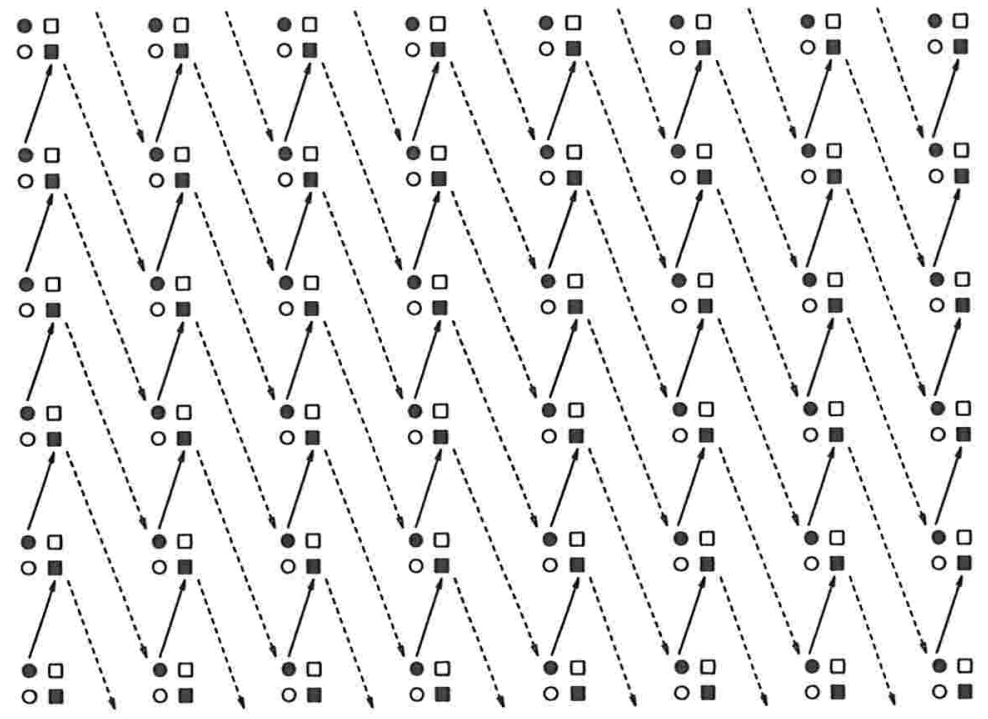

Figura 5.10: Dependência do ciclo $C_{2}$

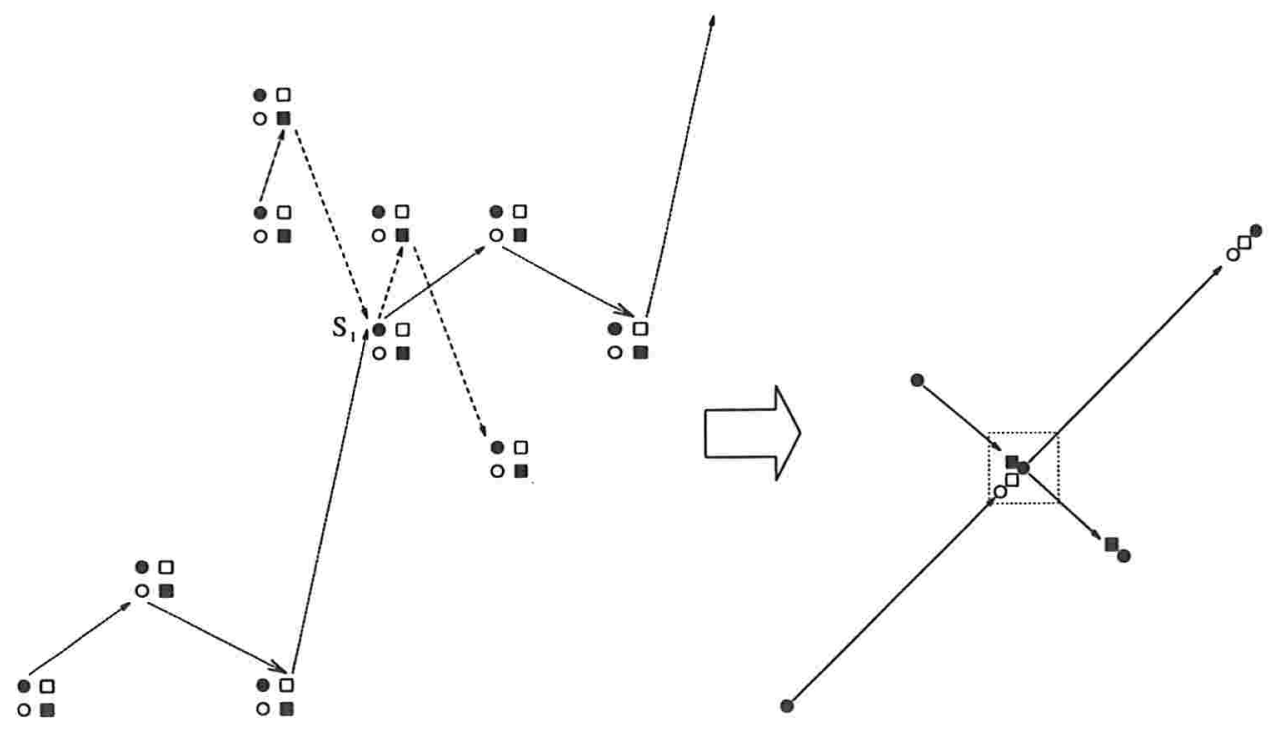

Figura 5.11: Dependência para $S_{1}$ e nova dependência para macro $\bar{S}(i, j)$ 


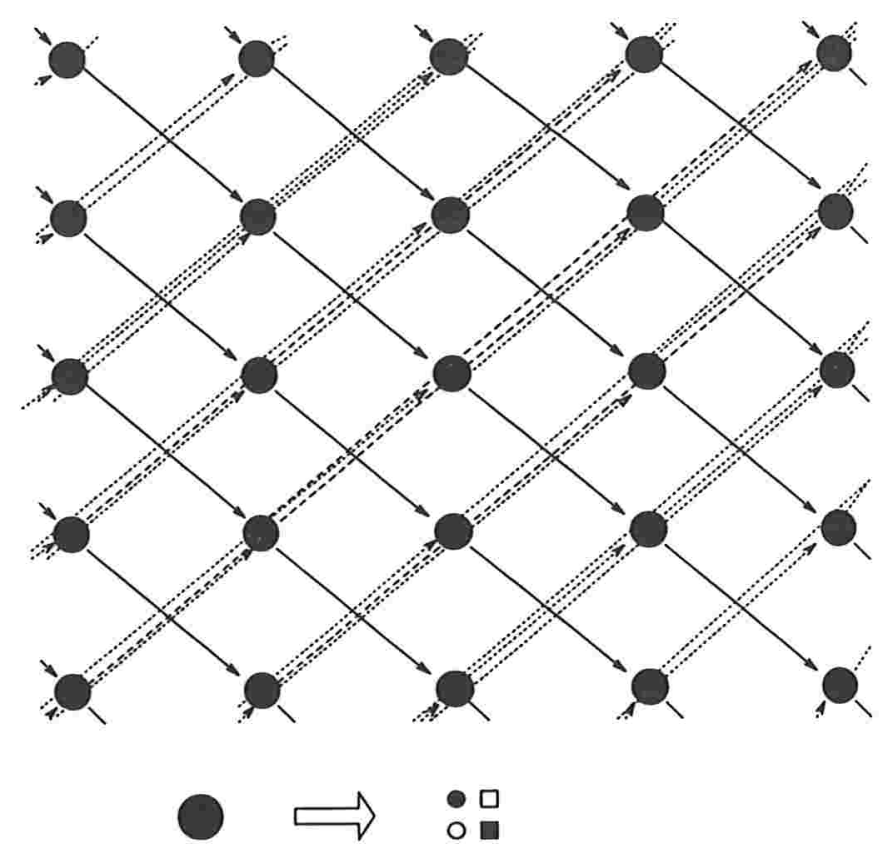

Figura 5.12: Após de redução de dependência (exemplo 5.2)

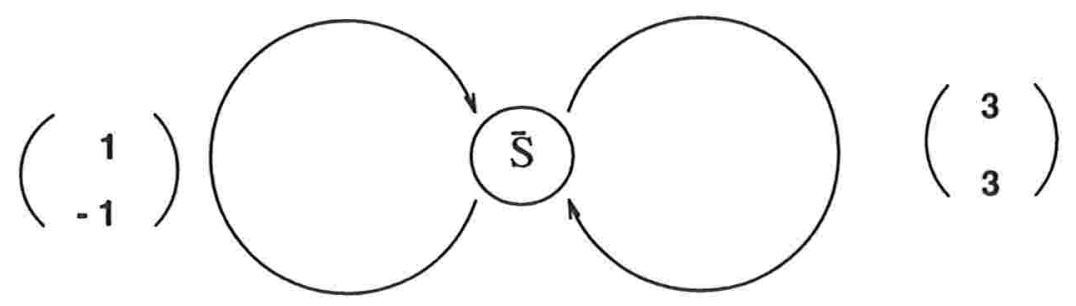

Figura 5.13: Novo grafo de dependência para o exemplo 5.2 


\section{Capítulo 6}

\section{Estudo comparativo entre os métodos RD e GTS para laços simples}

Neste capítulo, vamos fazer um estudo comparativo entre os dois métodos RD e GTS.

- Na seção 6.1, descreveremos o método RD' que é equivalente ao método RD.

- Na seção 6.2, mostraremos que o método GTS para um laço simples com uma recorrência hamiltoniana é um caso particular do método RD .

- Na seção 6.3, descreveremos os casos não tratados por RD, mas que podem ser tratados pelo método GTS utilizando a sincronização explícita para preservar as dependências de dados.

\subsection{Método RD'}

No capítulo 5 , já vimos o método RD. Nesta seção vamos formar o macro comando $\bar{S}$ de forma diferente e chamaremos o método RD'.

Vejamos de novo o exemplo 5.1(página 30). Por exemplo (veja a figura 6.1), considere o "zigzag" constituído pelo ciclo $S_{1}(2,1) \rightarrow S_{3}(3,1) \rightarrow S_{2}(3,2) \rightarrow S_{1}(4,2)$. Agora, em vez de juntar as computações $S_{3}(3,1)$ e $S_{2}(3,2)$ em $S_{1}(4,2)$, vamos juntar as computações $S_{3}(3,1)$ e $S_{2}(3,2)$ em $S_{1}(2,1)$ para formar um macro comando $\bar{S}^{\prime}$ que corresponde à seqüência de comandos:

$$
\bar{S}^{\prime} \begin{cases}S_{1}: & A(i, j)=B(i-1, j) \\ S_{3}: & C(i+1, j)=A(i, j) \\ S_{2}: & B(i+1, j+1)=C(i+1, j)\end{cases}
$$




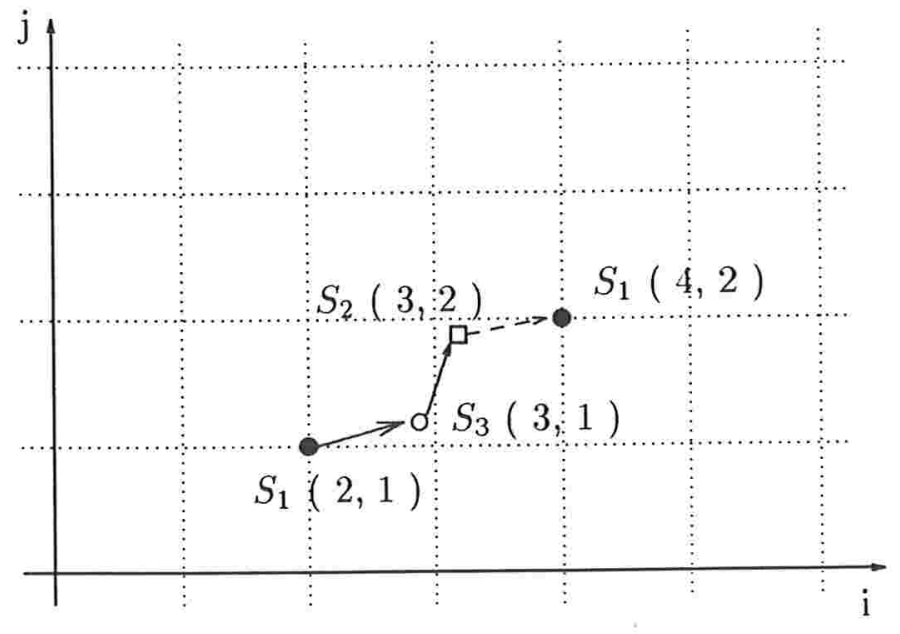

( a )

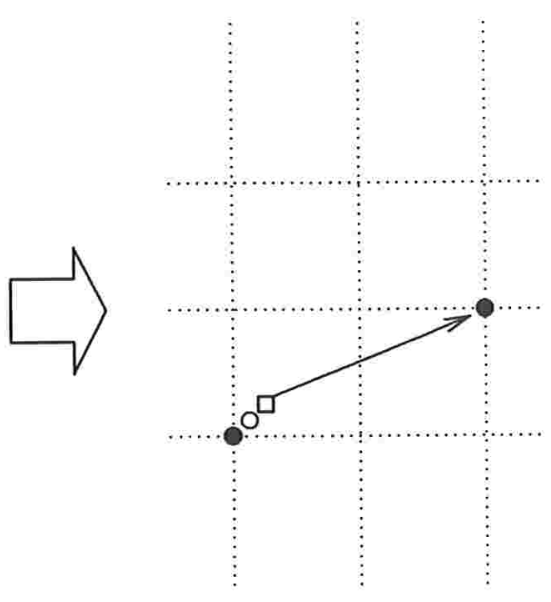

( b )

Figura 6.1: Redução de dependência e a formação de um macro

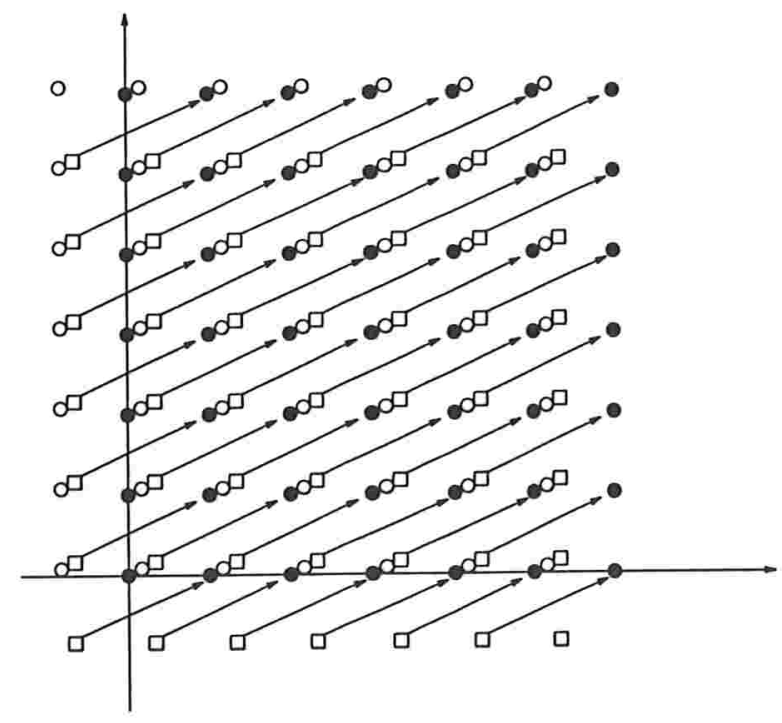

Figura 6.2: Após da redução de dependência 
Após a transformação da redução de dependência a todos os pontos de $D E$, obtemos a figura 6.2 , que mostra, também, que o número total de passos requeridos é igual a $\frac{N}{2}$, ou seja, o mesmo resultado obtido pelo método RD. Observamos que o RD e o RD' seguem a mesma idéia, diferindo apenas na formação do macro $\bar{S}^{\prime}$. Os dois métodos são equivalentes.

\subsection{Comparação entre dois métodos GTS e RD para um laço simples com uma recorrência hamiltoniana}

Nesta seção, vamos mostrar que o método GTS é um caso particular do método RD' no caso de laços simples com uma recorrência hamiltoniana. Como RD' é equivalente ao RD, então teremos mostrado que GTS é um caso particular de RD.

A seguir, resolveremos o exemplo 4.1 (ver a seção 4.2 do capítulo 4) aplicando o método RD'. A figura 6.3(a) mostra o domínio deste exemplo. Pelo método RD', para obter a representação unidimensional de $D E$ deste exemplo, projetamos cada $\left\{\left(S_{\alpha}, i\right) \mid \alpha \in\{1,2,3\}, i \in D o m\right\}$ em $R$ de modo ligeiramente deslocado um em relação ao outro (ver a figura 6.3(b)). Assim, podemos ver que existem vários "zig-zag's" de dependências que não se interferem um ao outro. Por exemplo, consideramos o "zig-zag" constituído pelo ciclo $S_{1}(1) \rightarrow S_{2}(2) \rightarrow S_{3}(4) \rightarrow S_{1}(6)$. Vejamos a figura 6.4. Vamos juntar as computações $S_{2}(2)$ e $S_{3}(4)$ em $S_{1}(1)$ para formar um macro comando $\bar{S}^{\prime}$ que corresponde à seqüência de comandos:

$$
\bar{S}^{\prime} \begin{cases}S_{1}: & A(i)=B(i-2)+2 \\ S_{2}: & C(i+1)=A(i) \times D(i+1) \\ S_{3}: & B(i+3)=C(i+1)\end{cases}
$$

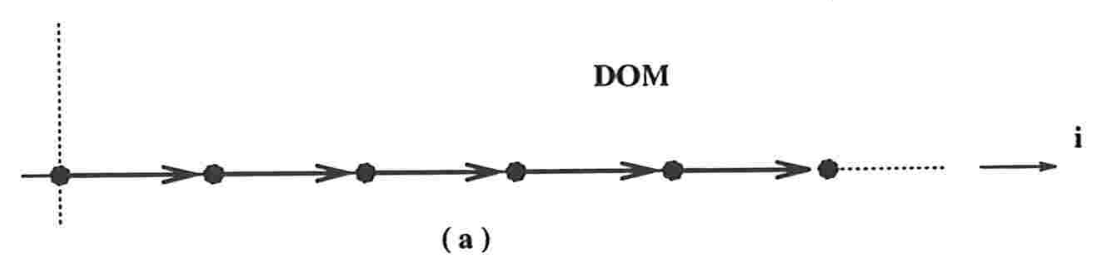

(a)

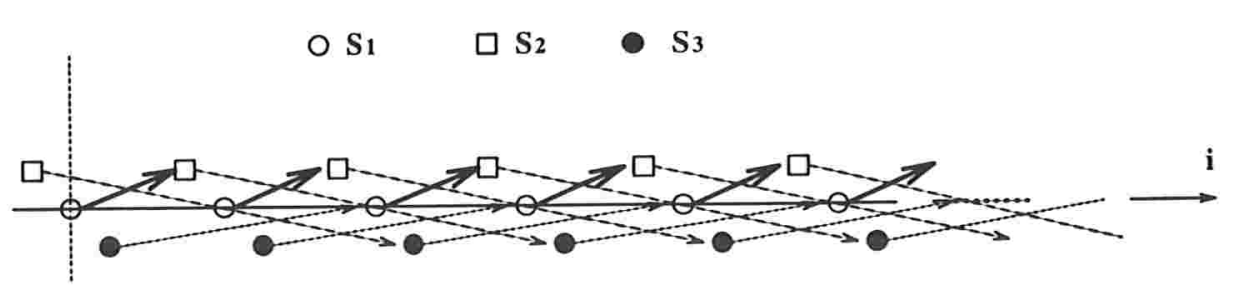

(b)

Figura 6.3: Dom e $D E$ do exemplo 4.1 


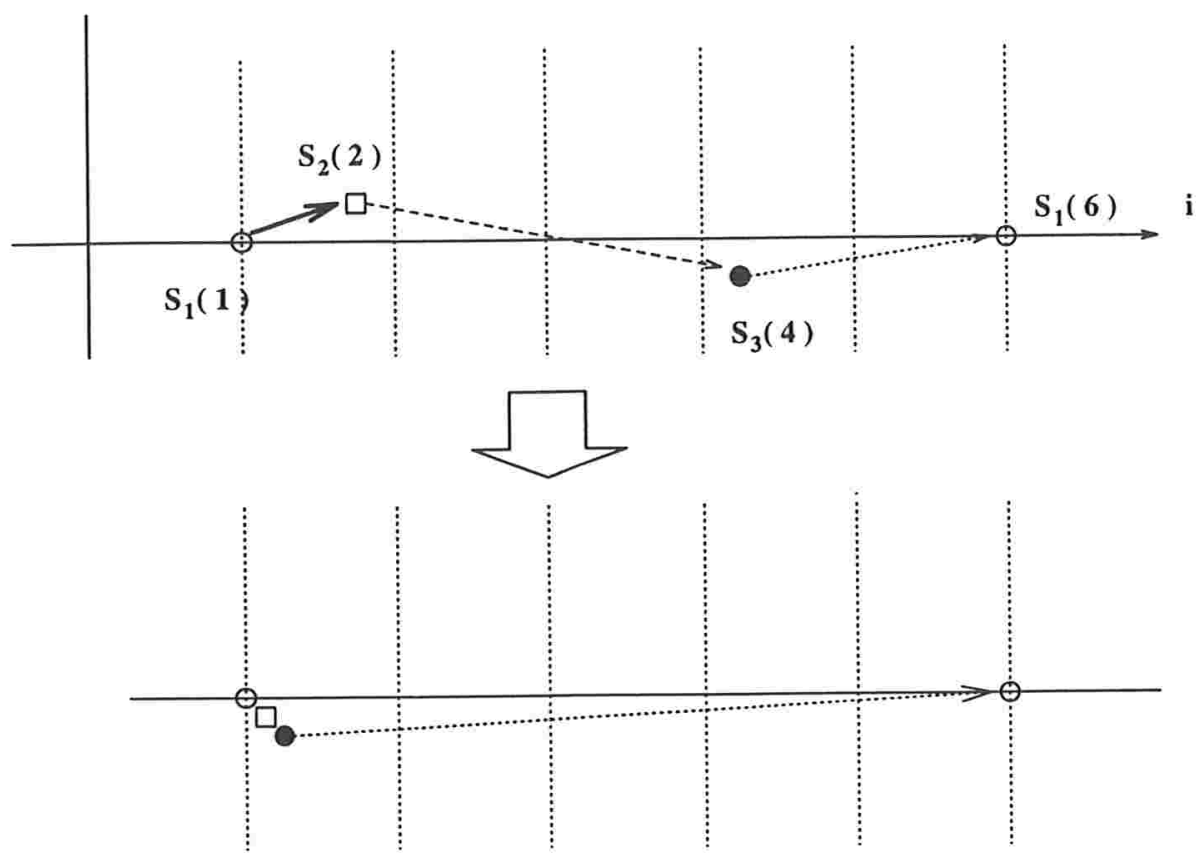

Figura 6.4: A redução de dependência

A figura 6.5 mostra as cinco "correntes" de dependências após a redução de dependência (RD') no caso de $N=10$. Pela figura 6.5 , torna-se fácil ver que o paralelismo deste exemplo é 5 , ou seja, o número total de passos requeridos é $\frac{N}{5}$, pois essas cinco "correntes" são independendes uma da outra. Além disso, podemos ilustrar a alocação dos processadores e as dependências entre as iteraçōes através da figura 6.6. Notamos que, na realidade, a figura 6.5 é idêntica à figura 4.5 da seção 4.2 do capítulo 4 , pois, na figura 4.5 , as setas tracejadas que representam as dependências entre os comandos são implícitas nos macros comandos $\bar{S}^{\prime}$ da figura 6.6. Por outro lado, podemos considerar esses comandos que estão ligados pelas setas tracejadas da figura 4.5 como os macros da figura 6.6. Como todos os comandos que estão na mesma "corrente" estão mapeados no mesmo processador, ou seja, todos os dados de dependência necessários a serem executados numa tarefa ficam no mesmo processador, então não existem comunicações entre os processadores. Esta é uma grande vantagem dos dois métodos GTS e RD'. A outra observação interessante é que a seqüência de comandos formada num macro $\bar{S}^{\prime}$ pelo método RD' é idêntica à sequência de comandos dentro do laço for-do, que é o ponto principal do algoritmo transformado na seção 4.2 do capítulo 4. Isso implica que podemos usar o método RD' para formalizar o método GTS no caso de laços simples com uma recorrência hamiltoniana. Como o método RD' é equivalente ao método RD, então, podemos dizer que o método GTS para o caso de laços simples com uma recorrência hamiltoniana é um caso particular do método RD. 


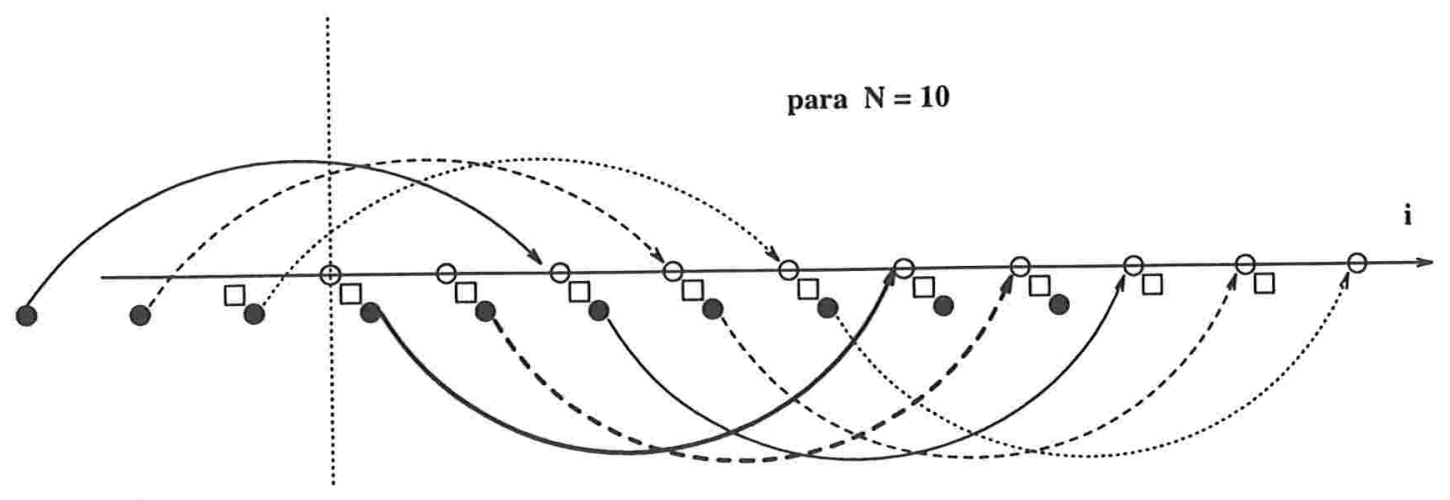

Figura 6.5: Após da redução de dependência
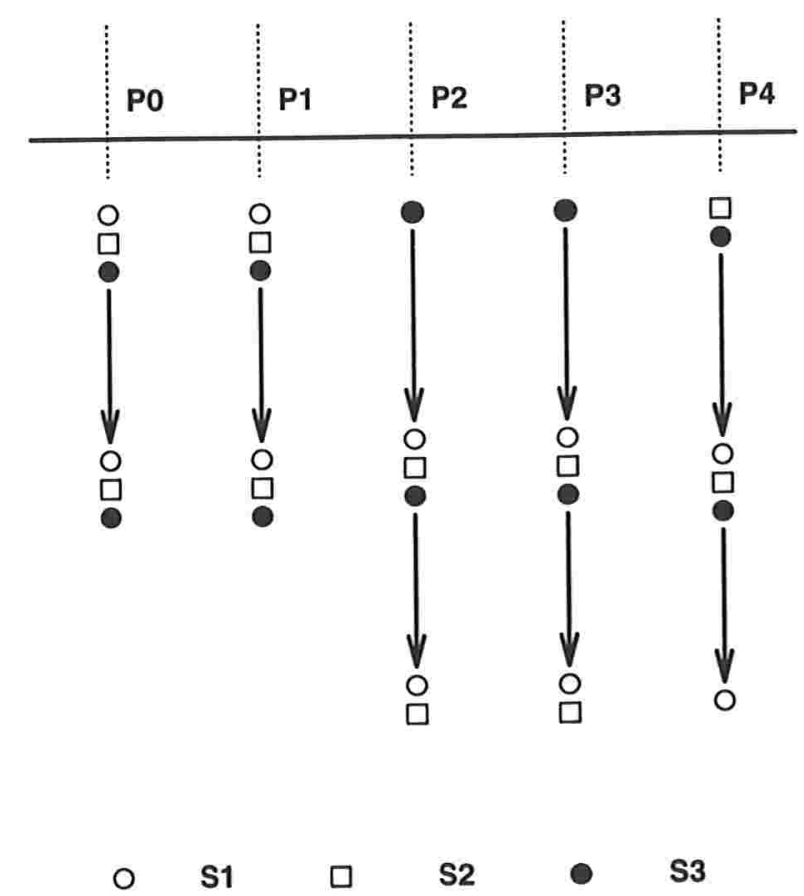

Figura 6.6: Alocação dos processadores e as dependência entre os macros 


\subsection{GTS pode tratar casos não tratados por RD utilizando a sincronização explícita}

Nesta seção, mostraremos que o método GTS trata um caso não tratado pelo RD, com o uso da sincronização explícita. Vamos considerar um laço de $n$ comandos com mais de uma recorrências. Definimos $B$ como sendo o conjunto de recorrências no laço (como já visto no capítulo 4). Vejamos um exemplo de um laço simples com múltiplas recorrências e seu grafo de dependência associado (ver a figura 6.7).

\section{Exemplo 6.1}
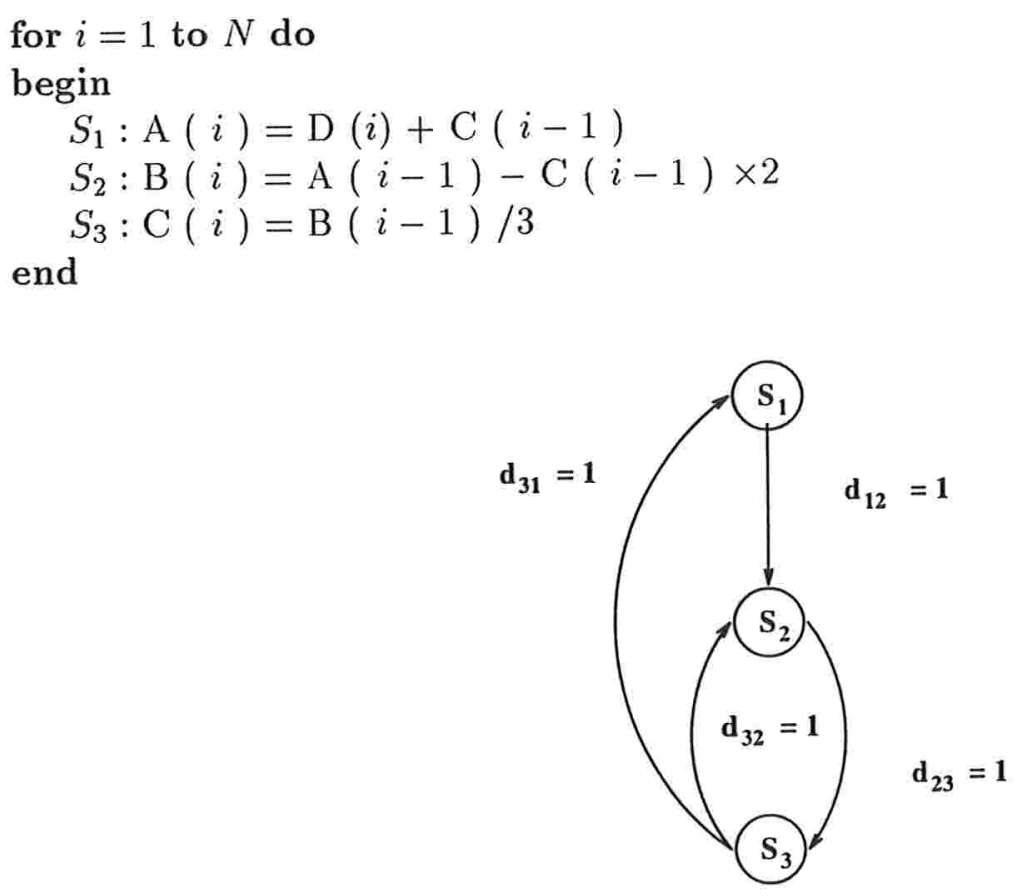

Figura 6.7: O grafo de dependências

No caso de um laço simples com múltiplas recorrências, o escalonamento será feito aplicandose o mesmo procedimento utilizado para uma recorrência hamiltoniana na seção 4.2 do capítulo 4. Seja a recorrência de escalonamento (scheduling recurrence) $R_{\text {sch }} \in B$ que inclui todos os comandos do laço $\left(\left|R_{s c h}\right|=n\right)$. Se não existe tal recorrência, $R_{s c h}$ terá que ser constituída pela adição de dependências ou arestas (ver apêndice A). Se existem mais de uma recorrência hamiltoniana, uma delas será escolhida minimizando o número de tarefas geradas. Portanto, $R_{\text {sch }}$ tem que satisfazer

$$
P=W\left(R_{s c h}\right) \leq W(R) \text { para todo } R_{s c h}, R \in B \text { tal que }\left|R_{s c h}\right|=|R|=n .
$$

(Lembramos que $W(C)$ é o peso do caminho $C$ - seção 4.1 do capítulo 4.) Obtida $R_{\text {sch }}$, as arestas que não pertencem à $R_{s c h}$ e representam dependências têm que ser sincronizadas explicitamente. 
Para o exemplo 6.1, temos $R_{1}=\left\{d_{23}, d_{32}\right\}$ e $R_{2}=\left\{d_{12}, d_{23}, d_{31}\right\}$. A recorrência escolhida será $R_{2}$, ou seja, $R_{s c h}=R_{2}$. Assim, temos o número de tarefas geradas $P=W\left(R_{s c h}\right)=$ $\sum_{d_{i j} \in R_{s c h}} d_{i j}=1+1+1=3$ (ver a figura 6.8(a), as setas tracejadas representam as sincronizações explícitas entre as iterações nas quais existe a dependência $d_{32}$ ).

Alguns mecanismos de sincronização são citados em [J. 89] e semáforos foram escolhidos como primitivo de sincronização. Para qualquer dependência (ou aresta) $d_{i j} \notin R_{s c h}$ no grafo indo de $S_{i}$ para $S_{j}$, a sincronização explícita tem que ser introduzida. O comando $S_{i}$, origem da dependência, sinalizará o fim da sua execução ao comando $S_{j}$, destino da mesma dependência, para permitir a sua execução. Para cada aresta $d_{i j}, P$ (números de tarefas) semáforos serão necessários $\left(\operatorname{sem}_{i j}(t), 0 \leq t<P\right)$. A operação signal no semáforo $\operatorname{sem}_{i j}(t)$ será inserida na tarefa $t$ depois do camando $S_{i}$, e sua operação associada wait será inserida na tarefa $t^{\prime}(0 \leq t<$ $\left.P, t \neq t^{\prime}\right)$.

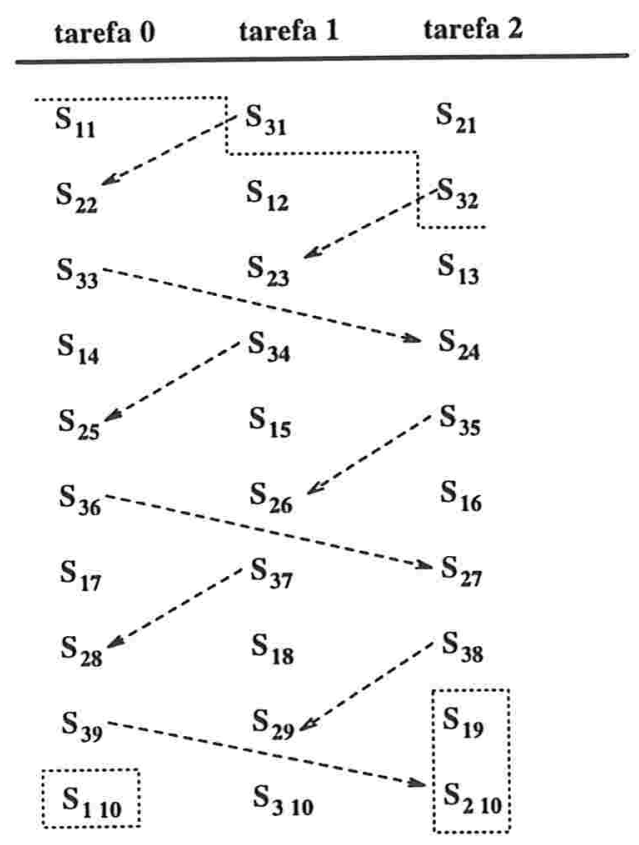

( a )

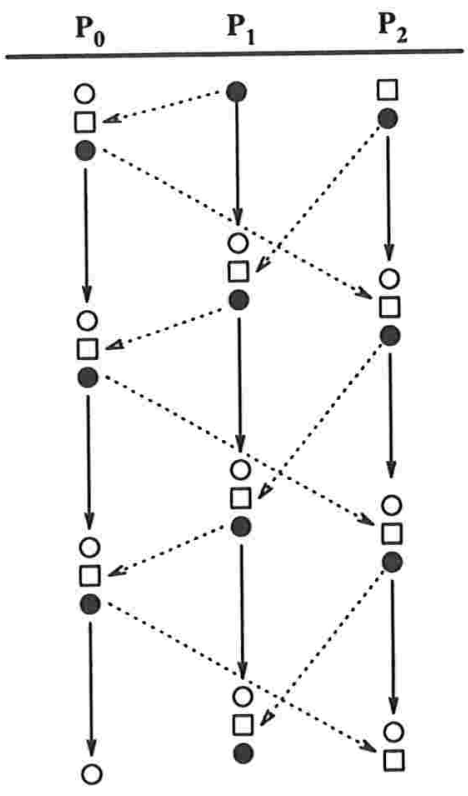

( b )

Figura 6.8: O escalonamento e a sincronização para exemplo 6.1 e alocação de processadores e a sincronização usando o RD'

A seguir mostramos o algoritmo paralelo usando semáforos como primitivo de sincronização.

\section{Algoritmo transformado:}

$$
\begin{aligned}
& \operatorname{sem}_{32}[0]=1 ; \operatorname{sem}_{32}[1]=0 \\
& \operatorname{sem}_{32}[2]=0 ; \\
& \text { for } j=0 \text { to } 2 \text { doacross } \\
& \quad \text { if }(j \geq 2) \\
& \quad \text { wait }\left(\operatorname{sem}_{32}[(j-2) \bmod 3]\right)
\end{aligned}
$$




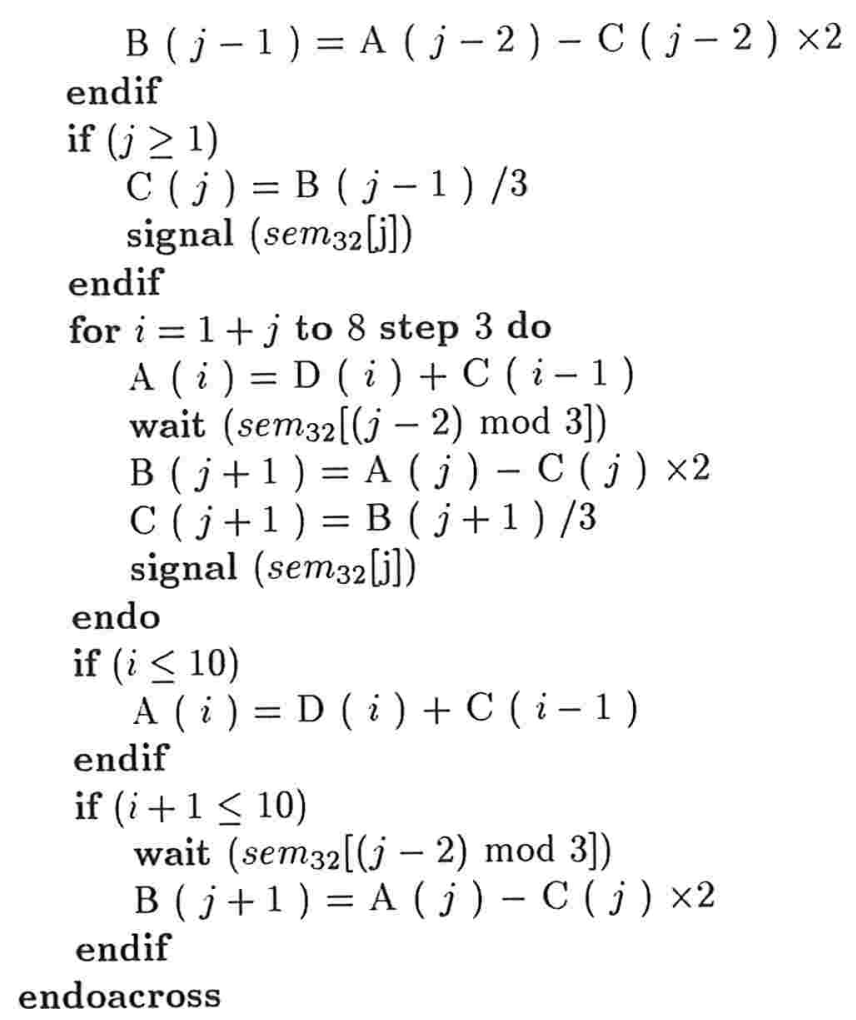

O método RD [Kun95a] não trata este caso. Mas, se aplicarmos o método RD' para $R_{\text {sch }}$ e usarmos o mecanismo da sincronização explícita para a aresta $d_{32} \notin R_{s c h}$, o resultado será o mesmo que o resultado obtido pelo método GTS (ver a figura 6.8(b), as setas pontilhadas representam as sincronizações explícitas entre as iterações nas quais existem a dependência $d_{32}$ ). Pois, trataremos $R_{s c h}$ da mesma maneira de uma recorrência hamiltoniana, e simplesmente acrescentaremos o mecanismo da sincronização para $d_{32} \notin R_{s c h}$. Portanto, junto com o mecanismo da sincronização explícita, o método RD pode ser estendido para resolver este caso.

Existe a possibilidade de resolver este caso sem utilizar o mecanismo de sincroização explícita. Os detalhes deste método serão discutidos no apêndice B. 


\section{Capítulo 7}

\section{Conclusão}

- Na seção 7.1, temos a conclusão desta dissertação.

\subsection{Conclusão}

As estruturas de laços constituem-se na maior fonte de paralelismo em programas seqüenciais. Portanto, é muito importante fazermos as análises necessárias para explorar o potencial de execução paralela dos laços.

Neste trabalho, mostramos vários métodos conhecidos para o encolhimento de ciclo como o encolhimento de ciclo simples, o encolhimento de ciclo seletivo, o encolhimento de ciclo seletivo generalizado (GSS), redução de dependências (RD), e GTS, um método de restruturar recorrências. Fizemos um estudo comparativo entre RD e GTS. Com este estudo, obtemos alguns resultados e algumas observações importantes.

A técnica do encolhimento de ciclo é usada para transformar laços seriais em uma forma paralela adequada para a execução no sistema de processadores paralelos. A transformação pode ser implementada num compilador re-estruturante. Apesar de certas limitações desta técnica, para alguns tipos de laços seriais, ela pode conseguir uma melhoria significativa. O encolhimento de ciclo generalizado aperfeiçoou e generalizou a técnica do encolhimento de ciclo seletivo e explorou mais paralelismo nos algoritmos com laços encaixados. No GSS, o método procura a transformação com tempo ótimo para algoritmos com conjunto de índices em qualquer poliedro convexo [M. 91].

O método GTS é baseado na análise detalhada do grafo de dependências de um laço. A geração de código é feita por travessia em grafo e reescrevendo os comandos baseado nas suas distâncias. Este método inclui na execução seqüencial de cada tarefa paralela, o número máximo de dependência. Outras dependências têm que ser sincronizadas explicitamente. No caso de laço simples, o GTS é capaz de obter mais paralelismo que outros métodos como o encolhimento de ciclo. O artigo Implementation of GTS [Jes94] mostrou o bom desempenho de implementação deste método. 
O método RD foi ilustrado por meio de domínio explícito, uma nova representação de dependência que auxilía identificar as dependências de modo mais eficiente e dá uma base intuitiva para redução de dependências. Essa técnica baseia-se na análise do grafo de dependência. Ela define macros constituídos de conjuntos de comandos para possibilitar a redução do número de passos e do número de comunicações entre processadores. Ela também permite uma análise simplificada para escalonamento.

Nós utilizamos vários exemplos ilustrativos para explicar melhor as técnicas mencionadas para o encolhimento de ciclo. Por exemplo, usamos o exemplo 3.2 para mostrar o ganho que pode ser obtido. O tempo seqüencial quadrático é reduzido para $\frac{N^{2}}{8}$ atráves da técnica do encolhimento de ciclo simples, para $\frac{N}{2}$ atráves do encolhimento de ciclo seletivo e para $\frac{N}{4}$ atráves do GSS.

A maior contribuição do trabalho é o estudo comparativo entre RD e GTS. Primeiro, desenvolvemos um método RD' que é equivalente ao método RD. Atráves da compraração entre RD' e GTS, concluímos que o método GTS, no caso de laço simples com uma recorrência hamiltoniana, é um caso particular do método RD. Por outro lado, no caso de múltiplas recorrências, GTS pode tratar os casos não tratados por RD usando o mecanismo de sincronização explícita. Quando não há uma recorrência hamiltoniana, utilizamos a técnica de adição de dependências para constituir uma recorrência hamiltoniana de mode que possamos aplicar o método GTS. Vemos nos apêndices que a técnica de adição de dependências permite a possibilidade de resolver alguns casos sem usar o mecanismo de sincronização explícita. Uma observação muito importante e significativa é que podemos utilizar o mecanismo de sincronização explícita ou a técnica de adição de dependências, dependendo dos casos, junto com método RD para resolver alguns casos adicionais não tratados por RD, ou seja, conseguimos estender o método RD. 


\section{Apêndice A}

\section{Adição de dependências ou arestas}

O método GTS exposto nos capítulos 4 e 6 se aplica quando houver uma recorrência hamiltoniana. Se não existe uma recorrência hamiltoniana no grafo de dependências, arestas novas ou arestas artificiais podem ser introduzidas para podermos aplicar o método.

Consideremos um laço simples em que não existe uma recorrência hamiltoniana. Seja $B$ o conjunto de recorrências do laço. Vamos definir $E^{\prime}$ como o conjunto de arestas $d_{i j}^{\prime}$ tal que em $E+E^{\prime}$ podemos achar uma recorrência hamiltoniana $R_{s c h}$. O grafo resultante será denotado $G^{\prime}\left(V, E+E^{\prime}\right)$. Seja $B^{\prime}$ o conjunto de recorrências de $G^{\prime}\left(V, E+E^{\prime}\right)$. Para cada recorrência $R \in B$, definiremos seu paralelismo por comando, a ser denotado por $\|_{c}(R)$, como

$$
\|_{c}(R)=\frac{w(R)}{|R|}
$$

O paralelismo do laço correspodente a $G$, denotado por $\|(G)$, será limitado pela sua recorrência mais restritiva:

$$
\|(G)=n \cdot \min _{R \in B}\left(\|_{c}(R)\right)
$$

onde $n$ é o número de comandos no laço (ver o exemplo a seguir).

Seja o paralelismo do laço, correspondente a $G^{\prime}, \|\left(G^{\prime}\right)$. Queremos $\|(G) \leq\|\left(G^{\prime}\right)$. Se quisermos gerar o código paralelo, as distâncias das arestas em $E^{\prime}$ devem ser tais que não limitem o paralelismo do laço. Portanto

$$
\left\|_{c}\left(R_{1}\right) \geq\right\|_{c}\left(R_{2}\right), \forall R_{1} \in B^{\prime}-B, R_{2} \in B
$$

Veja o seguinte exemplo e a figura A.1.

Exemplo A.1:

$$
\begin{aligned}
& \text { for } i=1 \text { to } N \text { do } \\
& \text { begin } \\
& \quad S_{1}: \mathrm{A}(i)=\mathrm{A}(i-3)+\mathrm{D}(i) \\
& S_{2}: \mathrm{B}(i)=\mathrm{A}(i-1)-\mathrm{C}(i-1) \times 2
\end{aligned}
$$




$$
\begin{aligned}
& S_{3}: \mathrm{C}(i)=\mathrm{B}(i-1) / 3 \\
& \text { end }
\end{aligned}
$$
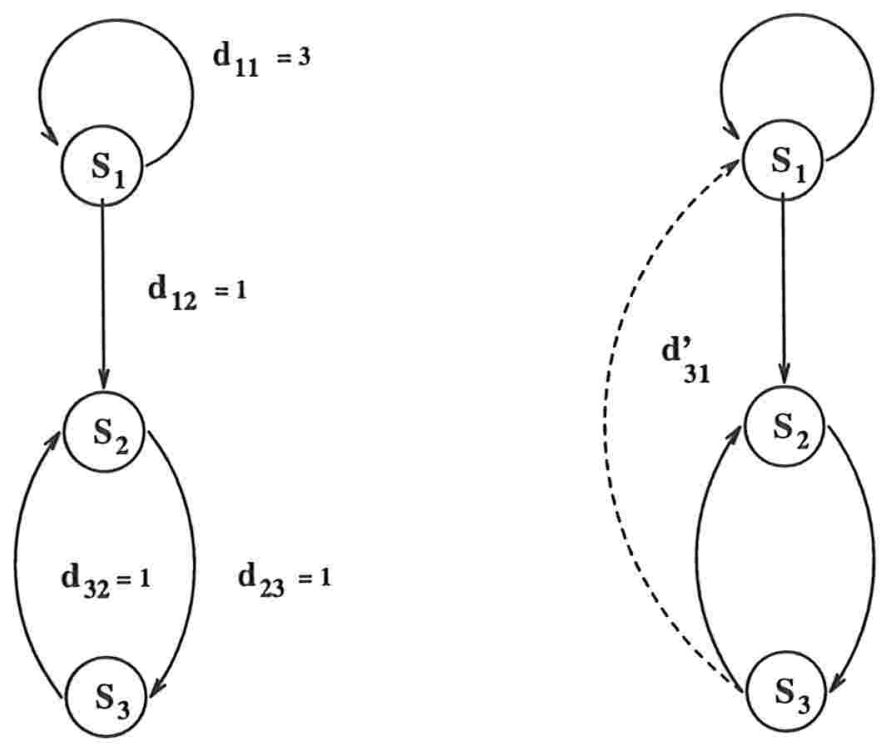

Figura A.1: O grafo de dependências e o grafo de dependências com uma aresta adicional

Para este exemplo, temos $R_{1}=\left\{d_{11}\right\}, R_{2}=\left\{d_{23}, d_{32}\right\}, R_{3}^{\prime}=\left\{d_{12}, d_{23}, d_{31}^{\prime}\right\}$ e $B^{\prime}=\left\{R_{1}, R_{2}, R_{3}^{\prime}\right\}$, $B=\left\{R_{1}, R_{2}\right\}$ e $B^{\prime}-B=\left\{R_{3}^{\prime}\right\}$. Agora, vamos ver como determinar a distância da aresta $d_{31}^{\prime}$. Como $\|_{c}\left(R_{1}\right)=3$ e $\|_{c}\left(R_{2}\right)=1$, temos que $\left\|_{c}\left(R_{3}^{\prime}\right)=\frac{w\left(R_{3}^{\prime}\right)}{\left|R_{3}^{\prime}\right|}=\frac{2+d_{31}^{\prime}}{3} \geq\right\|_{c}\left(R_{2}\right)=1 \Rightarrow d_{31}^{\prime} \geq 1$.

Vários conjuntos $E^{\prime}$ de arestas adicionais (ou artificiais) podem ser usados para obter uma recorrência hamiltoniana. Para cada um deles, o número total de tarefas geradas e as sincronizações explícitas (ver apêndice B) utilizadas podem ser diferentes. Um critério de seleção conveniente pode minimizar o número de tarefas $\left(P=w\left(R_{s c h}\right) \geq \|(G)\right)$. Se alguns $E^{\prime}$ satisfazem esta condição, selecione um com menos arestas adicionais (ou artificiais) para reduzir o custo de sincronização. 


\section{Apêndice B}

\section{Paralelização livre de sincronização explícita}

Esta parte do trabalho está baseada em [J. 89]. Neste apêndice, descreveremos como eliminar a sincronização explícita no caso de múltiplas recorrências usando a técnica de adição de dependências ou arestas.

No apêndice $\mathrm{A}$, já mostramos como introduzir as arestas artificiais para obter uma recorrência hamiltoniana. Existe um trade-off entre o número de tarefas e as sincronizações explícitas. Este leva a possibilidade de gerar uma recorrência hamiltoniana que não requer as sincronizações explícitas.

Dado um grafo de dependência $G(V, E)$, definimos o paralelismo livre da sincronização $\|_{l}(G)$ como sendo o número máximo de processadores independentes que executam as iterações do laço. $\mathrm{O}$ escalonamento para o laço simples com uma recorrência hamiltoniana sempre atinge este paralelismo. Para o laço simples com mútiplas recorrências, este paralelismo é sempre menor ou igual ao paralelismo do laço. Neste caso, temos que achar o conjunto $E^{\prime}=\left\{d_{i j}^{\prime} \mid S_{i}, S_{j} \in V\right\}$ tal que existe uma $R_{\text {sch }}$ que envolve todos os nós de $V$ e todas as arestas em $E$ não precisam ser sincronizadas.

Para laços onde o número de comandos é menor, todas as $R_{s c h}$ possíveis podem ser examinadas. Para cada uma delas, podemos avaliar as distâncias adicionais $d_{i j}^{\prime} \in E^{\prime}$ tal que as três condições abaixo sejam satisfeitas:

$$
\begin{aligned}
& \text { - } d_{i j}^{\prime} \geq 0 \\
& \text { - } d_{i j}^{\prime} \leq \min _{d_{k j} \in E}\left(d_{k j}\right) \\
& \text { - }\left(d_{i j}-w\left(C_{i j}\right)\right) \bmod w\left(R_{s c h}\right)=0, \forall d_{i j} \in E, C_{i j} \subset R_{s c h} .
\end{aligned}
$$

A solução trivial é que toda $d_{i j}^{\prime}=0$ menos uma tem um valor de um. Esta solução dá um resultado de execução sequencial, mas as vezes podemos obter a solução tal que $\|_{l}(G)=$ 
$w\left(R_{s c h}\right)>1$. Neste caso, a eficiência do processo de paralelização será medida por

$$
\eta=\left\|_{l}(G) /\right\|(G)
$$

Esta idéia pode ser utilizada para obter o paralelismo resultante se sincronizamos um dado número de arestas de $E$. Esta idéia deve ser usada para estabelecer um trade-off entre o número de arestas a ser sincronizadas e o paralelismo que o escalonamento oferece.

Agora, vejmos um exemplo e a figura B.1:

\section{Exemplo B.1:}

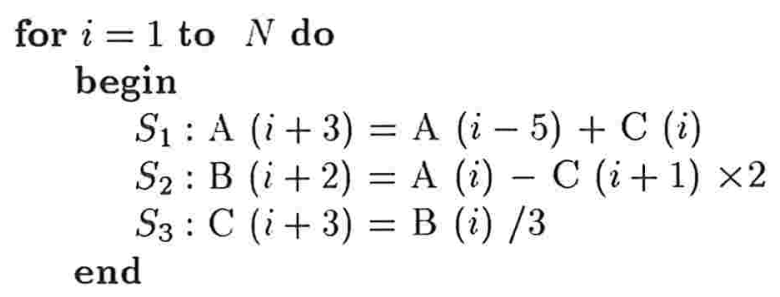

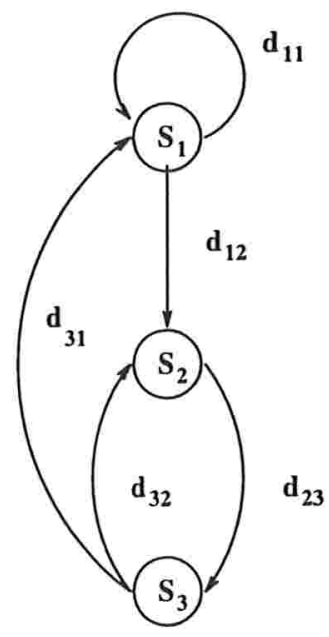

(a)

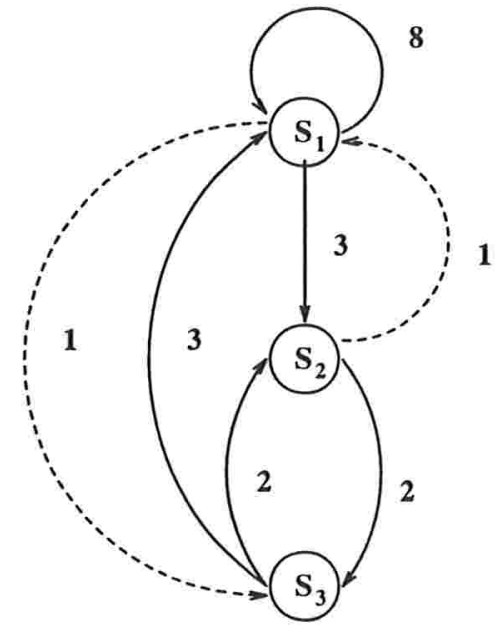

(b)

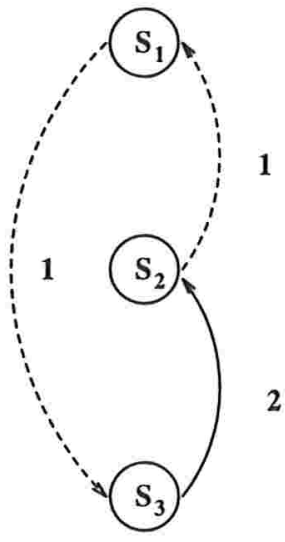

(c)

Figura B.1: O grafo de dependências (a) e o grafo de dependências com as arestas adicionais (b) e uma $R_{s c h}^{\prime}(\mathrm{c})$

Notamos que neste exemplo, o grafo (c) da figura B.1 pode ser executado com 4 processadores sem instruções de sincronização. Neste caso, uma recorrência de escalonamento (ou hamiltoniana) que atinge o paralelismo $\|_{l}(G)$ é $R_{s c h}^{\prime}=\left\{d_{13}^{\prime}, d_{32}, d_{21}^{\prime}\right\}$ com as distâncias associadas $d_{13}^{\prime}=1, d_{32}=2$ e $d_{21}^{\prime}=1$ (ver (b) e (c) da figura B.1). Agora, vamos descrever mais detalhadamente como chegamos a este resultado.

Pelas três condições citadas anteriormente, temos

- $d_{13}^{\prime}, d_{21}^{\prime} \geq 0$ 
- $d_{13}^{\prime}, d_{21}^{\prime} \leq \min _{d_{k}, \in E}\left(d_{k j}\right)=2$;

- $\left(d_{31}-w\left(C_{31}\right)\right) \bmod w\left(R_{s c h}\right)=0$ e $\left(d_{12}-w\left(C_{12}\right)\right) \bmod u\left(R_{s c h}\right)=0$;

onde $R_{\text {sch }}=\left\{d_{13}^{\prime}, d_{32}, d_{21}^{\prime}\right\} ; d_{12}, d_{31} \in E$ e $C_{12}=\left\{d_{13}^{\prime}, d_{32}\right\}, C_{31}=\left\{d_{32}, d_{21}^{\prime}\right\} \subset R_{\text {sch }}$.

Das condições impostas, obtemos

$$
\begin{aligned}
& 3-\left(2+d_{21}^{\prime}\right) \bmod \left(d_{13}^{\prime}+2+d_{21}^{\prime}\right)=0 \\
& 3-\left(2+d_{13}^{\prime}\right) \bmod \left(d_{13}^{\prime}+2+d_{21}^{\prime}\right)=0
\end{aligned}
$$

assim, a solução será $d_{21}^{\prime}=d_{13}^{\prime}=1$.

A seguir é o código paralelo gerado pelo laço seqüencial do exemplo.

\section{Algoritmo transformado:}

for $j=0$ to 3 doall

$$
\begin{aligned}
& \text { if }(j \geq 3) \\
& \mathrm{C}(j+1)=\mathrm{B}(j-2) / 3 \\
& \text { endif }
\end{aligned}
$$

\section{endif}

$$
\text { if }(j \geq 1)
$$

$$
\mathrm{B}(j-2)=\mathrm{A}(j-4)-\mathrm{C}(j-3) \times 2
$$

\section{endif}

$$
\begin{aligned}
\text { for } i=1+j \text { to } N \text { step } 4 \text { do } \\
\quad \mathrm{A}(i+3)=\mathrm{A}(j-5)+\mathrm{C}(i) \\
\mathrm{C}(i+4)=\mathrm{B}(i+1) / 3 \\
\mathrm{~B}(i+5)=\mathrm{A}(i+3)-\mathrm{C}(i+4) \times 2
\end{aligned}
$$

endo

$$
\text { if }(i \leq N)
$$

$$
\begin{gathered}
\mathrm{A}(i+3) \\
\text { endif }
\end{gathered}
$$

$$
\text { if } \begin{aligned}
& (i+1 \leq N) \\
& \quad \mathrm{C}(i+4)=\mathrm{B}(i+1) / 3
\end{aligned}
$$

\section{endif}

\section{endoall}

\section{Observação:}

- Apesar de ser possível fazer a distribuição de laços antes do GTS, é muito melhor aplicar o GTS ao laço inteiro antes de aplicar a distribuição do laço. A figura B.2(a) mostra o grafo de dependências de um laço com 4 comandos. Suponha uma unidade de tempo para executar cada comando, então a execução seqüencial do laço inteiro leverá $4 \mathrm{~N}$ unidades de tempo. Se a distribuição do laço for aplicada antes do GTS, o laço inteiro será dividido em dois blocos $\left(B_{1}=\left\{S_{1}, S_{2}\right\}\right.$ e $\left.B_{2}=\left\{S_{3}, S_{4}\right\}\right)$. A execução do primeiro bloco levará $N$ unidades de tempo e a execução do segundo será $(2 / 3) N$. Portanto, a execução seqüencial de dois blocos gastará $(5 / 3) N$ unidades de tempo. Se aplicarmos o GTS para laço inteiro, precisamos obter uma recorrência de escalonamento pela adição de arestas artificionais. 
Neste caso, obteremos o grafo mostrado na figura B.2(b) com uma aresta artificial $d_{41}=0$. Assim, o tempo de execução $N$ unidades será atingido.

- Para o laço simples com múltiplas recorrências, a eficiência do processo de paralelização pode ser medida por $\mu=P / \|(G)$. Se $\mu<1$, o paralelismo de laço não foi extraído totalmente. Se $\mu>1$, o número de processadores usados pode ser menor, neste caso, se a sincronização explícita for introduzida, o compromisso terá que ser tomado entre custo de bloquear processadores (busy waiting, por exemplo) e o overhead da mudança de tarefas.

- Vimos que o método GTS resolveu este exemplo sem a utilização de sincronização explícita aplicando a técnica de adição de dependências ou arestas artificiais. Podemos, também. aplicar o método $\mathbf{R D}$ ' para resolver este mesmo exemplo depois de usar a técnica de adição de dependências.

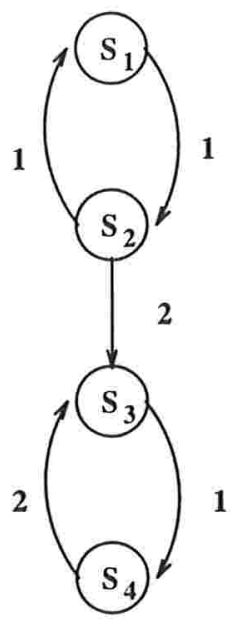

( a )

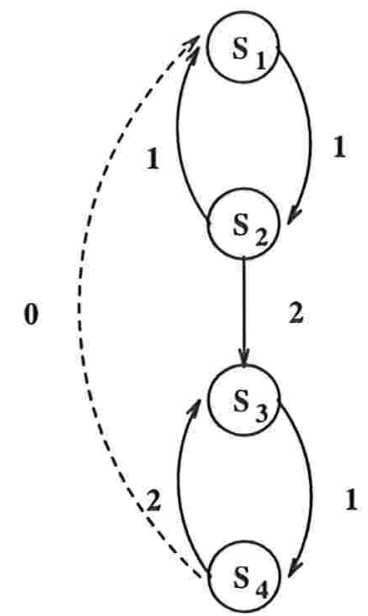

( b )

Figura B.2: O grafo de dependências (a) e o grafo de dependências com as arestas adicionais (b) 


\section{Bibliografia}

[C. 90] C. IV. Ho. L. S. Liu and J. P. Sheu. On the parallelism of nested for-loops using index shift method. In Proc. Internat. Conf. on Parallel Computing, August 1990.

[DR92] A. Darte and Y. Robert. Scheduling uniform loop nests. Technical report, Laboratoire de l'Informatique du Parallélisme-IMAG, Lyon, 1992.

[DR94] A. Darte and Y. Robert. Mapping uniform loop nests onto distributed memory architectu res. Parallel Computing, 20:679-710, 1994.

[IKK92] Hesham EL-Rewini In-Kyu Kim, Ted G. Lewis. Introduction to Parallel Computing. Prentice-Hall, 1992.

[J. 89] J. Torres. E. Ayguadé, J. Labarta and P. Borensztejn. GTS: Parallelization and vectorization of tight recurrences. In Supercomputing 89; Reno-Nevada, pages 531$529,1989$.

[Jes94] Jesús Labarta, Cristina Barrado and Patricia Borensztejn. Implementation of GTS. In Lecture Votes in Computer Science, PARLE'94 Parallel Architectures and Languages Europe, number 817, pages 565-576. 6th International PARLE, Greece, July 1994.

[Kun95a] Kunio, Okuda. Encolhimento de ciclo por redução de dependência. In Anais de VII Simpósio Brasileiro de Arquitetura de Computadores-Processamento de Alto Desempenho, SBC. Canela, pages 553-597, 1995.

[Kun95b] Kunio, Okuda. Paralelização de laços uniformes por reduçao de dependência. Technical Report RT-MAC-9507, IME/USP. São Paulo, 1995.

[Kun96a] Kunio, Okuda. Cycle shrinking by dependence reduction. In Euro-Par'96 Parallel Processing, Lecture Notes in Computer Science Series, volume 1123, pages 398-401. Springer-Verlag, 1996.

[Kun96b] Kunio, Okuda. Encolhimento de ciclos por redução de dependência. PhD thesis. IME/USP, 1996.

[LA89] Jesús Labarta and Eduard Ayguadé. GTS: Extracting full parallelism out of do loops. In Lecture Notes in Computer Science, PARLE'S9 Parallel Architectures Languages Europe, volume II, pages 43-54, June 1989. 
[M. 91] M. T. O'Keefe, W. Shang and J. A. B. Fortes. Generalized cycle shrinking parallel algorithms and VLSI architecture II. P. Quinton and Y. Robert (editores), North Holland, 1991.

[Pol88a] C. D. Polychronopoulos. Compiler optimization for enhancing parallelism and their impact on architecture design. IEEE Trans. Comput., 37(8):991-1004, 1988.

[Pol88b] C. D. Polychronopoulos. Parallel programmming and compilers, chapter 1, 2, 3. Kluwer Academic, 1988.

[RS92] Y. Robert and S. W. Song. Revisiting cycle shrinking. Parallel Computing, 18:481496, 1992.

[Wol89] M. Wolfe. Optimizing Supercompilers for Supercomputers. MIT Press. Cambrige, May 1989.

[Wol96] M. Wolfe. High Performance Compilers for Parallel Computing. Addison-Wesley. 1996. 